\title{
Evaluation of Evapotranspiration
}

\section{Estimation Methods and Their Impacts \\ on Crop Yield Simulations}

\author{
By Yang An \\ A thesis submitted to \\ the Faculty of Graduate Studies and Research \\ in partial fulfillment of \\ the requirements for the degree of
}

Master of Science

Department of Geography and Environmental Studies

Carleton University

Ottawa, Ontario

(C) Yang An, 2010 


$\begin{array}{ll}\begin{array}{l}\text { Library and Archives } \\ \text { Canada }\end{array} & \begin{array}{l}\text { Bibliothèque et } \\ \text { Archives Canada }\end{array} \\ \begin{array}{l}\text { Published Heritage } \\ \text { Branch }\end{array} & \begin{array}{l}\text { Direction du } \\ \text { Patrimoine de l'édition }\end{array} \\ \begin{array}{l}\text { 395 Wellington Street } \\ \text { Ottawa ON K1A ON4 } \\ \text { Canada }\end{array} & \begin{array}{l}\text { 395, rue Wellington } \\ \text { Ottawa ON K1A ON4 } \\ \text { Canada }\end{array}\end{array}$

Your file Votre référence

ISBN: 978-0-494-79597-2

Our file Notre référence

ISBN: 978-0-494-79597-2

NOTICE:

AVIS:

The author has granted a nonexclusive license allowing Library and Archives Canada to reproduce, publish, archive, preserve, conserve, communicate to the public by telecommunication or on the Internet, loan, distribute and sell theses worldwide, for commercial or noncommercial purposes, in microform, paper, electronic and/or any other formats.

The author retains copyright ownership and moral rights in this thesis. Neither the thesis nor substantial extracts from it may be printed or otherwise reproduced without the author's permission.

L'auteur a accordé une licence non exclusive permettant à la Bibliothèque et Archives Canada de reproduire, publier, archiver, sauvegarder, conserver, transmettre au public par télécommunication ou par l'Internet, prêter, distribuer et vendre des thèses partout dans le monde, à des fins commerciales ou autres, sur support microforme, papier, électronique et/ou autres formats.

L'auteur conserve la propriété du droit d'auteur et des droits moraux qui protège cette thèse. $\mathrm{Ni}$ la thèse ni des extraits substantiels de celle-ci ne doivent être imprimés ou autrement reproduits sans son autorisation.
In compliance with the Canadian Privacy Act some supporting forms may have been removed from this thesis.

While these forms may be included in the document page count, their removal does not represent any loss of content from the thesis.
Conformément à la loi canadienne sur la protection de la vie privée, quelques formulaires secondaires ont été enlevés de cette thèse.

Bien que ces formulaires aient inclus dans la pagination, il n'y aura aucun contenu manquant. 


\section{ABSTRACT}

Three EvapoTranspiration (ET) estimation methods included in the Daisy model, the Food and Agriculture Organization (FAO) Penman-Monteith, Samani and Hargreaves and Makkink methods, were evaluated using meteorological variables and ET measurements taken during the period of 2000 to 2004 over a mixed grass prairie site centred on a flux tower in Lethbridge, Alberta. Analysis of the standard scores of ET and meteorological variables showed that ET measurements and estimations by the three methods highly depended on solar radiation and temperature, but were less related to relative humidity and wind speed. The evaluation of ET methods against measurements indicated that all three methods performed better during the growing season but could not provide reliable ET estimations at other times during the year. The FAO Penman-Monteith method performed best, and showed the lowest estimation errors of MBE and RMSE. This was likely because of its theoretically physical basis and its consideration of vapour pressure deficit (VPD). The evaluation of the impact of ET estimation methods on crop yield simulations suggested that ET methods with better ET estimations generally correspond to better crop yield simulations. 


\section{ACKNOWLEDGEMENTS}

During the completion of this thesis I have received valuable encouragement and support from many people who deserve to be recognized. This section provides a good opportunity for me to heartily offer my regards and blessings to all of them.

I would like to start out by thanking the Geomatics and Landscape Ecology Research Laboratory (GLEL) for providing me with the necessary tools and resources to work on my thesis. Great thanks to my supervisor, Scott Mitchell, whose grateful guidance, support and patience from the preliminary to the concluding level enabled me in progress towards the successful completion of this thesis. Also, I would like to express my gratitude towards my advisor, Andrew Davidson, for his valuable advice, comments and guidance on numerous aspects of my research and thesis.

Special thanks to Agriculture and Agri-Food Canada (AAFC) and Alberta Crop Insurance of Agriculture Financial Services Corporation (AFSC) for providing the soil and crop yield data sources used in this study, respectively. Additional thanks to Larry Flanagan and the data collection team at the Lethbridge FluxNet Canada site for collecting the data, and FluxNet Canada for distributing them in a standardized form. I am also grateful to the contributions of other people: Ross McKenzie offered valuable suggestions on the typical management activities applied at the agricultural lands of Lethbridge. Per Abrahamsen gave excellent advice on the problems encountered when running the Daisy model for simulation. Additional thanks to Xiaoyuan Geng, Silim Salim, Dave Howlett and David Hildebrand for their help in sharing ideas/materials and giving me valuable advice at various stages during the completion of this thesis.

I acknowledge the financial support for this study provided by Government Related Initiatives Program (GRIP) - "Integrating remote sensing data into selected models to enhance operational decision support for crops, drought and agricultural water management" of Agriculture and Agri-Food Canada, and the Department of Geography and Environmental Studies of Carleton University. 


\section{TABLE OF CONTENTS}

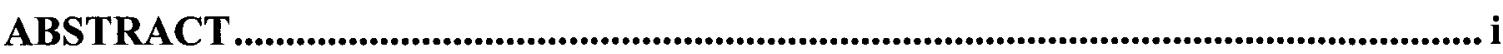

ACKNOWLEDGEMENTS ..................................................................................................... ii

TABLE OF CONTENTS ...................................................................................................ii

LIST OF TABLES...................................................................................................... vi

LIST OF FIGURES ........................................................................................................... vii

LIST OF ABBREVIATIONS ........................................................................................... ix

Chapter 1 Introduction .................................................................................................................... 1

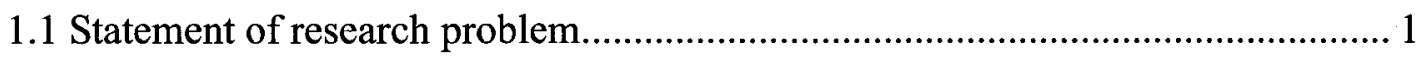

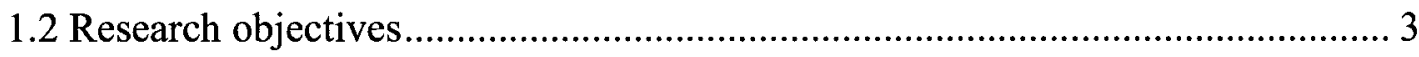

Chapter 2: Literature Review....................................................................................................... 4

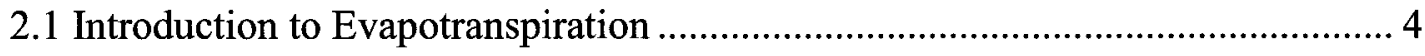

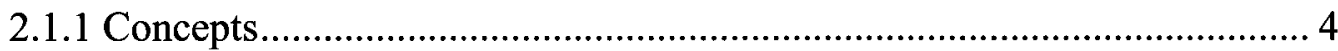

2.1.2 Factors Affecting Evapotranspiration ....................................................... 6

2.2 Evapotranspiration Estimation Techniques........................................................... 8

2.2.1 Measurement Techniques....................................................................... 8

2.2.2 Mathematical Methods........................................................................11

2.2.3 Limitations of Evapotranspiration Estimation Methods ............................ 17

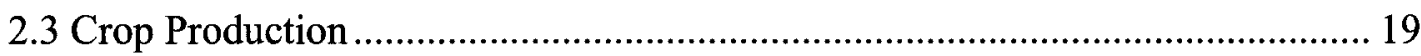

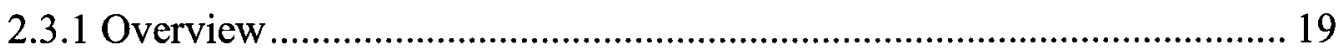

2.3.2 Factors Affecting Crop Production ........................................................... 19

Chapter 3 Methodology ….................................................................................................................... 26

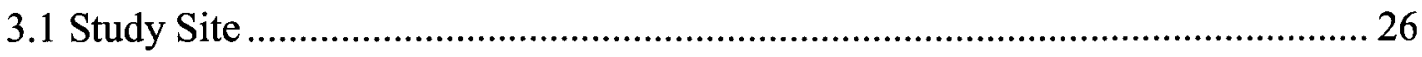

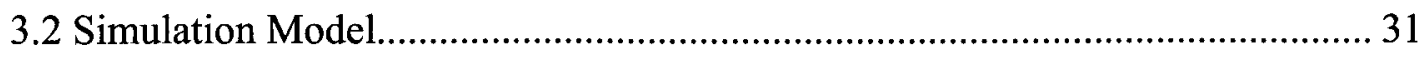

3.2.1 Model Description ................................................................................... 31

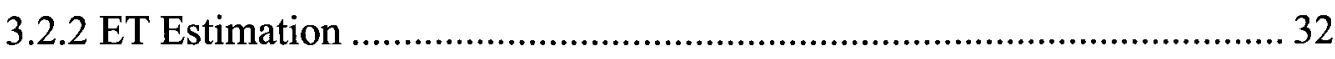




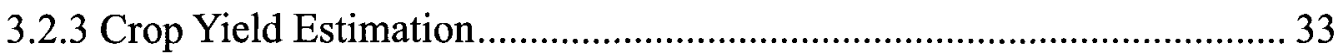

3.3 Evapotranspiration Estimation Methods....................................................... 35

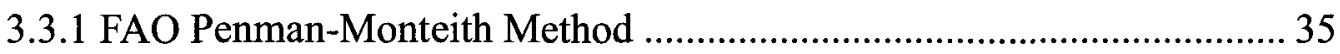

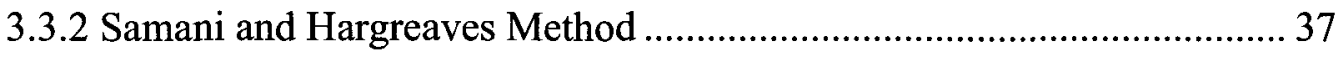

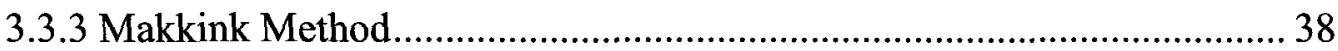

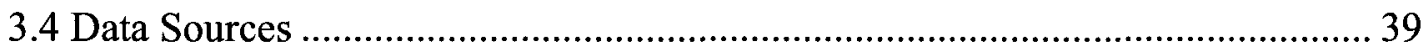

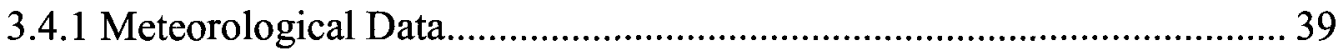

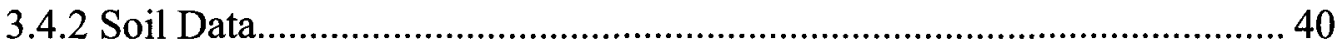

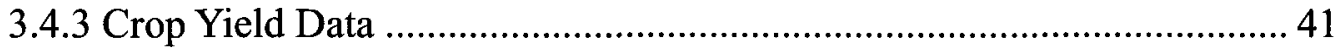

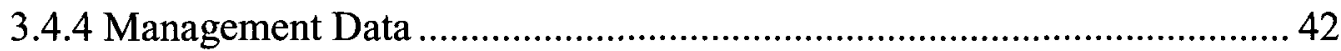

3.5 Modeling and Data Processing ...................................................................... 44

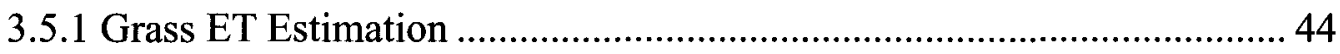

3.5.2 Crop Yield Estimation.............................................................................. 44

3.5.3 Standardization of ET and Meteorological Variables ............................... 45

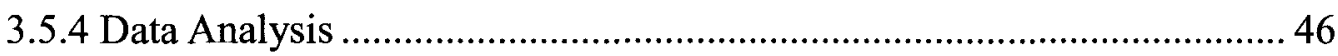

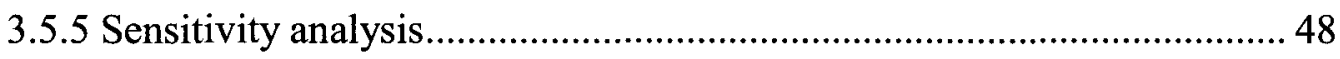

Chapter 4 Results and Discussion ............................................................................................... 50

4.1 Dependence of ET on Meteorological Variables ................................................ 50

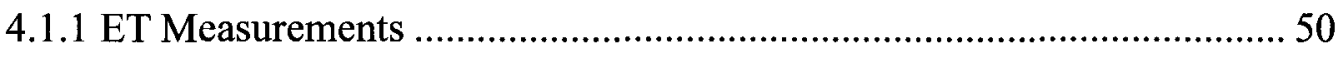

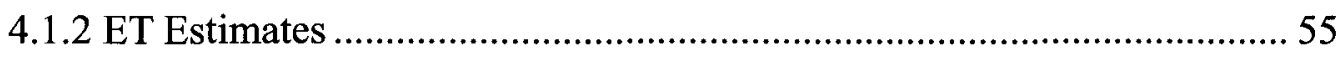

4.2 Performance evaluation of ET Estimation methods ............................................ 61

4.3 The impact of ET methods on crop yield simulations ......................................... 71

4.3.1 Insured crop yields ............................................................................. 71

4.3.2 Evaluation on the impact of ET methods on crop yield simulations ....... 77

4.3.3 Effect of management data on crop yield simulations ............................... 84

Chapter 5 Synthesis ............................................................................................................................ 86 


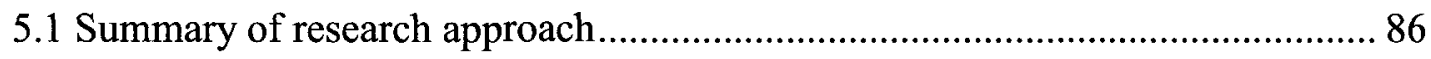

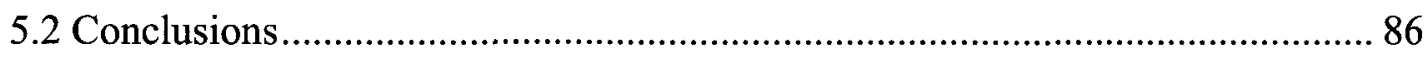

5.3 Limitations and Recommendations for Future Research.................................... 88

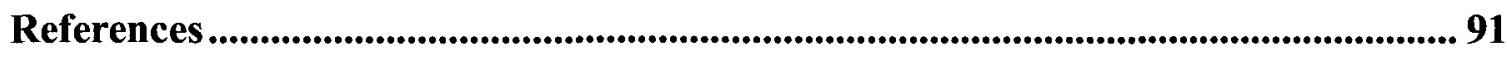




\section{LIST OF TABLES}

Table 3-1 List of typical management data at the study site for the period of 2000 to 2004. .43

Table 4-1 Coefficient of determination $\left(\mathrm{R}^{2}\right)$ between ET and meteorological variables .54

Table 4-2 $\mathrm{R}^{2}$ between daily ET measurements and estimations by the FAO Penman-Monteith, Samani and Hargreaves, and Makkink methods for 2000 to 2004 over grass .65

Table 4-3 Summary of error analysis of daily ET estimations by the FAO Penman-Monteith, Samani and Hargreaves, and Makkink methods compared to measurements for 2000 to 2004 over grass .66

Table 4-4 Monthly average precipitation from May to September for a historic period of 1971 to 2000 , and total recorded precipitation in each month from 2000 to 2004 .66

Table 4-5 $\mathrm{R}^{2}$ between ET measurements and ET estimates by the FAO Penman-Monteith, Samani and Hargreaves, and Makkink methods, by month, for the period 2000 to 2004 over grass 69

Table 4-6 Summary of error analysis of ET estimates by the FAO Penman-Monteith, Samani and Hargreaves, and Makkink methods, by month, for the period 2000 to 2004 over grass .70

Table 4-7 Insured and simulated crop yields using the FAO Penman-Monteith, Samani and Hargreaves, and Makkink methods for the period of 2000 to 2004 .75

Table 4-8 Summary of error analysis of daily ET estimations by the FAO

Penman-Monteith, Samani and Hargreaves, and Makkink methods compared to measurements in the growing seasons for 2000 to 2004 over grass .84 


\section{LIST OF FIGURES}

Figure 2-1 Photosynthetic radiation response curve showing the variability of photosynthesis in response to increasing radiation (Larcher, 1995) .....................21

Figure 2-2 Effect of temperature on photosynthesis (Oechel, 1976).................23

Figure 3-1 Location of the study site in Alberta (Sims et al., 2005) .................27

Figure 3-2 Configuration of the Alterba Township System (AGS, 2009) .............29

Figure 3-3 Schematic representation of the agro-ecosystem model Daisy (Hansen et al., 1990) 32

Figure 4-1 Comparisons of standard scores between daily ET measurements and meteorological variables (standard scores of 0 correspond to the 5 year average for that variable on that specific day)

Figure 4-2 Comparisons of standard scores between daily ET estimations by the FAO Penman-Monteith method and meteorological variables (standard scores of 0 for each variable correspond to the 5 year average on that specific day) .......................57

Figure 4-3 Comparisons of standard scores between daily ET estimations by the Samani and Hargreaves method and meteorological variables (standard scores of 0 for each variable correspond to the 5 year average over 5 years on that specific day)

Figure 4-4 Comparisons of standard scores between daily ET estimations by the Makkink method and meteorological variables (standard scores of 0 for each variable correspond to the 5 year average on that specific day)

Figure 4-5 Comparisons between daily ET measurements and estimations by the FAO Penman-Monteith, Samani and Hargreaves and Makkink methods for 2000 to 2004 ...63 Figure 4-6 Insured (boxplot) and simulated crop yields using the FAO Penman-Monteith, Samani and Hargreaves and Makkink methods for the period of 2000 to 2004 .74 
Figure 4-7 Daily solar radiation, air temperature and precipitation from May to August for the period of 2000 to 2004 76

Figure 4-8 Measured LAI of native grass during the growing season for 2000 to 2004 .77

Figure 4-9 Difference between DAISY simulated crop yields resulting from three ET estimation methods and insured crop yields for the period of 2000 to 2004 (Crop yield difference of 0 refers to the simulated crop yield equal to the mean of insured crop yields of

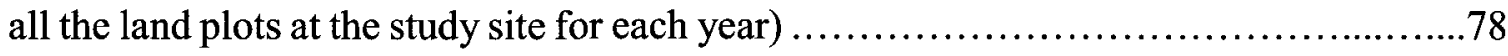
Figure 4-10 Simulated LAI of spring wheat resulting from three ET estimation methods during the growing season of 2000 to 2004 .79

Figure 4-11 Daily predictions of soil water, root extraction, net photosynthesis and daily yield allocation using the three ET estimation methods in the growing season of 2001, compared to precipitation (top pane) . .81

Figure 4-12 Daily predictions of soil water, root extraction, net photosynthesis and daily yield allocation using the three ET estimation methods in the growing season of 2002, compared to precipitation (top pane)

Figure 4-13 Variability of crop yield simulation in response to variability of the amount of fertilizer supply in 2001 .85 


\section{LIST OF ABBREVIATIONS}

$\begin{array}{ll}\text { AAFC } & \text { Agriculture and Agri-Food Canada } \\ \text { AARD } & \text { Alberta Agriculture and Rural Development } \\ \text { AFSC } & \text { Alberta Crop Insurance of Agriculture Financial Services Corporation } \\ \text { AGS } & \text { Alberta Geological Survey } \\ \text { ATS } & \text { Alberta Township System } \\ \text { BR } & \text { Bowen ratio } \\ \text { DIS } & \text { Fluxnet Canada Data Information System } \\ \text { FAO } & \text { Food and Agriculture Organization } \\ \text { LAI } & \text { leaf area index } \\ \text { MBE } & \text { mean bias error } \\ \text { NDVI } & \text { normalised difference vegetation index } \\ \text { NSDB } & \text { National Soil DataBase } \\ \text { RMSE } & \text { root mean square error } \\ \text { R } & \text { coefficient of determination } \\ \text { VPD } & \text { vapour pressure deficit }\end{array}$




\section{Chapter 1 Introduction}

\subsection{Statement of research problem}

Evapotranspiration (ET) is a controlling factor in the water cycle and energy transport among the biosphere, atmosphere and hydrosphere, and therefore plays an important role in hydrology, meteorology, and agriculture (Bates et al., 2008; Brutsaert, 1986; Jackson et al., 1981). Understanding ET dynamics helps to predict regional-scale surface runoff and groundwater, simulate large-scale atmospheric circulation and global climate change and schedule field-scale irrigations and tillage operations over cropland, (Idso et al., 1975; Su, 2002). Therefore, the capability to accurately estimate ET in land surface water and energy budget modeling at different temporal and spatial scales could be a valuable asset in hydrology, climatology and agriculture.

There exists a multitude of methods for measurement and estimation of ET (Hatfield, 1983; Itenfisu et al., 2000; Rango, 1994; Winter et al., 1995). These methods were derived from different theoretical assumptions, including empirical relations (Kohler et al., 1955), water budget (Guitjens, 1982; Singh, 1989), energy budget (Fritschen, 1966; Kustas and Norman, 1996), mass transfer (Harbeck, 1962) and combinations of them (Penman, 1948). Furthermore, all ET methods present different structural complexity and data requirements 
(Kalma et al., 2008; Kairu, 1991; Wilks and Riha, 1996). However, it is difficult to select the most appropriate ET method for a given study. This is mostly due to lack of objective criteria for method selection (Singh and Xu, 1997). Getting a better understanding of ET methods over temporal and spatial scales could be an approach to solve this problem.

ET, as a main controlling factor on matter and energy exchange between crop and atmosphere, significantly affects crop production processes (Pirmoradian and Sepaskhah, 2005; Van Bavel, 1968). The proportion of water uptake from soil by roots going to transpiration can exceed 90\% (Xu and Singh, 1998). Present-day crop yield models usually have specific submodels for estimating ET (Abrahamsen and Hansen, 2000; van Ittersum et al., 2003). However, due to wide differences among available ET estimation methods (summarized above), crop yield simulations resulting from different choices of ET submodel also differ. Therefore, there is a need to examine the impacts of ET estimation method on crop yield simulations.

This study focuses on the Canadian Prairies, where unpredictable and erratic weather predominates most of the growing season (Bole and Pittman, 1980; Richardson et al., 2006). The characteristics provide an ideal environmental background for ET and crop yield simulations based on their high degree of dependence on meteorological parameters and of sensitivity to environmental variability. 


\subsection{Research objectives}

The following research objectives are identified in this study:

1) to test the dependence of ET on the main meteorological variables affecting ET processes using both ET measurements and estimations by different methods;

2) to evaluate the performance of ET estimation methods used in this study against measurements under the same meteorological and environmental conditions;

3) to examine the impacts of ET estimation methods on crop yield simulation.

These objectives are examined at a specific site in Lethbridge, Alberta, and are assumed to be applicable to at least similar agro-environmental conditions across the northern mixed-grass prairie. 


\section{Chapter 2: Literature Review}

This chapter reviews the published literature relating to the study of ET and crop production. It is presented in three sections. The first section introduces general information about ET, including the relevant concepts and factors affecting it. The second section discusses two types of techniques used to quantify ET: measurement and mathematical estimation. The third section reviews crop production, focusing on the effect of various environmental factors on crop production.

\subsection{Introduction to Evapotranspiration}

\subsubsection{Concepts}

Evapotranspiration (ET) refers to the physical processes whereby liquid water is vaporized from evaporating surfaces into the atmosphere (Allen et al., 1998; Li and Lyons, 1999; Penman, 1948). It generally consists of evaporation and transpiration. Evaporation accounts for the processes whereby liquid water is converted to water vapour and lost from lakes, rivers, pavements, soils and wet vegetation surfaces (Allen et al., 1998; Su, 2002). Transpiration accounts for the vaporization of liquid water within the plant from leaf surfaces through stomata (Idso et al., 1975; Su, 2002). In plants nearly all the water taken 
up from soil is lost by transpiration and only a tiny fraction is used within plants (Larcher 1995).

The term ET is generally used because evaporation and transpiration occur simultaneously and there is no easy way to distinguish between them (Kalma et al., 2008). When a plant is small and the canopy shades little of the ground area, ET is predominated by evaporation. However, as the plant develops over the growing period and the canopy shades more and more of the ground area, or even completely covers the soil surface, transpiration becomes the main process (Larcher 1995).

Commonly used terms relevant to ET consist of reference ET $\left(\mathrm{ET}_{\mathrm{o}}\right)$, potential $\mathrm{ET}\left(\mathrm{ET}_{\mathrm{p}}\right)$ and actual $\mathrm{ET}\left(\mathrm{ET}_{\mathrm{a}}\right)$. $\mathrm{ET}_{\mathrm{o}}$ refers to the ET from a reference surface with sufficient water supply, usually a hypothetical grass surface with specific characteristics (Batchelor, 1984; Hansen, 1984; Morton, 1969). The concept of $\mathrm{ET}_{\mathbf{o}}$ was introduced to study the evaporative demand of the atmosphere independently of plant type, development stage and management activities (Allen et al., 1998). $\mathrm{ET}_{\mathrm{p}}$ refers to the $\mathrm{ET}$ of plants that are grown in large fields under excellent agronomic, soil water and management conditions, and achieve full production under given climatic conditions (Morton, 1969; Van Bavel, 1966). It differs distinctly from $\mathrm{ET}_{\mathrm{o}}$ as the ground cover, canopy properties and aerodynamic resistance of the plant are different from the hypothetical grass surface. $E T_{a}$ is the ET of plants based on 
the non-optimal management and environmental constraints such as the soil salinity, low soil fertility, water shortage or waterlogging, and presence of pests and diseases (Allen et al., 1998; Jensen et al., 1997). $\mathrm{ET}_{\mathrm{p}}$ acts as the driving force in $\mathrm{ET}_{\mathrm{a}}$ modeling and constitutes the upper limit for $\mathrm{ET}_{\mathrm{a}}(\mathrm{LeDrew}, 1979)$.

\subsubsection{Factors Affecting Evapotranspiration}

\subsubsection{Meteorological Parameters}

Energy is required for ET processes to change the state of water from liquid to vapour (Larcher, 1995; Morton, 1990). This energy is mainly available from direct solar radiation and, to a lesser extent, the ambient temperature of air (Allen et al., 1998). The driving force to remove water from the evaporating surface depends on the difference between water vapour pressure of the evaporating surface and that of the surrounding atmosphere (Bosen, 1960). Further, wind speed significantly affects the movement of vapour flow in the air. Hence, solar radiation, air temperature, air humidity and wind speed are the main meteorological parameters to consider when assessing the ET processes (Morton, 1994; Xu and Singh, 1998). 


\subsubsection{Management and Environmental Conditions}

Environmental factors such as soil moisture, soil salinity, land fertility, penetrability of soil horizons, diseases and pests all pose significant effects on plant development and ET processes (Allen et al., 1998; Willigen, 1991). The effect of soil moisture on ET is primarily controlled by the magnitude of the water deficit and soil type (Chaudhury, 1985). Too much water may result in waterlogging and limit water uptake via roots by inhibiting respiration (Larcher 1995). Management activities, such as the application of fertilizers, the type of cultivation and irrigation practices used, also affect the ET process (Prihar et al., 1976; Proffitt et al., 1985). Cultivation practices and the type of irrigation system can alter the microclimate of the canopy by affecting the wetting of the soil and plant surface (Ritchie, 1971; Sutton, 1949). Other factors, including ground cover, plant density and plant architecture, should also be considered when assessing ET.

\subsubsection{Plant Characteristics}

Plant characteristics also pose a significant effect on ET processes. Different kinds of plants differ in their albedo, resistance to transpiration, height, roughness, and rooting system (Singh, 1989). All these plant characteristics result in different ET levels under the identical meteorological and environmental conditions (Allen et al., 1998; Bathke et al., 
1992). Plants also present different transpiration rates in the different development stages (Chavan and Pawar, 1988).

Generally, when water supply from the soil is sufficient to satisfy the ET demand, meteorological parameters play the dominant role in governing ET processes. However, under conditions of low precipitation over long periods, long intervals between irrigations, or limited upward water transport from the water table is limited, soil moisture in the upper layers drops and plants suffer from water deficit. This may limit plant development and reduce ET. Under these circumstances, plants directly exert the main controlling influence on the ET processes through stomatal control of water loss (Allen et al., 1998).

\subsection{Evapotranspiration Estimation Techniques}

\subsubsection{Measurement Techniques}

ET measurement techniques depend on a variety of instruments, and include pan-measurement, use of weighing lysimeters, and Bowen ratio (BR) and eddy covariance techniques (Li et al., 2009). 


\section{Pan-measurement}

Evaporation from an open water surface provides an index of the integrated effect of radiation, air temperature, air humidity and wind on ET (Allen et al., 1998). The pan-measurement instruments consist of an evaporation pan to hold water and water level sensors to read the depth of water evaporates from the pan. Based on the instruments one can determine the quantity of evaporation at a given location (Bosman, 1990). This technique has proved its practical value and has been used successfully to estimate $\mathrm{ET}_{\mathrm{o}}$ by observing the evaporation loss from a water surface (Bosman, 1987).

\section{Weighing lysimeter}

Weighing lysimeters make direct measurements of water loss from growing crops or trees and the soil surface around them, and thus, provide basic data to validate other ET prediction methods. The water loss via ET can be worked out by calculating the difference between the amount of precipitation in a field and the amount lost through the soil (Edwards, 1986). A weighing lysimeter is used to detect losses of soil moisture by constantly weighing a huge block of soil in a field and the measured moisture loss is assumed to be caused by ET (Yang et al., 2000).

\section{Bowen ratio}

The Bowen ratio (BR) is a micrometeorological variable representative of the ratio of the sensible and latent heat fluxes (Bausch and Bernard, 1992). BR is measured as the ratio of the gradients of temperature and vapour pressure or humidity across two fixed heights 
above the surface. Sensible heat flux is calculated from simultaneous radiometer measurements of net radiation and soil heat flux (Verma, 1990). Once the BR and sensible heat fluxes are known, one can solve for latent heat flux, or ET (Revheim and Jordan, 1976; Verma, 1990). The BR approach assumes absence of horizontal energy fluxes, therefore it cannot be used inside canopies. It further assumes that the turbulent transfer coefficients for sensible heat and water vapour are equal (Ashktorab et al., 1989).

\section{Eddy correlation system}

The eddy correlation system is widely applied for the determination and monitoring of energy components and carbon dioxide and water vapour mass fluxes in situ at a half-hour time scale (Leuning et al., 1990). All of these fluxes are obtained with the eddy covariance technique, which evaluates the means, variances and co-variances of the vertical wind vector with its horizontal wind counterpart, with sonic temperature, and water vapour as well as carbon dioxide mixing ratios (Leuning et al., 1990). Instruments used include a 3D sonic anemometer to obtain the orthogonal wind vectors and sonic temperature, and a folded, open path $\mathrm{H}_{2} \mathrm{O} / \mathrm{CO}_{2}$ infrared gas analyzer to measure water vapour and carbon dioxide mixing ratios. The eddy correlation systems are used at locations where other methods for surface flux measurements, such as BR systems, are difficult to employ (Wilson et al., 2001). 


\subsubsection{Mathematical Methods}

Commonly-applied ET mathematical estimation methods can be categorized as either empirical methods or analytical methods (Verstraeten, 2008). Empirical methods are often accomplished by employing empirical relationships between ET measurements and meteorological factors via site-specific parameterization using regression analysis. These methods may make use of data mainly derived from remote sensing observations with minimum ground-based measurements. Analytical methods involve the establishment of physical processes at the scale of interest with varying complexity and require a variety of direct and indirect measurements from sources such as remote sensing technology and ground-based instruments ( $\mathrm{Li}$ et al., 2009; Rango, 1994). These methods are discussed further in the following sections.

\subsubsection{Empirical Methods}

The general theory of empirical methods relates the daily ET to daily net radiation $\left(\mathrm{R}_{\mathrm{n}}\right)$ and difference between instantaneous surface temperature $\left(T_{s}\right)$ and air temperature $\left(T_{a}\right)$ measured at a reference height near midday over diverse surfaces with variable vegetation cover (Caselles et al., 1992; Jackson et al., 1977; Seguin and Itier, 1983). ET estimated in this manner can be expressed as (Seguin and Itier, 1983): 


$$
E T_{d}=\left(R_{n}\right)_{d}-B\left(T_{s}-T_{a}\right)_{i}^{n}
$$

where the subscripts i and d refer to instantaneous (near mid-day) and daily, respectively; B and $\mathbf{n}$ are site-specific regression coefficients, $\mathbf{B}$ depends on surface roughness and wind speed, and $\mathrm{n}$ depends on atmospheric stability.

The main assumptions in this empirical equation are that daily soil heat flux is negligible and that the instantaneous midday value of sensible heat flux adequately expresses the influence of partitioning daily net radiation into turbulent fluxes (Kairu, 1991). Several investigations have tested and validated this statistical relationship by estimating daily ET under various atmospheric conditions and vegetation covers (Carlson et al., 1995; Carlson and Buffum, 1989). All the contributions have shown that the error of this equation for daily ET calculation is approximately $1 \mathrm{~mm} /$ day, indicating that this empirical relation can provide reliable ET estimation at a regional level (Seguin et al., 1994).

Other widely applied empirical methods include the Makkink, Romanenko, Thornthwaite, and Samani and Hargreaves models (Jackson, 1985; Singh and Xu, 1997). The advantages of the empirical methods include: 1) input variables generally include only radiation and temperature. Thus, application of these simplified empirical equations are very convenient as long as these ground-based meteorological measurements and remotely sensed radiometric surface parameters are available; 2) these methods are reliable over a 
homogeneous area with site-specific regression coefficients, such as B and $\mathrm{n}$ in equation [1]

(Li et al., 2009). However, we need to determine these site-specific coefficients, which may limit the model's application over regional scales with variable vegetation cover. Regression relationships are often subject to rigorous local calibrations which have proved to limit global validity (Kairu, 1991). Further, testing the accuracy of the methods under a new set of conditions is laborious, time-consuming and costly.

\subsubsection{Analytical Methods}

The residual method of surface energy balance is the most widely applied analytical method to estimate ET at different temporal and spatial scales (Allen et al., 2007; Su, 2002). The FAO Penman-Monteith model is an example using this method.

\section{Surface energy balance}

Surface energy balance expresses the instantaneous energy exchange in the soil-vegetation-atmosphere continuum (Bastiaanssen et al., 1998; Moran et al., 1989; Roerink et al., 2000). Energy fluxes in the surface energy balance method include:

1) incoming shortwave and longwave radiation;

2) outgoing surface reflected and emitted radiation;

3) soil heat flux $(G)$, representing the energy that conducts into or out of the substrate soil;

4) sensible heat flux $(H)$, representing the energy transfer between ground and 
atmosphere, which is the driving force to warm/cool the air above the surface;

5) latent heat flux (LE or $\lambda \mathrm{E}$ ), representing the energy corresponding to ET, i.e. the energy needed to change the phase of water from liquid to gas;

6) heat storage in the photosynthetic vegetation and soil; and

7) horizontal advective heat flow.

The difference between the incoming and outgoing radiation is surface net radiation $\left(R_{n}\right)$

(Boni et al., 2001), representing the total heat energy source in the surface energy balance method. Generally heat storage in vegetation and soil surfaces and horizontal advective heat are negligible due to the negligible change in their instantaneous statements (Li et al., 2009).

When heat storage in photosynthetic vegetation and soil, and horizontal advective heat flow are not considered, the instantaneous surface energy balance equation can be expressed mathematically as (Bastiaanssen et al., 1998; Brown and Rosenberg, 1973):

$$
\lambda E=R n-G-H
$$

where $\mathrm{E}$ is the ET rate $\left(\mathrm{kg} \mathrm{m}^{-2} \mathrm{~s}^{-1}\right)$ and $\lambda$ is the latent heat of water vaporization $\left(\mathrm{J} \mathrm{kg}^{-1}\right)$. Each component of energy balance equation, including $R_{n}, G$ and $H$, can be estimated by combining remote sensing based parameters of surface radiometric temperature and shortwave albedo from visible, near infrared and thermal infrared wavebands with a set of ground based meteorological variables of air temperature, wind speed, humidity and other 
auxiliary surface measurements (Boni et al., 2001; Hatfield et al., 1983; Reginato et al., 1985).

$R_{n}$, the total energy budget partitioned into different energy fluxes, can be estimated from the sum of the difference between the incoming and the reflected outgoing shortwave radiation $(0.15$ to $5 \mu \mathrm{m})$, and the difference between the downwelling atmospheric and the surface emitted and reflected longwave radiation ( 3 to $100 \mu \mathrm{m})$. It can be calculated using the following equation (Jackson, 1985; Kustas and Norman, 1996):

$$
R_{n}=\left(1-\alpha_{s}\right) R_{s}+\varepsilon_{s} \varepsilon_{a} \sigma T_{a}^{4-} \varepsilon_{s} \sigma T_{s}^{4}
$$

where $\alpha_{\mathrm{s}}$ is surface shortwave albedo, usually calculated as a combination of narrow band spectral reflectance values from remote sensing measurements; $R_{s}$ is incoming shortwave radiation, determined by a combined factors of solar constant, solar inclination angle, geographical location and time of year, atmospheric transmissivity, ground elevation, etc.; $\varepsilon_{\mathrm{s}}$ is surface emissivity, evaluated either as a weighted average between bare soil and vegetation (Li and Lyons, 1999) or as a function of Normalised Difference Vegetation Index (NDVI) (Bastiaanssen et al., 1998); $\varepsilon_{\mathrm{a}}$ is atmospheric emissivity, estimated as a function of vapour pressure; $\sigma$ is the Stefan-Boltzman constant, $5.67 \times 10^{-8} \mathrm{~W} \mathrm{~m}^{-2} \mathrm{~K}^{-4}$; $\mathrm{T}_{\mathrm{a}}$ is air temperature measured at a reference height; $T_{\mathrm{s}}$ is surface temperature.

Traditionally, G is measured with sensors buried beneath the surface soil and is directly 
proportional to the thermal conductivity and the temperature gradient with depth of the topsoil (Bastiaanssen et al., 1998). G varies considerably from dry bare soil to well watered vegetated areas, depending on the soil's thermal conductivity and the vertical temperature gradient, and cannot be measured remotely (Zhang et al., 1995). Many studies found that the ratio of $G / R_{n}$ ranges from 0.05 for full vegetation cover or wet bare soil to 0.5 for dry bare soil (Daughtry et al., 1990; Li and Lyons, 1999) and this ratio is exponentially related to leaf area index (LAI), NDVI (Allen et al., 2007), soil surface temperature (Bastiaanssen, 2000) and solar zenith angle (Gao et al., 1998) based on field observations. Therefore, this ratio is often taken as constant or estimated as a function of LAI, NDVI, solar zenith angle, vegetation cover, and soil moisture.

$H$ in the single-source energy balance model is calculated by combining the difference of aerodynamic and air temperatures with the aerodynamic resistance $\left(r_{a}\right)$ (Chehbouni et al., 2001; Hatfield et al., 1983). The straightforward equation can be expressed as (Kustas, 1990):

$$
H=\rho c_{p}\left(T_{a e r o}-T_{\mathcal{J}}\right) / r_{a}
$$

Where $\rho$ is the air density; $c_{p}$ is specific heat of air at constant pressure; $T_{\text {aero }}$ is aerodynamic surface temperature at the canopy source/sink height; $T_{\mathrm{s}}$ is surface temperature; $r_{a}$ is aerodynamic resistance to sensible heat transfer between the canopy source/sink height and the bulk air at a reference height above the canopy. Aerodynamic 
resistance $r_{a}$ is often calculated from local data of wind speed, surface roughness length and atmospheric stability conditions (Seguin, 1984). Therefore aerodynamic resistance to heat transfer must be adjusted locally according to different surface characteristics.

\subsubsection{Limitations of Evapotranspiration Estimation Methods}

Although a variety of estimation methods have been applied to estimate ET distribution at different spatial scales ranging from field to regional and continental scales, each method has its own advantages and disadvantages and can only be applied successfully to some conditions (Kairu, 1991). For example, the empirical methods have the advantages of computational timesaving and less requirement of ground-based measurements over homogeneous areas, but over regions with great variability of land surface characteristics, it can not always function successfully ( $\mathrm{Li}$ et al., 2009); the physically based, analytical methods are able to provide ET estimations in good agreement with measurements, but generally have a large data requirement. None of today's ET methods can be expanded to worldwide scales without any modification and improvement (DehghaniSanij et al., 2004).

Although we can retrieve quantitative land surface variables from remote sensing data, such as surface temperature, vegetative coverage, plant height, etc., accuracy of these variables still needs to be improved for use in the ET estimation methods. Retrieval of 
radiometric surface temperature is weakened by the influences of vegetation architecture, sunlit fractional of vegetation and solar zenith angle, etc., especially in heterogeneous regions (Allen et al., 2007). When sensor viewing changes from one angle to another, the received radiances will also change due to the differing amounts of soil and vegetation in the field of view (Carlson et al., 1995).

Meteorological data, including solar radiation, air temperature, atmospheric pressure, relative humidity and wind speed, are indispensable to estimate ET. Because the meteorological stations are often sparsely and irregularly located, interpolation must be used to obtain the meteorological variables at the satellite pixel scale from discrete meteorological stations for regional ET estimations (Seguin and Itier, 1983). In some cases that significant variability of meteorological and terrain conditions exists over the whole region, the accuracy of interpolated meteorological data is limited (Gurney and Camillo, 1984), consequently affecting the reliability of ET estimations.

Scaling effects also limit the application of ET estimation methods (Gowda et al., 2007; McCabe and Wood, 2006). Parameters and variables obtained at one scale may not be used at other scales without introducing error (Carlson et al., 1995). Scaling effects generally occur when methods with derived surface fluxes parameters at local scale may not be extended for application at a larger scale due to heterogeneities of land surface and 
non-linearity of these methods (Brunsell and Gillies, 2003).

\subsection{Crop Production}

\subsubsection{Overview}

The need for crop production modelling is increasing with the changing climate and emerging crisis in food security, due to the growing world population and conversion of crop land into biofuels and others (Macdonald and Hall, 1980; Prasad et al., 2006). Regional estimates of crop production are important for supporting policy planning and decision-making in large agricultural lands (Dumanski and Onofrei, 1989; Macdonald and Hall, 1980; Hargreaves, 1975; Hutchinson, 1991). The main approaches to estimate crop production include remote sensing-based calculations, crop growth models, agro-meteorological models and statistical sampling methods (Dadhwal and Ray, 2000;

Prasad et al., 2006).

\subsubsection{Factors Affecting Crop Production}

Crops that grow at a particular location interact with the surrounding environment for continued energy and substance exchange through various metabolic activities, such as photosynthesis, respiration, ET, uptake of water and nutrients, and senescence (Porter and 
Semenov, 2005). All metabolic activities are significantly influenced by meteorological and environmental factors, such as solar radiation, air temperature, water availability, soil fertility, and soil penetrability (Stanhill and Cohen, 2001; Brooks et al., 2001). The intensity, duration and distribution of these factors in the growing season play important roles in crop growth and production processes (Larcher, 1995). As the main controlling factors, solar radiation, temperature and water are introduced in the following sections.

\subsubsection{Solar Radiation}

Crop growth is maintained by energy from solar radiation. By means of photosynthesis, carbon dioxide is fixed into carbohydrates and the secondary products (Ballantine and Forde, 1970; Stanhill and Cohen, 2001). As a result, solar radiation exerts a significant influence on crop growth as photosynthesis is an energy-driven biochemical process and short-wave solar radiation functions as the primary energy source.

A general trend of photosynthetic radiation response curve (Figure 2-1) relates the variability of photosynthesis with increasing radiation. It reveals the efficiency at which solar radiation is utilized by photosynthesis or the net exchange of $\mathrm{CO}_{2}$ between a leaf and the atmosphere (Bohning and Burnside, 1956; Bjorkman, 1968; Mache and Loiseaux, 1973). When solar radiation is extremely low, the amount of $\mathrm{CO}_{2}$ released by respiration 
exceeds the amount of $\mathrm{CO}_{2}$ fixed by photosynthesis, resulting in a negative value for crop net productivity. This is often the case in the evening. When photosynthesis exceeds respiration, fixation rate increases with increasing radiation intensity, initially showing a linear proportionality between net photosynthesis and radiation intensity. This stage is a radiation-limited photosynthesis process (Larcher, 1995). The higher radiation intensity helps to maintain the higher photosynthesis rate for crop growth and the more biomass accumulation and crop production (Bohning and Burnside, 1956). If radiation intensity reaches the radiation-saturated point at which radiation intensity is said to be 'saturating' for photosynthesis, further increase of radiation does not cause the increase of photosynthesis rate (Larcher, 1995; Bjorkman et al., 1972).

photosynthesis: mg C fixed (mg chl $)^{-1} \mathrm{hr}^{-1}$

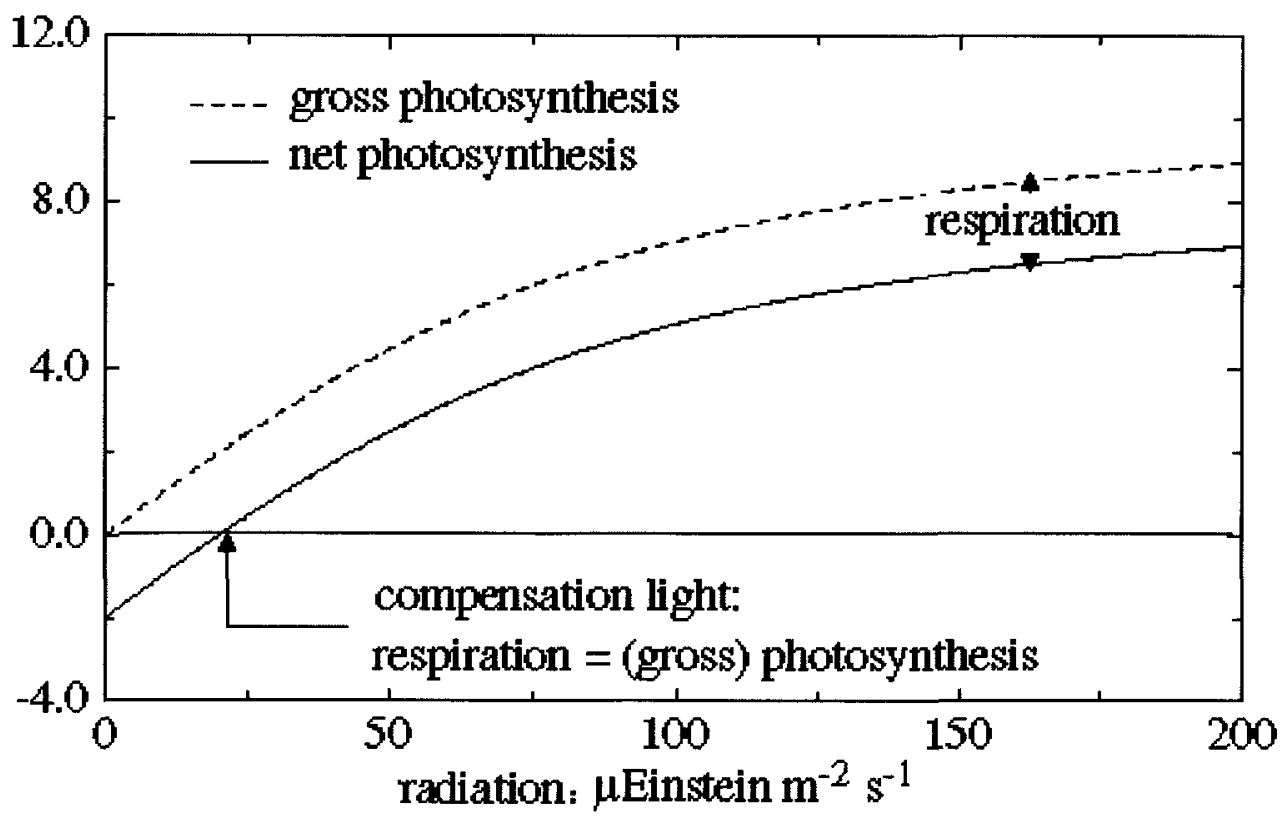

Figure 2-1 Photosynthetic radiation response curve showing the variability of photosynthesis in response to increasing radiation (Larcher, 1995) 
However, solar radiation functions not only as the main energy source stimulating crop development, but also occasionally as a stress factor. Overloading radiation may result in lower radiation quantum utilization and lower crop production (Larcher 1995).

\subsubsection{Temperature}

Metabolic processes are actually a combination of numerous biochemical reactions which depend on temperature variability. According to Van't Hoff's reaction rate-temperature rule, biochemical reaction rate rises exponentially with increasing temperature (Davidson and Janssens, 2006).

The effects of temperature on crop photosynthesis can be illustrated by Figure 2-2. At lower suboptimal temperatures, photosynthesis rate increases gradually with the increasing temperature until the temperature optimum is reached. The position and span of the temperature optimum is species-dependent and also varies with external environmental conditions (Johnson and Kanemasu, 1983; Kemp and Blacklow, 1982). Generally, for agricultural $\mathrm{C}_{3}$ (cool season) crops the temperature optimum is about $20-30^{\circ} \mathrm{C}$, while for $C_{4}$ (warm season) crops in warmer habitats it is about $30-40^{\circ} \mathrm{C}$ (Larcher, 1995). When temperature rises above the temperature optimum, photosynthesis rate decreases. Further temperature increases and crop photosynthesis slows down rapidly due to interruption of 
various reactions involved in carbon metabolism (Ballantine and Forde, 1970). The more heat-sensitive the crop, the sooner photosynthesis gets weakened (Grace, 1988). It is said that the agricultural $C_{3}$ crops may function abnormally when temperature reaches about 40 ${ }^{\circ} \mathrm{C}$, and about $50^{\circ} \mathrm{C}$ for $\mathrm{C}_{4}$ (Larcher, 1995).

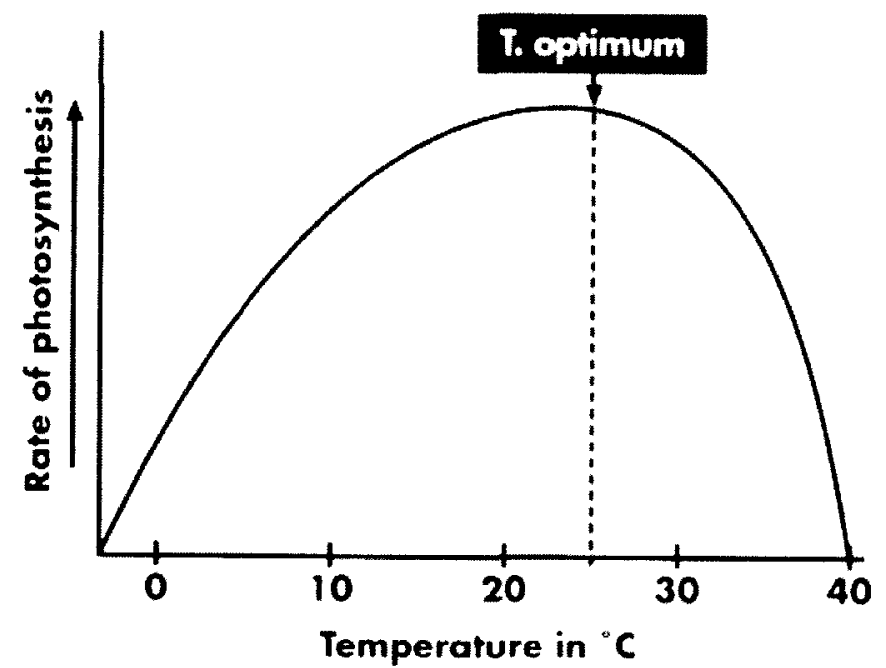

Figure2-2 Effect of temperature on photosynthesis (Oechel, 1976)

\subsubsection{Water}

Generally water is an essential component in and makes up the largest proportion of living tissues. Crop water content varies by tissue type (de Jong van Lier and Libardi, 1997; Richter, 1997). On average, water occupies $85 \%-90 \%$ in fresh fruits, $80 \%-90 \%$ in leaves, $70 \%-95 \%$ in roots and at least about $10 \%-15 \%$ in ripe seeds (Larcher, 1995). Further, water is an essential medium in all metabolic reactions (Ehlig, 1962). Crops can only maintain an active metabolic state with a sufficient water supply and if the cells dry out, the 
metabolic processes may suspend (Hsiao, 1973).

Water is important in photosynthesis (Feddes and Rijtema, 1972; Irmak et al., 2000). Firstly, water is a necessary substance combined with carbon dioxide to form carbohydrates - the main product of photosynthesis. Secondly, water functions as the medium of biochemical matter transportation from soil to leaves to the atmosphere through transpiration (Pockman et al., 1995). Thirdly, a large amount of water is necessary to maintain cell volume and turgor of the protoplasm (Gardner and Ehlig, 1963; Richter, 1997). Because crops take up carbon dioxide and give off water simultaneously via leaf stomata, the reduction of water lost by transpiration also causes the reduction of carbon fixation by photosynthesis. Therefore, efficiency of photosynthesis directly depends on the leaf/crop conductance to transpiration (Feddes and Rijtema, 1972; Larcher, 1995).

Previous studies have examined the variability of crop production in response to different levels of water supply (Brooks et al., 2001; Xie et al., 2003; Katerji et al., 2009). Brooks et al. (2001) simulated crop production with the Sirius wheat model at two locations in UK using different precipitation scenarios and indicated that as precipitation decreased crop production dropped progressively. Xie et al. (2003) evaluated the importance of meteorological variables for crop modeling with the ALMANAC model in eight Texas counties and found that decreases and increases of precipitation, respectively, 
corresponded to decreases and increases of simulated crop production for both maize and sorghum. Katerji et al. (2009) worked on durum wheat and barley in a factorial salinity-drought environment and found that crop production by both crops decreased significantly with drought. 


\section{Chapter 3 Methodology}

This chapter is presented in five sections. The first section introduces general information about the study site. The second section describes the model used to run ET and crop yield simulations. The third section introduces three ET estimation methods used in this study. The fourth section outlines the meteorological, soil and crop yield data sources. The last section discusses the methods used to process data.

\subsection{Study Site}

The study site is centred on the Lethbridge Flux Tower, Alberta, Canada, at the latitude of $49.43^{\circ} \mathrm{N}$, longitude of $112.56^{\circ} \mathrm{W}$ and altitude of $951 \mathrm{~m}$ above sea level (Figure 3-1). The tower is approximately $145 \mathrm{~km}$ east of the Canadian Rockies and $95 \mathrm{~km}$ north of the border with the United States (Montana). The vegetation on which the tower is located is classified as mixed grass prairie, occurring in the northern portion of the Great Plains, which is the second largest eco-zone in North America with area of approximately 2.6 million square kilometers (Flanagan and Johnson, 2005; Wever et al., 2002). The major species at the study site consist of Agropyron spp. (wheat grasses), Tragopogon dubius (goat's beard), Vicia americana (wild vetch, American vetch), Koleria cristata (June grass), Eurotia lanata (winter fat), Stipa comata (spear grass, needle-and-thread grass), Achillea 
millefolium (common yarrow); Artemisia frigida (pasture sage); Carex spp. (sedges, Bouteloua gracilis (blue grama grass).

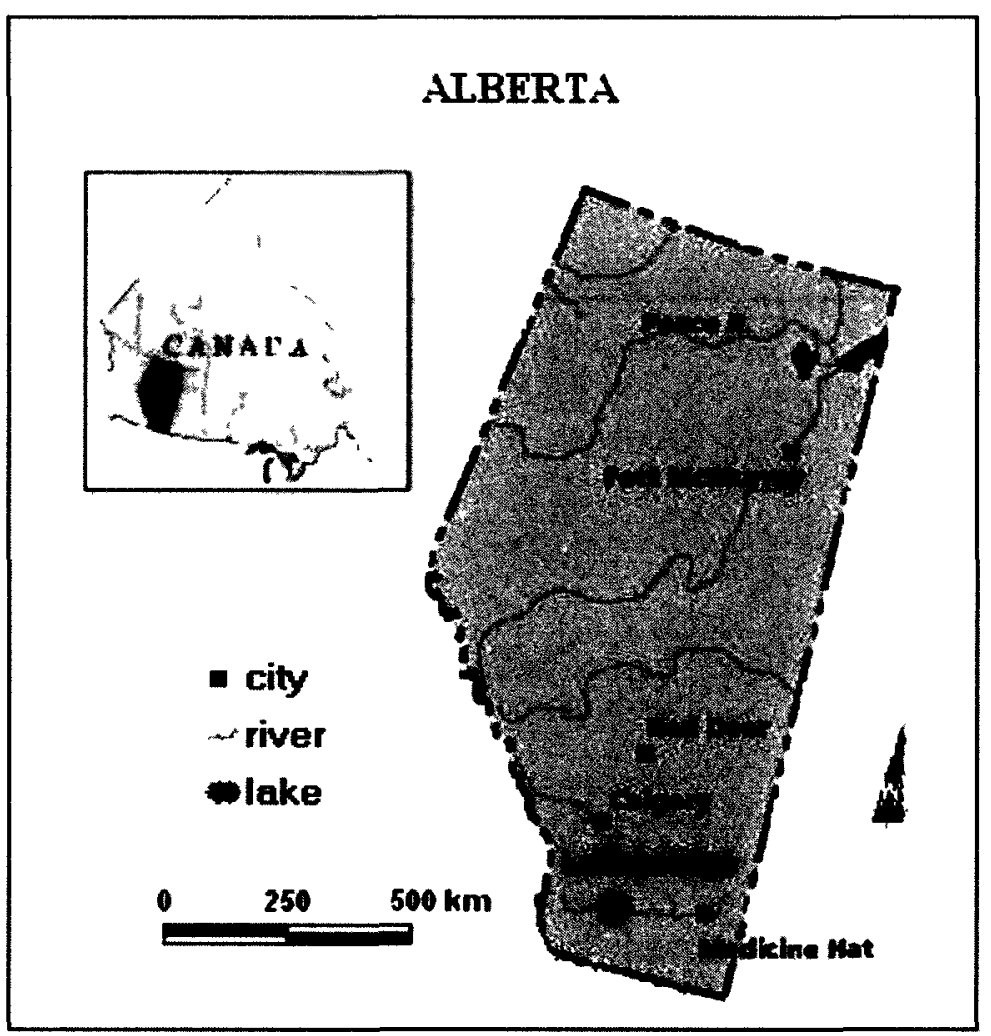

Figure 3-1 Location of the study site in Alberta (Sims et al., 2005)

The flux tower site described above is used for ET predictions over native grasslands. Further analyses of the impacts of ET on predicted crop yield take advantage of the fact that this site is surrounded by cultivated land. Crops planted on this agricultural land include wheat, mustard, canola, barley, and chickpea. Agricultural field locations in the prairies are generally referenced with respect to a hierarchical township, range and section grid system. Figure 3-2 represents Alberta's Township System (ATS), the grid network 
used for referencing legal land descriptions (AGS, 2009). It classifies Alberta into fields in 3 levels: township, section and quarter, in decreasing order. A township covers a six mile by six mile square and is further divided into 36 sections, each measuring one mile by one mile (640 acres). A section can be further divided into 4 quarters: NE, NW, SE and SW, each covering 160 acres. All crop yield comparisons in this study use data from 4 townships surrounding the flux tower site: T006-R20-W4, T006-R19-W4, T005-R20-W4 and T005-R19-W4. 


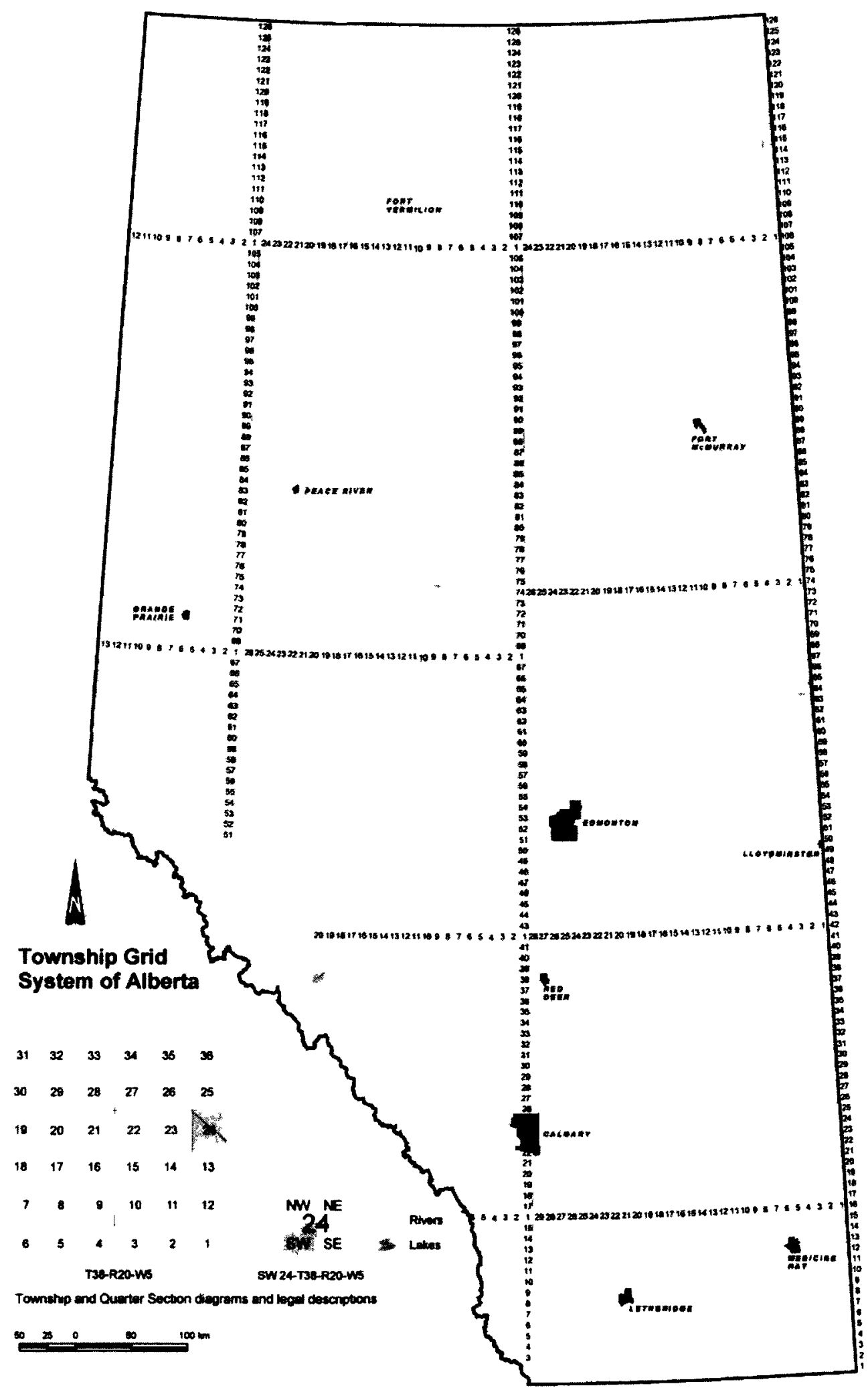

Figure 3-2 Configuration of the Alberta Township System (AGS, 2009) 
The high altitude of $951 \mathrm{~m}$ above sea level and close proximity to the Rocky Mountains provides the study site with cooler summers and warmer winters than other regions in the prairies, which extends the growing season for grass and shortens the period with snow cover. The prairie has a semi-arid, moderately cool climate with a mean temperature of $17.1^{\circ} \mathrm{C}$ in summer and $-6.2^{\circ} \mathrm{C}$ in winter (Gilmanov et al., 2005; Ponton et al., 2006). The mean annual precipitation is $378 \mathrm{~mm}$ with $32 \%$ falling in May and June on average (Wever et al., 2002). During the summer months mean pan evaporation often exceeds mean precipitation by at least $200 \%$ and even $300 \%$ (Flanagan and Johnson, 2005). Mean annual wind speed is $5.2 \mathrm{~m} \mathrm{~s}^{-1}$ out of the west (Ponton et al., 2006).

Most soil at the study site has a clay loam texture with $25 \%$ - $38 \%$ sand, $36 \%$ - $40 \%$ silt and $26 \%$ - 35\% clay (Flanagan et al., 2002). The average dry bulk density for $1 \mathrm{~m}$ depth of top soil is $1.4 \mathrm{~g} \mathrm{~cm}^{-3}$ (AAFC, 2007c). The average monthly aboveground biomass was 88.382 $\mathrm{g} \mathrm{m}^{-2}$ (Ponton et al., 2006). Canopy height varies with different years as low as $18.5 \mathrm{~cm}$ in 2001 and as high as $39 \mathrm{~cm}$ in 2003 (Ponton et al., 2006). 


\subsection{Simulation Model}

\subsubsection{Model Description}

The Daisy model (Hansen et al., 1990) is used in this study to simulate ET over grass and cultivated surfaces, as well as crop yield. Daisy is a process-based model that describes the soil-crop-atmosphere system based on the simulation of the physiological interactions between ecosystem variables and crop growth processes under alternate management strategies (Abrahamsen and Hansen, 2000; Hansen et al., 1990; Jensen et al., 1994a: Petersen et al. 1995). Daisy contains 5 submodels to simulate the dynamics of soil, crop and atmosphere features, including water balance, heat balance, solute balance, crop production and agricultural management submodels.

The Daisy model requires weather, management, soil and vegetation data to conduct simulations, among which default parameters for many common types of vegetation have been provided in the model and the others need to be provided by users (Figure 3-3). Weather data include solar radiation, air temperature, precipitation, vapour pressure or relative humidity, wind speed and $\mathrm{ET}_{0}$. Soil data include soil texture, humus content, dry bulk density, maximum root depth, groundwater depth, soil hydraulic properties, $\mathrm{C} / \mathrm{N}$ ratio in the humus, etc. Management data generally include the crop type, the amount and type of the fertilizer applied, the amount of irrigation applied and how it was applied (surface, 
overhead or subsoil), the type of tillage operations and the exact dates for applying the management operations. The Daisy model in many cases is able to adjust to the available data, either by using simpler models internally or by trying to synthesize the missing data from what is available (Hansen et al., 1990).

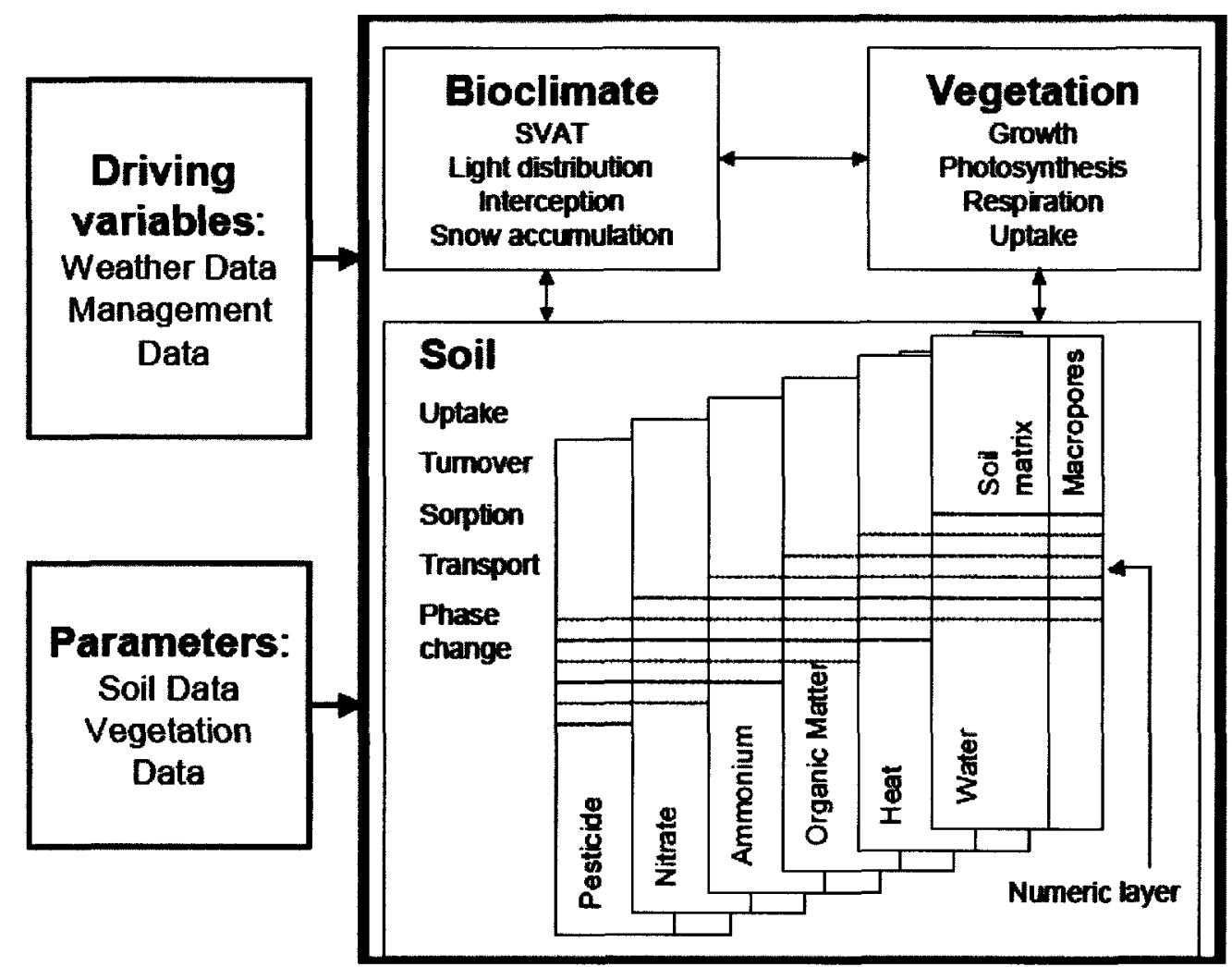

Figure 3-3 Schematic representation of the agro-ecosystem model Daisy (Hansen et al., 1990)

\subsubsection{ET Estimation}

The Daisy model does not estimate $\mathrm{ET}_{\mathrm{a}}$ directly, rather it predicts $\mathrm{ET}_{\mathrm{o}}, \mathrm{ET}_{\mathrm{p}}$ and $\mathrm{ET}_{\mathrm{a}}$ in sequence. $\mathrm{ET}_{\mathrm{o}}$ is calculated by the ET estimation methods explained in section 3.3. $\mathrm{ET}_{\mathrm{p}}$ is 
determined by multiplying $\mathrm{ET}_{\mathrm{o}}$ by the crop coefficient $\mathrm{K}_{\mathrm{c}}$. $\mathrm{K}_{\mathrm{c}}$ represents an integration of the differences between the field vegetation and reference grass, including canopy height, albedo of the vegetation-soil surface, canopy resistance and evaporation from soil. It is specified for each type of vegetation and varies by growth stage. $\mathrm{ET}_{\mathrm{a}}$ is determined by multiplying $\mathrm{ET}_{\mathrm{p}}$ by the stress coefficient $\mathrm{K}_{\mathrm{s}}$, which represents the effects of environmental and management stress on crop growth. If there is no stress exerting on the plant growth, $\mathrm{K}_{\mathrm{s}}$ equals to 1; otherwise, $\mathrm{K}_{\mathrm{s}}$ is below 1. All the ET in this thesis for analysis referred to $\mathrm{ET}_{\mathrm{a}}$.

\subsubsection{Crop Yield Estimation}

The Daisy model estimates photosynthesis based on the calculation of light distribution within the canopy and light response curves. For the light distribution calculation, the canopy is divided into $n$ distinct layers, each containing $1 / n$ of the total LAI. The adsorption of light within layer $i$, counted from the top of the canopy, can be calculated as:

$$
S_{a, l}=\left(I-\rho_{c}\right) S_{1,0}\left(e^{-k_{\mathrm{c}}(1-l) \Delta L_{a \mathrm{a}}}-e^{-k_{\mathrm{d}} \Delta I_{c a}}\right)
$$

where $S_{a, i}$ is the absorbed light in layer $i, \rho_{\mathrm{c}}$ is the reflection coefficient of the canopy, $S_{v, 0}$ is the incident light above the canopy, $k_{c}$ is the extinction coefficient, and $\Delta L a i=L a i / n$ is the LAI within each canopy layer. Both of $\rho_{\mathrm{c}}$ and $k_{c}$ are crop specific. 
The gross photosynthesis within the whole canopy is calculated by accumulating the contribution from the individual layers by applying a light response curve:

$$
\Delta F_{1}=x \Delta L_{a !} F_{m}\left(1-\exp \left(-\frac{\varepsilon}{F_{m}} \frac{S_{a, 1}}{\Delta L_{a !}}\right)\right)
$$

where $\Delta F_{l}$ is the gross photosynthesis for layer $i$ for the considered crop, $x$ is the LAI fraction of the crop, $F_{m}$ is a crop specific photosynthetic rate at saturated light intensity and $\varepsilon$ is a corresponding initial light use efficiency at low light intensity.

The Daisy model also assumes that transpiration as well as $\mathrm{CO}_{2}$ assimilation is governed by stomatal response and that leaf stomata are open when intercepted water is evaporated from the leaf surfaces. These assumptions lead to the approximation:

$$
F_{w}=F_{p} \frac{E_{t}+E_{l}}{E_{t, p}+E_{l, p}}
$$

where $F_{w}$ is water-limited photosynthesis, $F_{p}$ is potential photosynthesis, $E_{t}$ and $E_{t, p}$ is actual and potential transpiration, respectively, and $E_{l}$ and $E_{l, p}$ is actual and potential evaporation of intercepted water, respectively.

After subtracting the crop respiration from gross photosynthesis, this net production is partitioned between the considered crop components, including root, stem, leaf and storage organs. The fraction of net production goes to different crop components is crop 
specific and varies with the development stage. The net production that goes to storage organs is presented as annual crop yield.

\subsection{Evapotranspiration Estimation Methods}

There are three ET estimation methods built into the water balance submodel of Daisy to estimate ET: the FAO Penman-Monteith, Samani and Hargreaves, and Makkink methods. Description of each method is provided in the following sections.

\subsubsection{FAO Penman-Monteith Method}

The FAO Penman-Monteith method is a physically-based analytical approach derived from the Penman-Monteith equation (Batchelor, 1984; Smith et al., 1991), a combination of the energy balance and mass transfer method, specifying the resistance factors of the reference surface. It defines the reference surface as a hypothetical surface of green grass with an assumed uniform height of $0.12 \mathrm{~m}$, a surface resistance of $70 \mathrm{~s} \mathrm{~m}^{-1}$ and an albedo of 0.23 under actively growing and adequately watered conditions (Allen, 2000). The FAO Penman-Monteith method to estimate $\mathrm{ET}_{\mathrm{o}}$ is derived as:

$$
E T_{0}=\frac{0.408 \Lambda\left(R_{n}-G\right)+\gamma \frac{900}{T+273} u_{2}\left(e_{s}-e_{a}\right)}{\Delta+\gamma\left(1+0.34 u_{2}\right)}
$$


Where

$\mathrm{ET}_{\mathrm{o}}$ reference evapotranspiration $\left[\mathrm{mm} \mathrm{day}^{-1}\right]$,

$R_{n} \quad$ net radiation at the surface $\left[\mathrm{MJ} \mathrm{m}^{-2}\right.$ day $\left.^{-1}\right]$,

G soil heat flux density $\left[\mathrm{MJ} \mathrm{m}^{-2}\right.$ day $\left.^{-1}\right]$,

T air temperature at $2 \mathrm{~m}$ height $\left[{ }^{\circ} \mathrm{C}\right]$,

$\mathrm{u}_{2} \quad$ wind speed at $2 \mathrm{~m}$ height $\left[\mathrm{m} \mathrm{s}^{-1}\right]$,

$\mathrm{e}_{\mathrm{s}} \quad$ saturation vapour pressure $[\mathrm{kPa}]$,

$\mathrm{e}_{\mathrm{a}}$ actual vapour pressure $[\mathrm{kPa}]$,

$\Delta \quad$ slope of vapour pressure curve $\left[\mathrm{kPa}^{\circ} \mathrm{C}^{-1}\right]$,

$\gamma \quad$ psychrometric constant $\left[\mathrm{kPa}^{\circ} \mathrm{C}^{-1}\right]$.

To use Equation [8], site location information of altitude and latitude and standard climatological records of solar radiation, air temperature, relative humidity and wind speed are required. Altitude and latitude of the site location are needed to adjust the local psychrometric constant $(\gamma)$ and latitude is also involved in extraterrestrial radiation $\left(\mathrm{R}_{\mathrm{a}}\right)$ computation. Solar radiation is required to calculate $R_{n}$ based on a radiation balance model in combination with $R_{a}$. T is used to develop $\Delta$ and calculate vapour pressure deficit (VPD) $\left(e_{s}-e_{a}\right)$. Relative humidity is used to derive $e_{s}-e_{a}$. To ensure the integrity of ET $_{o}$ estimation, all the climatological parameters should be measured at $2 \mathrm{~m}$ or converted to this height (Allen, 2000). 


\subsubsection{Samani and Hargreaves Method}

The Samani and Hargreaves method is a temperature-based empirical approach (Hargreaves and Samani, 1985). It was developed from the Christiansen equation (1968), which uses a multiplicative method to relate ET to solar radiation, temperature, relative humidity and wind speed, respectively (Hargreaves and Allen, 2003; Samani, 2004). In an experiment conducted by Hargreaves (1975) on a cool season grass region at Davis, Calif., regressions were made using ET measurements as a function of various combinations of weather factors and showed that the multiplication of temperature by solar radiation explains $94 \%$ of variability of ET measurements and that of wind speed by relative humidity only explains about $10 \%$. Based on these results, coefficients for wind speed and relative humidity were left out of the equation to foster simplicity and reduce data requirements. Since then the Samani and Hargreaves method has been calibrated widely under various weather and environmental conditions and shown reasonable ET estimations with a global validity (Itenfisu et al., 2000; Samani, 2004).

Currently the Samani and Hargreaves method is generally described as:

$$
\mathrm{ET}_{\mathrm{o}}=0.408 \times 0.0023 \times\left(T_{\text {mean }}+17.78\right) \times\left(T_{\max }-T_{\min }\right)^{0.5} \times R_{\mathrm{a}}
$$

Where

$\mathrm{ET}_{\mathrm{o}}$ reference evapotranspiration $\left[\mathrm{mm} \mathrm{day}^{-1}\right]$,

$\mathrm{T}_{\text {mean }} \quad$ mean daily air temperature at $2 \mathrm{~m}$ height $\left[{ }^{\circ} \mathrm{C}\right]$, 


$$
\begin{aligned}
& \mathrm{T}_{\max } \text { daily maximum temperature at } 2 \mathrm{~m} \text { height }\left[{ }^{\circ} \mathrm{C}\right] \text {, } \\
& \mathrm{T}_{\min } \text { daily minimum temperature at } 2 \mathrm{~m} \text { height }\left[{ }^{\circ} \mathrm{C}\right] \text {, } \\
& \mathrm{R}_{\mathrm{a}} \quad \text { extraterrestrial radiation }\left[\mathrm{MJ} \mathrm{m}{ }^{-2} \text { day }^{-1}\right] .
\end{aligned}
$$

Due to the low data requirement, it is often applied under conditions where less data is available, and especially, when only air temperatures are available (Hargreaves and Allen, 2003). It is also used to estimate historical series of ET in irrigation and water resources systems, using historical air temperature records (Temesgen et al., 2005; Vanderlinden et al., 2004).

\subsubsection{Makkink Method}

The Makkink method is a radiation-based empirical approach to estimate $\mathrm{ET}_{\mathrm{o}}$ (Jacobs and Bruin, 1998; Xu and Chen, 2005). It was first proposed by Makkink (1957) for grass ET estimation, which empirically related grass ET to global radiation as well as other climatic coefficients (Jacobs and Bruin, 1998). After that the Makkink method has been calibrated widely in various environmental conditions (De Bruin, 1981; De Bruin, 1987; Hansen, 1984).

The Makkink method is now generally presented in the following form: 


$$
\mathrm{ET}_{\mathrm{o}}=0.7 \frac{\Delta}{\Delta+\gamma} \frac{R_{\mathrm{s}}}{\lambda}
$$

Where

$\mathrm{ET}_{0}$ reference evapotranspiration $\left[\mathrm{mm}\right.$ day $\left.^{-1}\right]$,

$\mathrm{R}_{\mathrm{s}} \quad$ solar radiation $\left[\mathrm{MJ} \mathrm{m}^{-2}\right.$ day $\left.^{-1}\right]$,

$\Delta \quad$ slope of vapour pressure curve $\left[\mathrm{kPa}^{\circ} \mathrm{C}^{-1}\right]$,

$\gamma \quad$ psychrometric constant $\left[\mathrm{kPa}^{\circ} \mathrm{C}^{-1}\right]$,

$\lambda \quad$ latent heat of vaporization $\left[\mathrm{MJ} \mathrm{kg}^{-1}\right]$.

The Makkink method requires solar radiation $\left(\mathrm{R}_{\mathrm{s}}\right)$ and air temperature. $\Delta$ is derived from air temperature and $\gamma$ is decided by the site location information of altitude and latitude. The Makkink method is often applied due to its low data requirement and simplicity.

\subsection{Data Sources}

\subsubsection{Meteorological Data}

Meteorological data used for model simulation in this study were obtained from the Fluxnet Canada Data Information System (DIS), which is maintained and updated regularly by Fluxnet-Canada. This DIS is the Internet based warehouse for all Canadian Fluxnet data, containing the standardized meteorological, physiological, flux and associated ecological data based on the continuous measurements of climate conditions 
and the carbon, water and energy exchanges between ecosystems and atmosphere (Barr et al., 2004; Morgenstern et al., 2004). Flux data for the Lethbridge site were available by month with a half-hour time step starting from 1998 to present, and was quality checked and processed to FluxNet Canada standards, but not gap filled. The only data gaps in the variables used in this study were ET measurements during some winter periods. In these cases, ET was interpolated by averaging ET values in the weeks preceding and following the missing day(s).

Meteorological data from the Lethbridge Flux Tower used in this study included solar radiation, air temperature, precipitation, relative humidity and wind speed, for the period of 2000 to 2004. Furthermore, daily ET measurements used to validate modelled ET and ecological parameters (soil moisture, leaf area index) at the study site at specific days for 2000 to 2004 were also obtained from the Fluxnet Canada DIS.

\subsubsection{Soil Data}

Soil data were obtained from the National Soil DataBase (NSDB), which serves as the national archive for land resources information collected by federal and provincial field surveys or created by land data analysis projects (AAFC, 2007c). Soil data are organized within a vector-based thematic information system, within which the map is separated into 
polygons with relatively homogeneous soil attribute features and each polygon is recorded uniform soil attribute features. Each map/dataset within the NSDB contains a series of ARC/Info coverages showing both spatial and attribute features for various components of the map, for example the distribution of soil type and the hydraulic conductivity of soil (AAFC, 2007c). The soil in each polygon is further divided into different layers by depth. This study uses soil texture (relative proportions of sand, silt and clay particles), humus content, dry bulk density and soil hydraulic (including water conductivity of saturated soil and the soil saturation point) parameters to define soil properties of the study site.

\subsubsection{Crop Yield Data}

Crop yield data in this study were obtained from the Alberta Crop Insurance of Agriculture Financial Services Corporation (AFSC), which is a provincial crown corporation that provides farmers, agribusinesses and other small businesses in Alberta with crop insurance, farm loans, commercial loans and farm income disaster assistance. On average the AFSC insures about 11-12 million acres, 14,000 clients and 100,000 fields. Yields are collected from the crop and hay insurance clients. Various agricultural fields and crop characteristics are integrated into the crop insurance files, including year, crop type, numeric code of the crop, irrigated condition, soil condition (fallow, stubble or irrigated), numeric code for the municipality, meridian, township, range, section, part, field area, 
yield and client. The combination of meridian, township, range, section and part defines the location of field in the ATS (as explained in Section 3.1). Crop yield is also measured and recorded based on the ATS. In this study crop yield of spring wheat from 2000 to 2004 at the study site covering 4 townships: T006-R20-W4, T006-R19-W4, T005-R20-W4 and T005-R19-W4 surrounding the Lethbridge Flux Tower were used for validating the crop yield simulation. Despite the limits to this cropping practice data, it is actually rich compared to generally available data, due to privacy concerns. A data confidentiality agreement was signed with AFSC, which prohibits the presentation of yields in specific fields in this thesis.

\subsubsection{Management Data}

Beyond what was contained in the insurance database, no specific records of management data were available for the cultivated fields surrounding the study site. Typical management data suggested by Ross McKenzie (pers. comm.), a Research Scientist with Alberta Agriculture and Rural Development (AARD) at Lethbridge, were used for each year in this study. Typically, spring wheat is seeded in the last two weeks of April if soil and environmental conditions permit, and harvest of spring wheat takes place in the last two weeks of August, depending on growing season precipitation and weather conditions in August. Most farmers in the Lethbridge area seed spring wheat directly without cultivating 
the soil before seeding and also apply fertilizer at the time of seeding in a one-pass system. Typically about 50 to $70 \mathrm{~kg} / \mathrm{ha}$ of nitrogen is applied. Irrigation was applied irregularly as needed. When crop water use is low (about $2 \mathrm{~mm} /$ day) at early growth stages and if no precipitation is received, irrigation might be applied at rate of 20 to 25 $\mathrm{mm}$ every 10-14 days. And at peak crop water use of $7 \mathrm{~mm} /$ day, irrigation could occur once every 4 days. Based on these typical conditions, management activities and the corresponding applying dates in Table 3-1 were applied to simulate crop development. In this study irrigation was not taken into account for simulation because it was difficult to make a defendable assumption based on the variety of real-world practices.

Table 3-1 List of typical management data at the study site for the period of 2000 to 2004

\begin{tabular}{l|l}
\hline \hline Management activity & Management data \\
\hline Crop & spring wheat \\
\hline Sowing date & April 23 \\
\hline Fertilizing date & April 24 \\
\hline Fertilizing amount & $60.0 \mathrm{~kg} / \mathrm{ha}$ (nitrogen) \\
\hline Harvesting date & August 23 \\
\hline \hline
\end{tabular}




\subsection{Modeling and Data Processing}

\subsubsection{Grass ET Estimation}

As mentioned above, the Daisy model requires weather, soil, management and vegetation data to conduct simulations. Weather data, including solar radiation, air temperature, precipitation, relative humidity and wind speed, for the period of 2000 to 2004 were integrated into the format required by the Daisy model. Soil properties, including soil texture, humus content, dry bulk density and soil hydraulic conductivity, were specified by selecting the model-provided soil parameters that best matched the conditions reported in the NSDB. Management activities were not given because the grasses at the study site grew in the natural state and no management activities were applied. Instead of the default values by the Daisy model, LAI values (ecological parameter) were specified for grass in the vegetation file using data from the flux tower. Separate model runs were conducted for each ET estimation method. Output variables selected for further analysis included $\mathrm{ET}_{\mathrm{a}}$ and soil water.

\subsubsection{Crop Yield Estimation}

The same weather and soil data described above were used for crop yield. Management data as listed in Table 3-1 were specified in the interface file. Default vegetation data for 
spring wheat were used for crop yield estimation. The model was run for each ET estimation method and each year from 2000 to 2004 . Output collected for further analysis included soil water, root extraction, and spring wheat crop variables: development stage, LAI, accumulated net photosynthesis and crop yield.

\subsubsection{Standardization of ET and Meteorological Variables}

One objective in this study is to evaluate the dependence of ET on meteorological variables. This is qualitatively fulfilled by comparing the annual distributions between ET and each meteorological variable. If obviously consistent patterns are observed, this suggests that ET depends highly on the corresponding meteorological variable, and vice versa. However, due to the differences in data dimension, it is impossible to compare the distribution patterns between ET and each meteorological variable directly. Using dimensionless quantities helps to solve this problem. In this study, calculation of standard score (also called $z$-score and normal score) is used to standardize ET and meteorological variables into the dimensionless values. A standard score is a measure of standard deviations of a datum from the mean of dataset (Richard and Morris, 2000). It is derived by subtracting the mean from an individual datum and then dividing the difference by the standard deviation of the dataset. The mathematical formula to calculate the standard score is described as Equation 11. 


$$
Z_{i}=\left(X_{i}-\mu\right) / \sigma
$$

Where $Z$ is the standard score of $X_{l}, X_{l}$ is a variable or datum, $i$ is the $i$ th value in the dataset, $\mu$ is the mean of dataset and $\sigma$ is the standard deviation of dataset.

The standard score equation was applied to the daily values of ET measurements, ET estimations by three ET methods and meteorological variables, including solar radiation, air temperature, humidity and wind speed for the period of 2000 to 2004. Firstly, due to the significant variability of ecosystem factors between years, for visualization of the dependence of ET on meteorological variables, the daily 5 year average was calculated for each variable. Then the standard score equation was applied to standardize the daily means. For the calculation of $\mu$ and $\sigma$, the daily values in all 5 years were used.

\subsubsection{Data Analysis}

Qualitative visualization of the dependences of ET on meteorological variables is provided by comparing the distributions of standard scores between ET and each meteorological variable. To get a quantitative understanding of ET dependences, the coefficient of determination $\left(\mathrm{R}^{2}\right)$ between daily values of ET and each meteorological variable using values for all 5 years (2000 to 2004) is calculated in this study. $\mathrm{R}^{2}$ represents the proportion

of the variance in a dependent variable that is accounted for by other variable (Healy, 1984). 
It is a measure to determine how certain one can make predictions from a particular model/relationship. $\mathrm{R}^{2}$ is calculated as:

$$
R^{2} \equiv 1-\frac{S S_{\mathrm{err}}}{S S_{\mathrm{tot}}}
$$

where $S S_{e r r}$ is the sum of squared residuals, and $\mathrm{SS}_{\text {tot }}$ is the sum of squared deviations from the mean of the dependent variable:

$$
\begin{aligned}
& S S_{\mathrm{err}}=\sum_{i}\left(y_{i}-f_{i}\right)^{2} \\
& S S_{\mathrm{tot}}=\sum_{i}\left(y_{i}-\bar{y}\right)^{2},
\end{aligned}
$$

where $y_{i}$ is the variable in the dataset, and $f_{i}$ is the dependent variable. In this study, $y_{i}$ represents each meteorological variable and $f_{i}$ represents ET.

The performance of the three ET methods, including the FAO Penman-Monteith, Samani and Hargreaves, and Makkink method, was evaluated via correlation $\left(\mathrm{R}^{2}\right)$ and error analysis. In each case, the alternative estimates of $\mathrm{ET}$ refer to $\mathrm{ET}_{\mathrm{a}}$ calculated by Daisy as a result of the three different methods to estimate $\mathrm{ET}_{\mathrm{0}}$. The mean bias error (MBE) and the root mean square error (RMSE) are both error measures used to represent the average differences between predicted $(P i)$ and observed $(O i)$ values (Jacovides and Kontoyiannis, 1995). The mathematical formulas are described as: 


$$
\begin{aligned}
& M B E=\frac{1}{n} \sum_{i=1}^{n}\left(P_{i}-O_{i}\right) \\
& R M S E=\sqrt{\frac{1}{n} \sum_{i=1}^{n}\left(P_{i}-O_{i}\right)^{2}}
\end{aligned}
$$

Both terms were calculated directly using daily flux tower ET measurements and Daisy $\mathrm{ET}_{\mathrm{a}}$ predictions. The MBE represents the degree of bias between observed and predicted values. Positive values indicate overestimation while negative values indicate underestimation. The RMSE measures the magnitude of error and is sensitive to large errors, since the errors are squared before they are averaged. Low values of MBE and RMSE are desired, but it is possible to have a large RMSE value and at the same time a small MBE, or relatively a small RMSE and a large MBE (Almorox et al., 2004).

\subsubsection{Sensitivity analysis}

In practice, management activities such as sowing date, the type and amount of fertilizer, harvest date, etc., are generally selected depending on the local metrological and environmental conditions of the specific year. However, in this study uniformly typical management activities between years were applied to simulate crop yields. This may contribute to the errors of crop yield simulations. Therefore, sensitivity analysis was used to assess the effect of management data on crop yield simulations. The amount of fertilizer applied was the independent variable. Sensitivity analysis was conducted by changing the 
fertilizing rate from $0 \mathrm{~kg} \mathrm{ha}^{-1}$ to $90 \mathrm{~kg} \mathrm{ha}^{-1}$ to examine the corresponding variability of simulated crop yield in 2001, while keeping the other meteorological, soil and management data constant. 


\section{Chapter 4 Results and Discussion}

This chapter is presented in four sections. The first section presents the dependence of ET on meteorological variables. Both ET measurements and ET estimates (by the FAO Penman-Monteith, Samani and Hargreaves, and Makkink methods) are evaluated with respect to meteorological measurements. The second section evaluates the performance of the ET models in more detail. The daily ET measurements and estimates for the period of 2000 to 2004 are used to conduct the evaluation. The third section discusses the impacts of different ET estimation methods on crop yield simulations. The last section provides sensitivity analysis to indicate the effect of management data on crop yield simulations.

\subsection{Dependence of ET on Meteorological Variables}

\subsubsection{ET Measurements}

The dependence of ET measurements on meteorological variables, including solar radiation, temperature, relative humidity and wind speed, was visualized by means of comparison of standard scores of the 5-year mean (Figure 4-1) and quantitatively evaluated through $\mathrm{R}^{2}$ (Table 4-1). Both comparisons indicated that ET measurements at the study site posed high dependence on solar radiation and temperature, while lower dependence on 
relative humidity and wind speed.

The overall distribution pattern of standard scores of daily ET measurements remained in accordance with those of solar radiation and temperature, presented more or less a reciprocal relationship with that of relative humidity, while having no obvious correlation between ET and wind speed (Figure 4-1). ET over mixed-grass prairies remained low with little variability from January to April, possibly due to the fact that the steady and low evaporation from snow cover dominated in the first 3 months. After that ET increased rapidly until peak values were reached in June. From July till end of the year ET showed an overall decreasing pattern. Solar radiation fluctuated in a similar pattern to ET. In the beginning of the year less solar radiation was intercepted by the grass surface. With gradual increase before June, solar radiation obtained the peak values in June and July. After that it decreased until the end of the year. Temperature also fluctuated in a similar pattern, but with the notable difference that the peak temperature occurred one month later than that of ET. Relative humidity generally remained lower during the period of mid-April to September than during the rest of the year. Wind speed fluctuated around the 5-year mean, with no large deviations from the mean and no obvious correlation with ET.

Correlations between daily ET measurements and the meteorological variables (Table 4-1) showed that both solar radiation and temperature accounted for the majority of variability 
of ET measurements, relative humidity accounted for a relatively small portion of variability and wind speed barely affected ET measurements. As much as 75\% of variability of ET measurements was accounted for by solar radiation. Temperature could also account for high variability of ET of $63 \%$ with $\mathrm{R}^{2}$ of 0.63 . Relative humidity only accounted for $23 \%$ of variability of ET and wind speed barely contributed to ET, giving an extremely low $\mathrm{R}^{2}$ of 0.03 . 


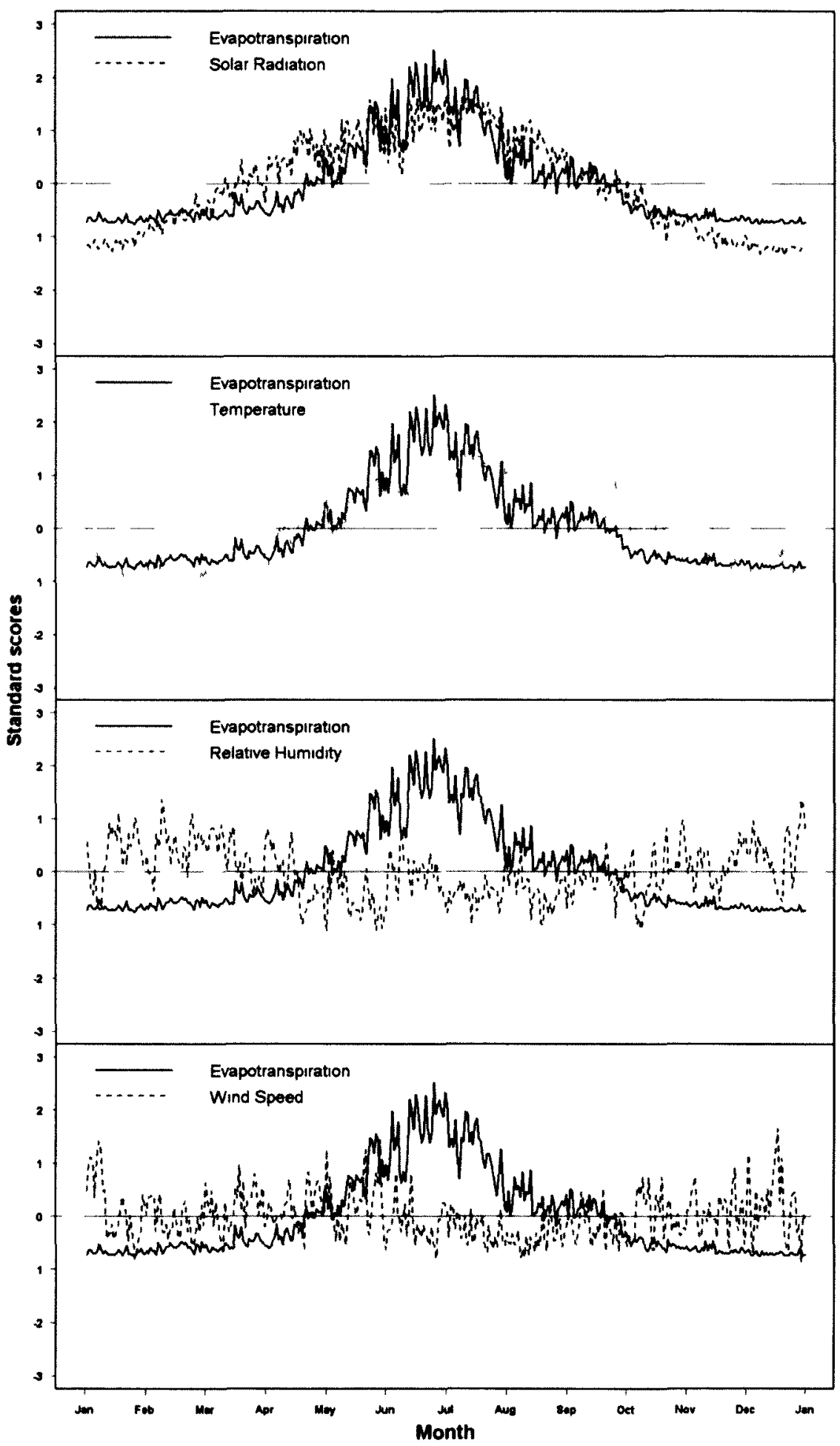

Figure 4-1 Comparisons of standard scores between daily ET measurements and meteorological variables (standard scores of 0 correspond to the 5 year average for that variable on that specific day) 
Table 4-1 Coefficient of determination $\left(\mathrm{R}^{2}\right)$ between ET and meteorological variables

\begin{tabular}{lcccc}
\hline \multirow{2}{*}{ Methods } & \multicolumn{4}{c}{$\mathrm{R}^{2}$} \\
\cline { 2 - 5 } & Solar Radiation & Air Temperature & Humidity & Wind Speed \\
\hline Flux tower measurement & 0.75 & 0.63 & 0.23 & 0.03 \\
\hline FAO Penman-Monteith & 0.75 & 0.67 & 0.30 & 0.01 \\
\hline Samani and Hargreaves & 0.80 & 0.72 & 0.25 & 0.05 \\
\hline Makkink & 0.83 & 0.70 & 0.26 & 0.04 \\
\hline \hline
\end{tabular}

With respect to physical ET processes, a high dependence of ET on solar radiation and temperature is because ET processes are determined by the amount of energy available to vaporize water, which comes from solar radiation and, to a lesser extent, the ambient air temperature (Allen et al., 1998). In the beginning of the year, less solar radiation is available and temperature remains low, so only a small amount of energy can be obtained by grass, and ET during this period is low. From April, with more available solar radiation and increasing temperature, ET over the grass increases. When it comes to June and July, adequate solar radiation is available, as well as high temperature, and the peak ET values are obtained, followed by declines with less available solar radiation and decreasing temperature. Relative humidity relates to the capacity of atmosphere to receive more evaporated water. If relative humidity of atmosphere is low, air has a high drying power to extract water via ET, and with relative humidity close to the saturation, ET slows down and might stop. In the first 4 months relative humidity of the atmosphere remains relatively 
high, less evaporation is needed; this more or less can explain the low ET measurements during this period. From May to September relative humidity remains low during most days, corresponding to a high drying power of the air, and more water is evaporated from grassy surfaces; as a result besides adequate solar radiation and high temperature, low relative humidity of atmosphere also contributes to this period of peak ET. After September with relatively high relative humidity in most days, ET remains low. Wind can accelerate air movement as ET proceeds. But during the period of 2000 to 2004 this study site presents a low wind speed with the mean of $4.6 \mathrm{~m} \mathrm{~s}^{-1}$ over the year, so its effect is not evident.

\subsubsection{ET Estimates}

The dependences of ET estimates by the FAO Penman-Monteith, Samani and Hargreaves and Makkink methods on meteorological variables, including solar radiation, temperature, relative humidity and wind speed, are visualized in Figure 4-2, Figure 4-3 and Figure 4-4, and their respective correlations are evaluated via $\mathrm{R}^{2}$ in Table 4-1. All three ET estimates depended highly on solar radiation and temperature, while less on relative humidity and wind speed.

The three ET methods showed similar general patterns in that the overall distributions of 
standard scores of ET estimates followed those of solar radiation and temperature, presented a reciprocal relationship with that of relative humidity, while having no obvious correlations with wind speed (Figure 4-2, Figure 4-3, Figure 4-4). ET estimates by the three methods remained low before mid-April, then increased rapidly until the peak values were reached in June. Values from July till end of the year showed an overall decreasing pattern. Solar radiation and temperature varied in the similar pattern to those of ET estimations, but with the notable difference that the peak temperature occurred one month later than the peak ET estimates. Relative humidity was relatively low during the period of mid-April to September and higher in the remaining periods. Wind speed fluctuated around the mean over the year, no big deviation appeared and no obvious correlations with ET estimations were found. 


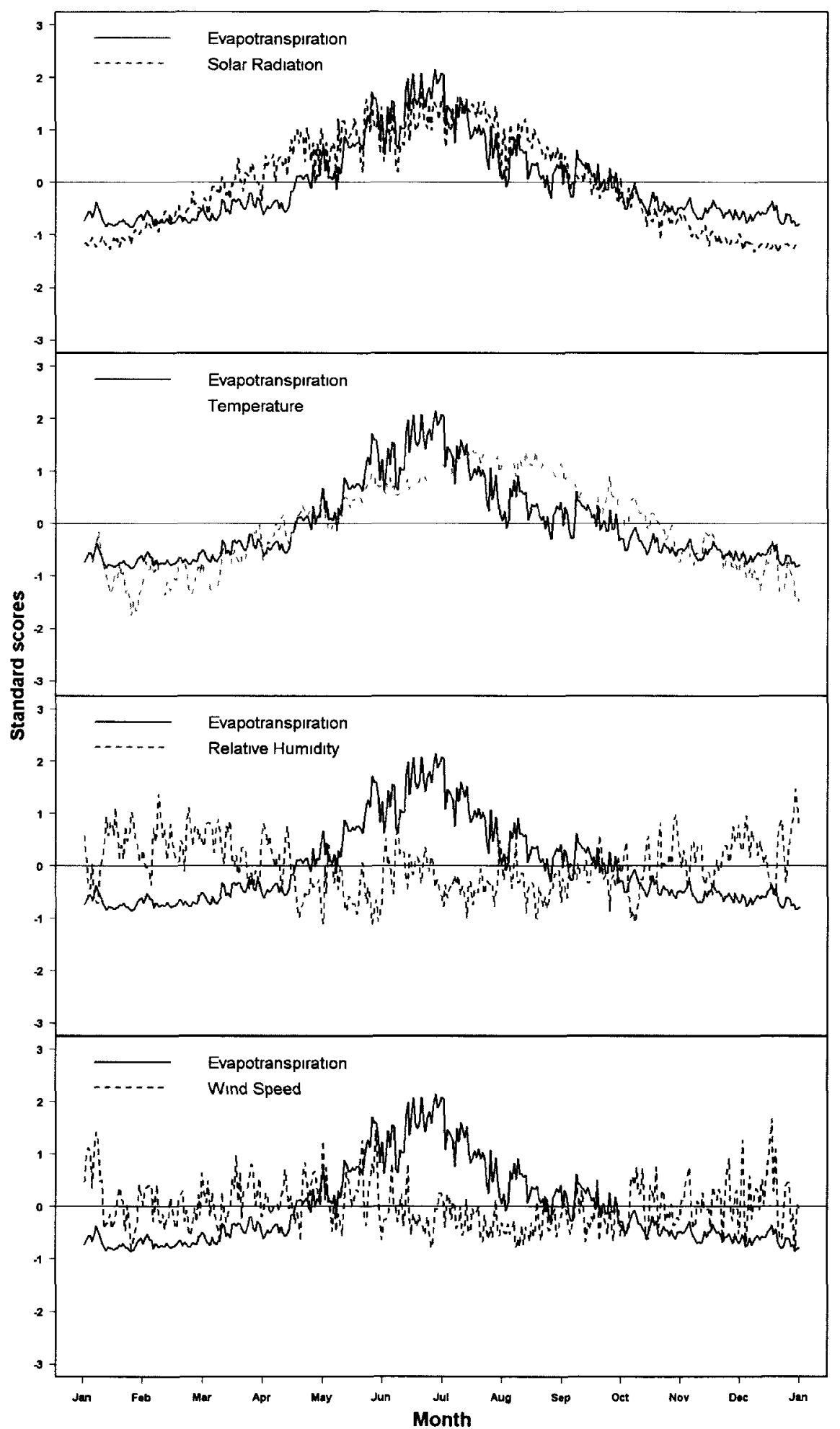

Figure 4-2 Comparisons of standard scores between daily ET estimations by the FAO Penman-Monteith method and meteorological variables (standard scores of 0 for each variable correspond to the 5 year average on that specific day) 


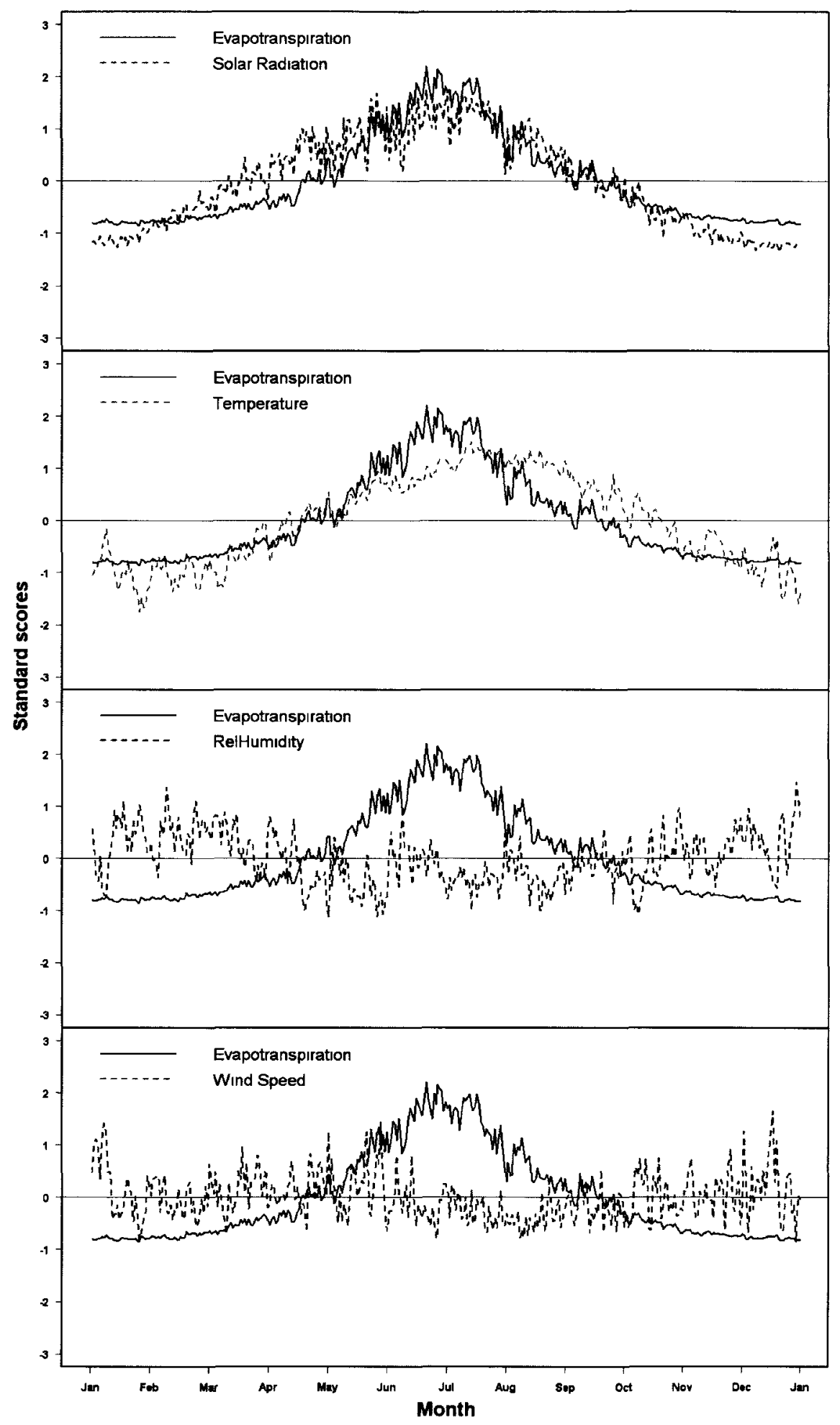

Figure 4-3 Comparisons of standard scores between daily ET estimations by the Samani and Hargreaves method and meteorological variables (standard scores of 0 for each variable correspond to the 5 year average over 5 years on that specific day) 


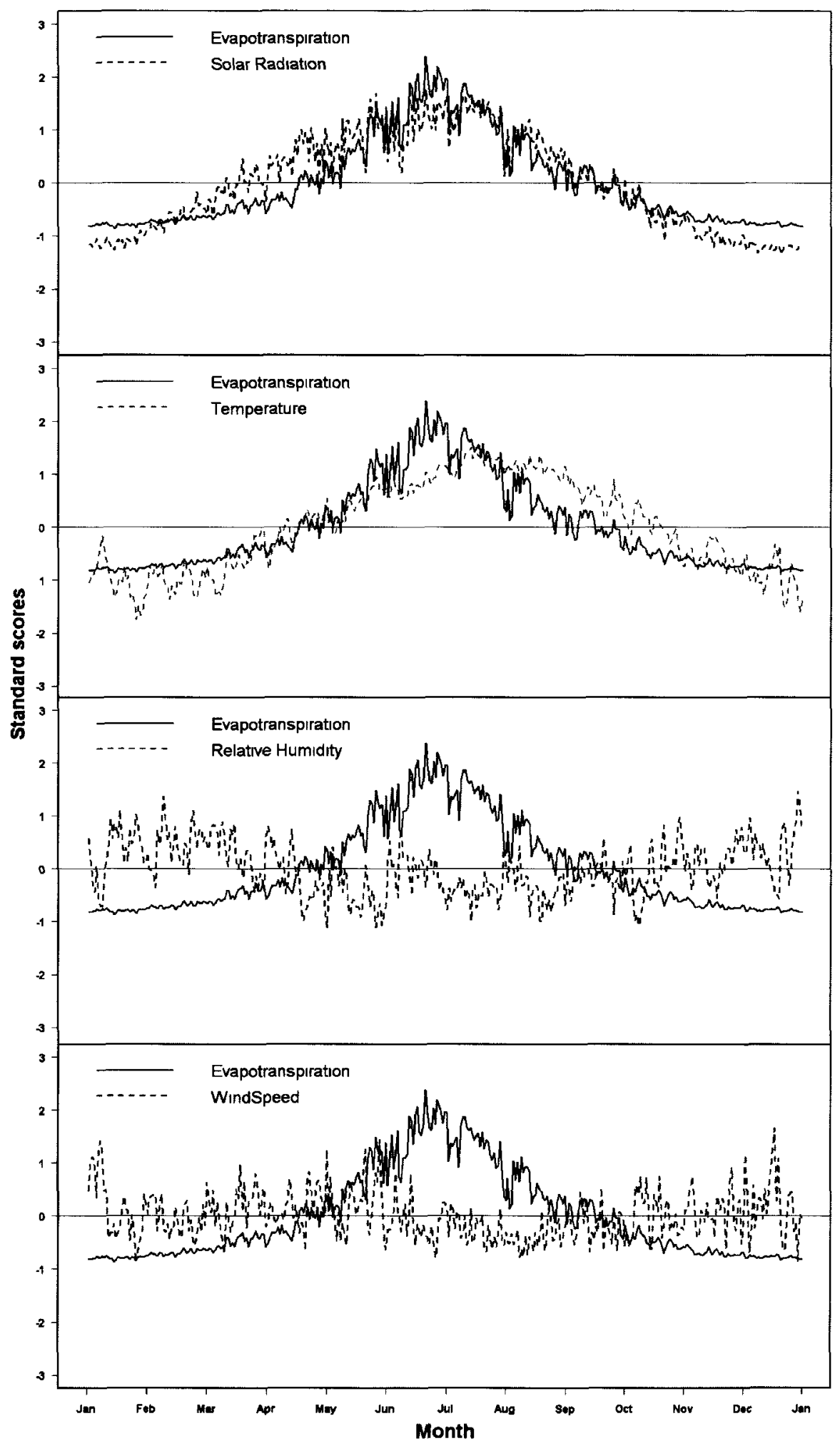

Figure 4-4 Comparisons of standard scores between daily ET estimations by the Makkink method and meteorological variables (standard scores of 0 for each variable correspond to the 5 year average on that specific day)

59 
Correlations between ET estimates by the FAO Penman-Monteith, Samani and Hargreaves, Makkink methods and meteorological variables in Table 4-1 indicate that both solar radiation and temperature accounted for the majority of variability of ET estimates, relative humidity accounted for a relatively small portion of variability and wind speed barely affected ET estimates. Among these meteorological variables, solar radiation always accounted for the most variability of ET estimates by three methods, referring to $\mathrm{R}^{2}$ of 0.75 , 0.80 and 0.83 , respectively. Temperature followed by accounting for more than $60 \%$ of variability of ET estimations with $R^{2}$ of $0.67,0.72$ and 0.70 . Relative humidity accounted for at most $30 \%$ of variability of ET estimates with $R^{2}$ of $0.30,0.25$ and 0.26 , respectively. Wind speed contributed very little variability to predicted ET in this study, according to its extremely low $R^{2}$ of $0.01,0.05$ and 0.04 .

$\mathrm{R}^{2}$ between ET and meteorological variables in Table 4-1 also indicated that the dependence of estimated ET on meteorological variables varied by prediction method. The FAO Penman-Monteith method presented equal $\mathrm{R}^{2}$ to that of ET measurements for solar radiation, and a little bit higher $\mathrm{R}^{2}$ for temperature and relative humidity, suggesting that this method assumes higher dependence on temperature and relative humidity than is warranted according to the measurements. Wind speed is not considered here due to its extremely low $\mathrm{R}^{2}$ values. Both of the Samani and Hargreaves and Makkink methods presented higher $\mathrm{R}^{2}$ than measurement for solar radiation and temperature, which is 
expected because solar radiation and temperature constitute their only data requirements. Among all three ET methods, the FAO Penman-Monteith method developed ET estimates closest to the physical processes with the relatively accurate dependence on solar radiation and temperature, probably due to its physical basis and involvement of various physical and physiological parameters for ET estimation.

\subsection{Performance evaluation of ET Estimation methods}

Comparisons between daily ET measurements and estimates by the FAO Penman-Monteith, Samani and Hargreaves and Makkink methods for 2000 to 2004 are indicated in Figure 4-5. All methods underestimated ET on most days of the study period with the magnitude of the underestimation differing based on the ET method used, time of the year, and between years (Figure 4-5). In 2000, the FAO Penman-Monteith method generally provided close ET estimations to measurements over the year. Both the Samani and Hargreaves and the Makkink methods underestimated ET through 2000, with daily MBE of $-0.18 \mathrm{~mm}$ and $-0.17 \mathrm{~mm}$, respectively (Table 4-3). In 2001 all three ET methods showed obvious underestimations in June and July with mean bias errors of $-0.18,-0.26$ and $-0.30 \mathrm{~mm}$, respectively, equal to $13 \%, 18 \%$ and $21 \%$ of the mean ET measurements during this period. In 2002 these methods generally provided ET estimates close to measurements over the year, exclusive of June. In June precipitation was extremely high 
with a total of $224.3 \mathrm{~mm}$. Most of the water reaching the soil and grass surface was evaporated, directly resulting in the considerably high ET measured in this month. However, the Daisy model assumed that a large amount of water was stored in the soil, predicting soil water of around $160 \mathrm{~mm}$ at the end of May and more than $260 \mathrm{~mm}$ on average in June regardless of ET prediction method. As a result ET was underestimated by all three methods. In 2003 observable underestimations of ET were found over the year with daily MBE values of $-0.19 \mathrm{~mm},-0.29 \mathrm{~mm}$ and $-0.27 \mathrm{~mm}$ for the three methods. The largest underestimations by all three methods that year occurred in the period of May to August. The magnitudes of underestimations were $0.65 \mathrm{~mm}, 0.79 \mathrm{~mm}$ and $0.79 \mathrm{~mm}$ daily on average, respectively, equal to $32 \%, 38 \%$ and $38 \%$ of the mean of ET measurements of this period. In 2004 the three ET methods again underestimated over the whole year, with MBEs of $-0.27 \mathrm{~mm},-0.33 \mathrm{~mm}$ and -0.35 . Largest underestimations by three methods were found from May to September with the magnitude of underestimations of $0.64 \mathrm{~mm}, 0.72$ $\mathrm{mm}$ and $0.78 \mathrm{~mm}$ daily on average, equal to $33 \%, 38 \%$ and $41 \%$ of the mean ET measurements of this period. 


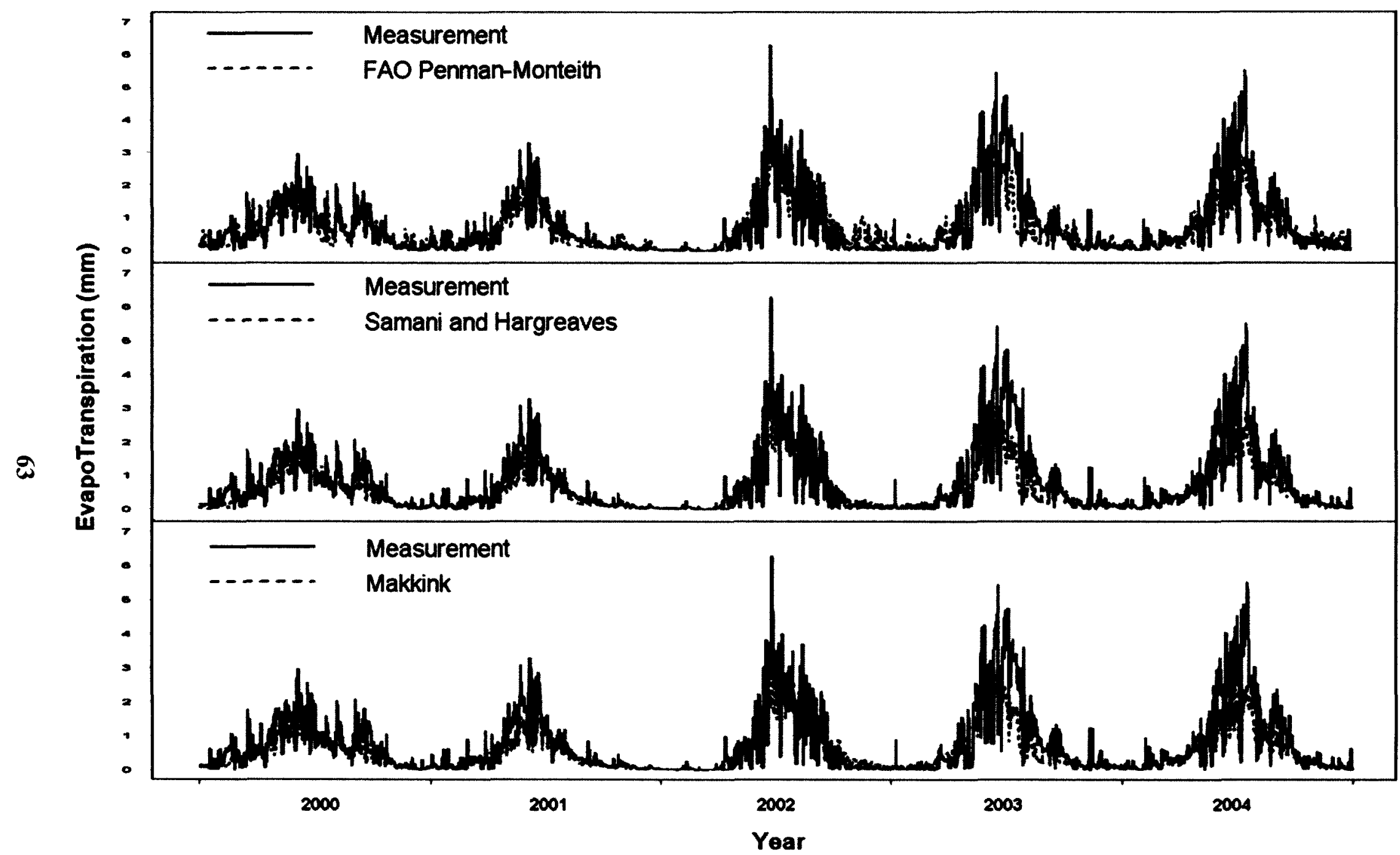

Figure 4-5 Comparisons between daily ET measurements and estimates by the FAO Penman-Monteith, Samani and Hargreaves and Makkink methods for 2000 to 2004 
Further error and correlation analyses between daily ET measurements and estimations by the FAO Penman-Monteith, Samani and Hargreaves and Makkink methods are shown in Tables 4-2 and 4-3. The FAO Penman-Monteith method performed better than the rest, with the best $\mathrm{R}^{2}$, MBE and RMSE values in 4 out of 5 years. The exception was 2002, when all three ET methods presented similar error and correlation statistics.

The better performance of the FAO Penman-Monteith method can be attributed to the consideration of vapour pressure deficit (VPD), which refers to the difference between the actual water vapour pressure and the saturation water vapour pressure at a particular temperature (Sadler and Evans, 1989). VPD reflects the ability of surface water evaporated to the atmosphere, showing a simple proportional relationship to ET (Grange and Hand, 1987). VPD is generally calculated from temperature and relative humidity (Jensen et al., 1990). When temperature is high or relative humidity is low, the atmosphere presents high VPD and produces high ET. The study site is a semi-arid region and presented fairly low relative humidity, between 50 and $60 \%$ in most days of the study period, which led to high VPD. The ability of the FAO Penman-Monteith method to include this in its prediction appears to have provided more appropriate ET estimates.

Considering the precipitation during the growing period for each year from 2000 to 2004 in comparison to the average monthly precipitation during a historic period of 1971 to 
2000 (Table 4-4), 2002 can be considered a representative wet year, with total precipitation of $452.5 \mathrm{~mm}$, whereas the other years all suffered from drought to varying degrees. The FAO Penman-Monteith method tended to perform better over the others in the drier years, while in the wet year similar ET estimations were obtained by all three methods. This implies that in the dry environments the ET methods that consider VPD as a controlling factor should be preferred, while in the wet environments the ET methods that mainly depend on solar radiation and temperature are sufficient to provide reliable ET estimations.

Table 4-2 $\mathrm{R}^{2}$ between daily ET measurements and estimations by the FAO Penman-Monteith, Samani and Hargreaves, and Makkink methods for 2000 to 2004 over grass

\begin{tabular}{cccc}
\hline & FAO Penman-Monteith & Samani and Hargreaves & Makkink \\
\hline 2000 & 0.79 & 0.72 & 0.74 \\
\hline 2001 & 0.86 & 0.83 & 0.83 \\
\hline 2002 & 0.78 & 0.78 & 0.81 \\
\hline 2003 & 0.85 & 0.79 & 0.81 \\
\hline 2004 & 0.90 & 0.83 & 0.84 \\
\hline \hline
\end{tabular}


Table 4-3 Summary of error analysis of daily ET estimations by the FAO Penman-Monteith, Samani and Hargreaves, and Makkink methods compared to measurements for 2000 to 2004 over grass

\begin{tabular}{ccccccc}
\hline \multirow{2}{*}{ Year } & \multicolumn{2}{c}{ FAO Penman-Monteith } & Samani and Hargreaves & \multicolumn{2}{c}{ Makkink } \\
\cline { 2 - 7 } & MBE & RMSE & MBE & RMSE & MBE & RMSE \\
\hline 2000 & -0.10 & 0.32 & -0.18 & 0.38 & -0.17 & 0.37 \\
\hline 2001 & -0.08 & 0.30 & -0.14 & 0.36 & -0.13 & 0.34 \\
\hline 2002 & 0.05 & 0.51 & -0.05 & 0.52 & -0.05 & 0.49 \\
\hline 2003 & -0.19 & 0.60 & -0.29 & 0.70 & -0.27 & 0.67 \\
\hline 2004 & -0.27 & 0.63 & -0.33 & 0.69 & -0.35 & 0.69 \\
\hline \hline
\end{tabular}

Table 4-4 Monthly average precipitation from May to September for a historic period of 1971 to 2000 , and total recorded precipitation in each month from 2000 to 2004

\begin{tabular}{ccccccc}
\hline \multirow{2}{*}{ Year } & \multicolumn{6}{c}{ Precipitation (mm) } \\
\cline { 2 - 7 } & May & June & July & August & September & Total \\
\hline $1971-2000$ & 53.5 & 63 & 47.5 & 45.8 & 39.6 & 249.4 \\
\hline 2000 & 5.7 & 34.2 & 3.9 & 25.5 & 44.1 & 113.4 \\
\hline 2001 & 16.8 & 41.0 & 6.4 & 0 & 2.6 & 66.8 \\
\hline 2002 & 55.5 & 224.3 & 40.3 & 72.5 & 59.9 & 452.5 \\
\hline 2003 & 47.8 & 62.8 & 5.1 & 11.2 & 25.0 & 151.9 \\
\hline 2004 & 62.1 & 60.0 & 50.3 & 28.3 & 4.7 & 205.4 \\
\hline \hline
\end{tabular}


Over short-term periods the FAO Penman-Monteith method generally predicted variability of daily ET in accordance with measurements, especially when the inflection values occurred, while the Samani and Hargreaves and Makkink method showed ET simulations in a smoothly varying pattern over the year. This indicates that the FAO Penman-Monteith method is more sensitive to the variability of environmental factors than the other methods.

Correlation between daily ET measurements and estimates by the all three methods by month showed that ET estimations varied depending on the time of the year (Table 4-5). All three methods provide $\mathrm{R}^{2}$ higher than 0.5 in the growing months, including April, May, June, July, August and September, while $\mathrm{R}^{2}$ lower than 0.5 in the remaining months. In the growing months solar radiation and temperature remained high, and the ET estimation methods were able to better reveal the variability of ET in response to these inputs. During this period of adequate energy supply by solar radiation and temperature, grasses were expected to be fully developed and remained in the optimal physiological phase (Larcher, 1995). This is well suited to the development and calibration basis of the ET estimation methods, therefore, one can expect better ET estimations. The best performance of the three methods occurred in May and June with $R^{2}$ of 0.66 and 0.74 respectively for the FAO Penman-Monteith method, 0.68 and 0.60 for the Samani and Hargreaves method and 0.70 and 0.76 for the Makkink method, whereas the poorest performance occurs in November and December with the extremely low $\mathrm{R}^{2}$ of around or below 0.1 for all these 
methods.

The error analysis of ET estimations by method and month (Table 4-6) showed that all three ET methods underestimated ET in most months of the year, and the FAO Penman-Monteith method generally performed better than the others in the growing months. Based on MBE, the FAO Penman-Monteith method underestimated ET in 7 months, the Samani and Hargreaves method underestimated ET in 10 months and the Makkink method in 9 months. The largest underestimates of daily ET occurred in June and July with differences of $0.65 \mathrm{~mm}$ and $0.63 \mathrm{~mm}, 0.75 \mathrm{~mm}$ and $0.50 \mathrm{~mm}$, and $0.78 \mathrm{~mm}$ and $0.58 \mathrm{~mm}$ for the FAO Penman-Monteith, Samani and Hargreaves and Makkink methods, respectively. RMSE showed that in the growing months the FAO Penman-Monteith method presented the best RMSE in 4 out of 6 months-May, June, July and August, among the three methods, whereas each of the Samani and Hargreaves and Makkink method provided the best RMSE only in 1 month. During the remaining months the FAO Penman-Monteith method performed poorest with the worst RMSE in 5 out of 6 months, whereas the Samani and Hargreaves and Makkink method provided the best RMSE in 3 and 4 months (the Samani and Hargreaves and Makkink method presented equal RMSE in November), respectively. 
Table 4-5 $\mathrm{R}^{2}$ between ET measurements and ET estimates by the FAO Penman-Monteith, Samani and Hargreaves, and Makkink methods, by month, for the period 2000 to 2004 over grass

\begin{tabular}{lccc}
\hline \hline Month & FAO Penman-Monteith & Samani and Hargreaves & Makkink \\
\hline January & 0.38 & 0.21 & 0.23 \\
\hline February & 0.29 & 0.23 & 0.40 \\
\hline March & 0.49 & 0.39 & 0.49 \\
\hline April & 0.58 & 0.57 & 0.58 \\
\hline May & 0.66 & 0.68 & 0.70 \\
\hline June & 0.74 & 0.60 & 0.76 \\
\hline July & 0.52 & 0.49 & 0.53 \\
\hline August & 0.61 & 0.53 & 0.55 \\
\hline September & 0.58 & 0.55 & 0.61 \\
\hline October & 0.34 & 0.27 & 0.29 \\
\hline November & 0.03 & 0.05 & 0.06 \\
\hline December & 0.09 & 0.08 & 0.05 \\
\hline \hline
\end{tabular}


Table 4-6 Summary of error analysis of ET estimates by the FAO Penman-Monteith, Samani and Hargreaves, and Makkink methods, by month, for the period 2000 to 2004 over grass

\begin{tabular}{lcccccc}
\hline \multirow{2}{*}{ Month } & \multicolumn{2}{c}{ FAO Penman-Monteith } & \multicolumn{2}{c}{ Samani and Hargreaves } & \multicolumn{2}{c}{ Makkink } \\
\cline { 2 - 7 } & MBE & RMSE & MBE & RMSE & MBE & RMSE \\
\hline January & 0.06 & 0.15 & -0.04 & 0.13 & -0.02 & 0.12 \\
\hline February & -0.03 & 0.20 & -0.10 & 0.23 & -0.06 & 0.20 \\
\hline March & 0.05 & 0.23 & -0.05 & 0.22 & -0.01 & 0.20 \\
\hline April & -0.03 & 0.29 & -0.09 & 0.29 & -0.07 & 0.28 \\
\hline May & -0.25 & 0.55 & -0.43 & 0.67 & -0.42 & 0.66 \\
\hline June & -0.65 & 0.94 & -0.75 & 1.12 & -0.78 & 1.04 \\
\hline July & -0.63 & 1.10 & -0.50 & 1.07 & -0.58 & 1.09 \\
\hline August & -0.19 & 0.49 & -0.15 & 0.51 & -0.16 & 0.50 \\
\hline September & -0.13 & 0.39 & -0.26 & 0.46 & -0.27 & 0.44 \\
\hline October & 0.12 & 0.23 & 0.01 & 0.17 & 0.03 & 0.18 \\
\hline November & 0.13 & 0.29 & -0.02 & 0.17 & 0 & 0.17 \\
\hline December & 0.13 & 0.22 & 0 & 0.08 & 0.01 & 0.09 \\
\hline \hline
\end{tabular}




\subsection{The impact of ET methods on crop yield simulations}

Spring wheat yields for the period of 2000 to 2004 were simulated by the Daisy model using the FAO Penman-Monteith, Samani and Hargreaves, and Makkink methods to estimate ET. Due to the limited availability of management data, assumed uniform management activities between years, including sowing date, the type and amount of fertilizer and harvest date, were implemented to conduct crop yield simulations. In this section, first insured crop yields from 2000 to 2004 are indicated; secondly the impact of different ET methods on crop yield simulation is evaluated; lastly sensitivity analysis is conducted to show the effect of management data on crop yield simulation.

\subsubsection{Insured crop yields}

Insured crop yields for all insured spring wheat fields surrounding the study site from 2000 to 2004 are shown in Figure 4-6 and Table 4-7. Large differences in yield existed between years. When referring to solar radiation and temperature of the growing periods in 5 years (Figure 4-7), solar radiation generally remained high with the averages of each year ranging from $241.54 \mathrm{~W} / \mathrm{m}^{2}$ to $272.47 \mathrm{~W} / \mathrm{m}^{2}$, indicating that energy availability did not limit crop development in these years, and temperature increasing quickly over the growing seasons also appeared to be appropriate for crop growth. The insured crop yields 
remained low in 2000 and 2001, with the average of $647.81 \mathrm{~kg} \mathrm{ha}^{-1}$ in 2000 and $740.73 \mathrm{~kg}$ $\mathrm{ha}^{-1}$ in 2001 for all the land plots. Since spring wheat is a type of grass, it is expected to have somewhat similar phenological patterns as native grasses; Figure 4-8 shows measured LAI of grass at the flux tower during the study period. Comparing annual LAI peaks of the native grasses to annual wheat yields, it is reasonable to assume that, low crop yields are related to lower LAI in 2000 and 2001, with the maximum of 0.45 and 0.5 , respectively. Assuming the crops suffered from similar poor leaf growth, photosynthesis levels would have been far below that of other years, resulting in low total allocation to grain production. In addition, both 2000 and 2001 exhibited severe drought during the growing period of May to August. Precipitation of this period in 2000 was $69.3 \mathrm{~mm}$ on total and in 2001 was $64.2 \mathrm{~mm}$, leading to low water availability in the soil. To avoid a great quantity of water loss by transpiration, crops would have to close leaf stomata partially or even completely. This would result in limited carbon dioxide assimilation and accordingly low crop production.

The insured crop yields in 2003 remained low, with an average of $1241.46 \mathrm{~kg} \mathrm{ha}^{-1}$. This was likely due to low precipitation in July and August, with amounts as low as $5.1 \mathrm{~mm}$ and $11.2 \mathrm{~mm}$ in each month, even though adequate precipitation of $47.8 \mathrm{~mm}$ and $62.8 \mathrm{~mm}$ fell in the previous two months of the growing season (Figure 4-7). The distribution of precipitation over the growing season generally poses a significant impact on crop yield 
(Eck, 1984; Musick and Dusek, 1980). Previous studies have indicated that summer annual crops present yield reduction in response to soil water deficit at any growth phase (Denmead and Shaw, 1960; Howe and Rhoades, 1955). Moreover, in some cases when total precipitation over the growing season corresponds to water deficit in amount, but precipitation shows a well-distributed pattern to meet water demands of crop growth, it is still possible to obtain an adequate or even superior crop yield (Whitmore, 2000).

In 2002 and 2004, when relatively higher grass LAI values were measured (maximum of 1.22 and 0.89 for each year) and precipitation was well distributed from May to August in each year, high insured crop yields were produced of $2633.59 \mathrm{~kg} \mathrm{ha}^{-1}$ in 2002 and 3467.14 $\mathrm{kg} \mathrm{ha}^{-1}$ in 2004, averaged across the fields. 


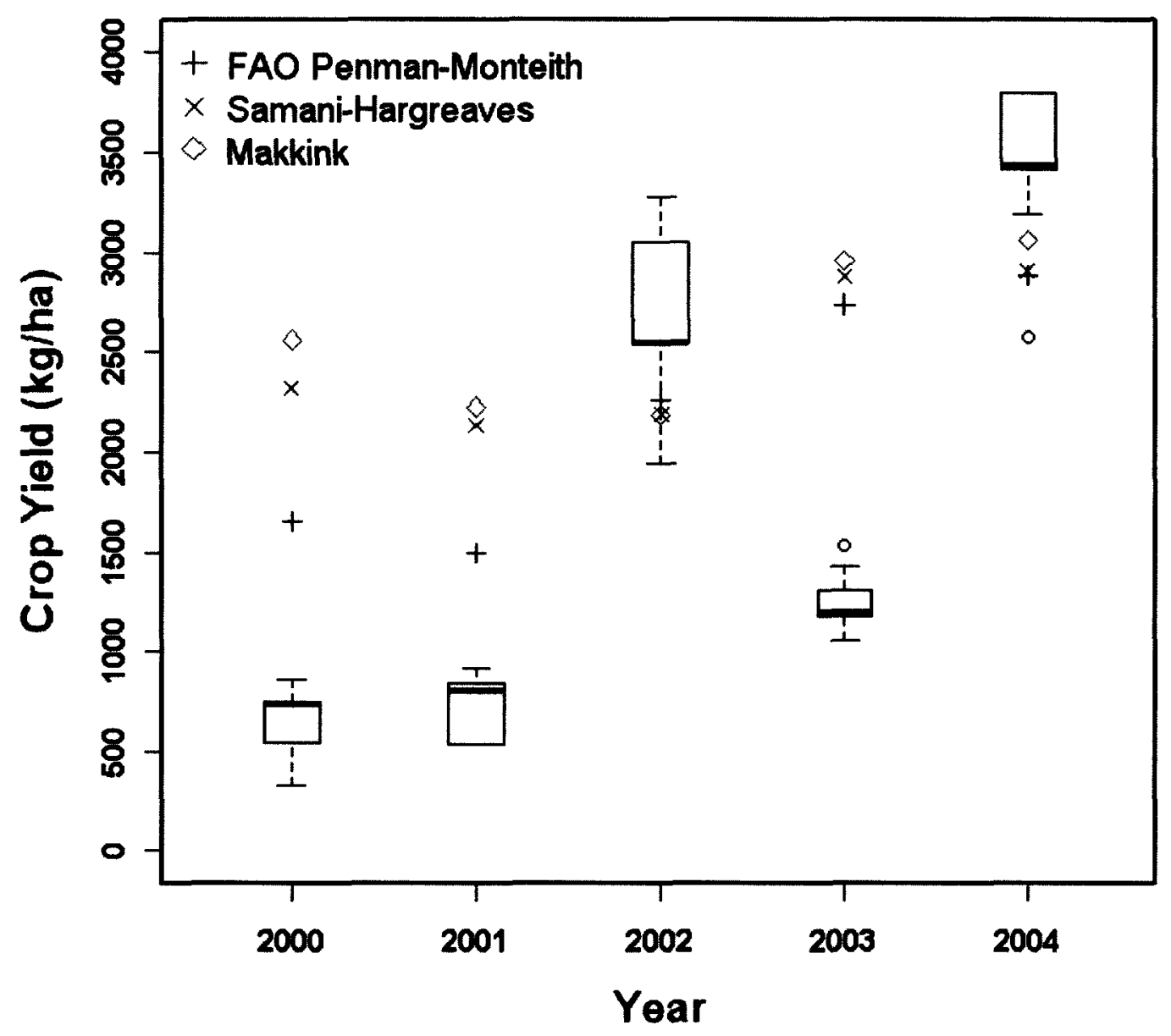

Figure 4-6 Insured (boxplot) and simulated crop yields using the FAO Penman-Monteith, Samani and Hargreaves and Makkink methods for the period 2000 to 2004 
Table 4-7 Insured and simulated crop yields using the FAO Penman-Monteith, Samani and Hargreaves, and Makkink methods for the period 2000 to 2004

\begin{tabular}{lccccccc}
\hline & \multicolumn{2}{c}{ Insured Crop Yield $\left(\mathrm{kg} \mathrm{ha}^{-1}\right)$} & \multicolumn{3}{c}{ Simulated Crop Yield $\left(\mathrm{kg} \mathrm{ha}^{-1}\right)$} \\
\cline { 2 - 7 } Year & \multirow{2}{*}{ Minimum } & Maximum & Mean & FAO & Samani and & \\
& & & & Penman-Monteith & Hargreaves & \\
\hline 2000 & 330.98 & 857.09 & 647.81 & 1650.55 & 2317.64 & 2562.81 \\
\hline 2001 & 535.99 & 918.84 & 740.73 & 1497.88 & 2136.42 & 2227.11 \\
\hline 2002 & 1941.42 & 3277.69 & 2633.59 & 2186.69 & 2192.85 & 2633.59 \\
\hline 2003 & 1057.16 & 1536.34 & 1241.46 & 2740.21 & 2882.98 & 2959.14 \\
\hline 2004 & 2573.74 & 3798.86 & 3467.14 & 2884.96 & 2907.51 & 3063.57 \\
\hline \hline
\end{tabular}




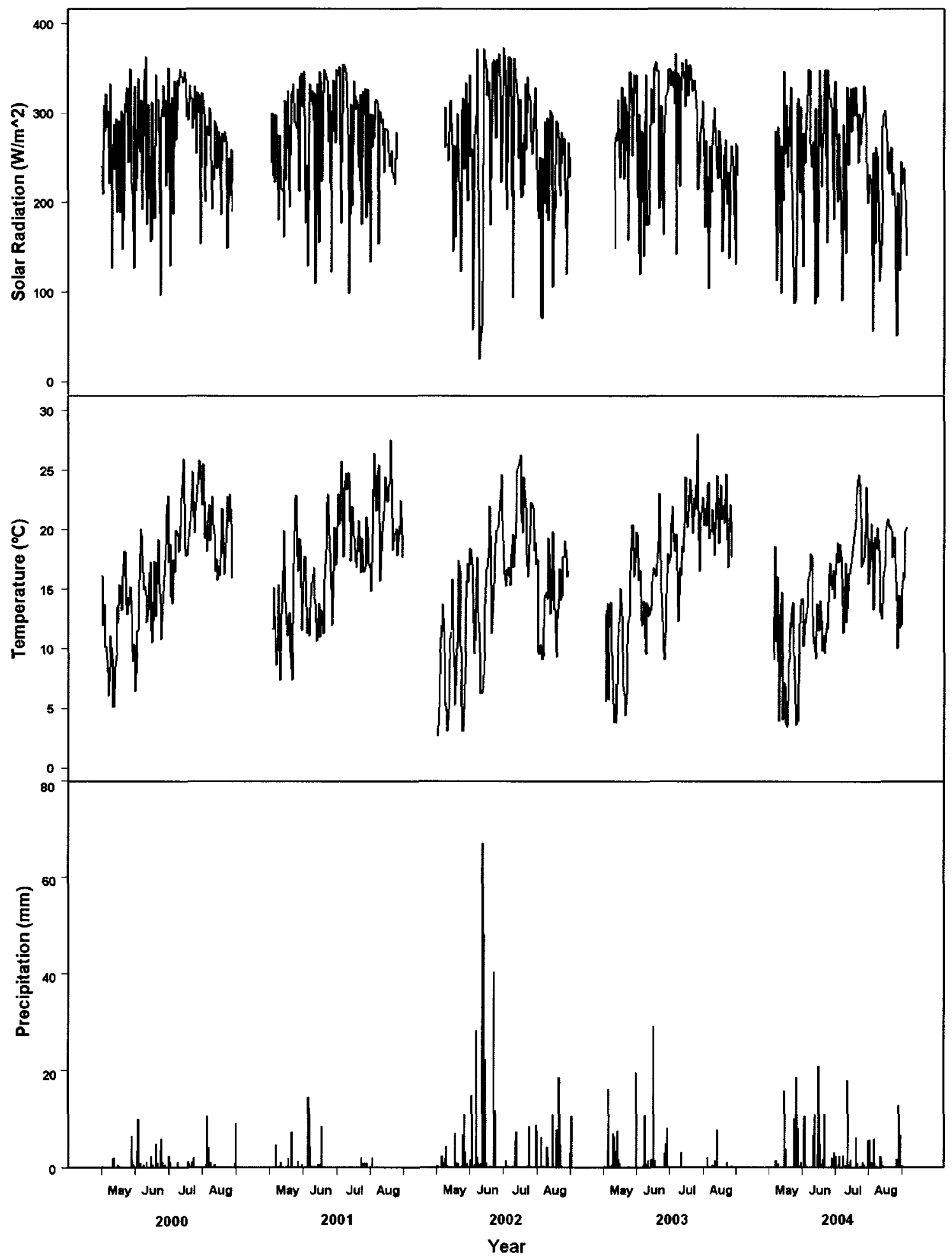

Figure 4-7 Daily solar radiation, air temperature and precipitation from May to August for the period 2000 to 2004 


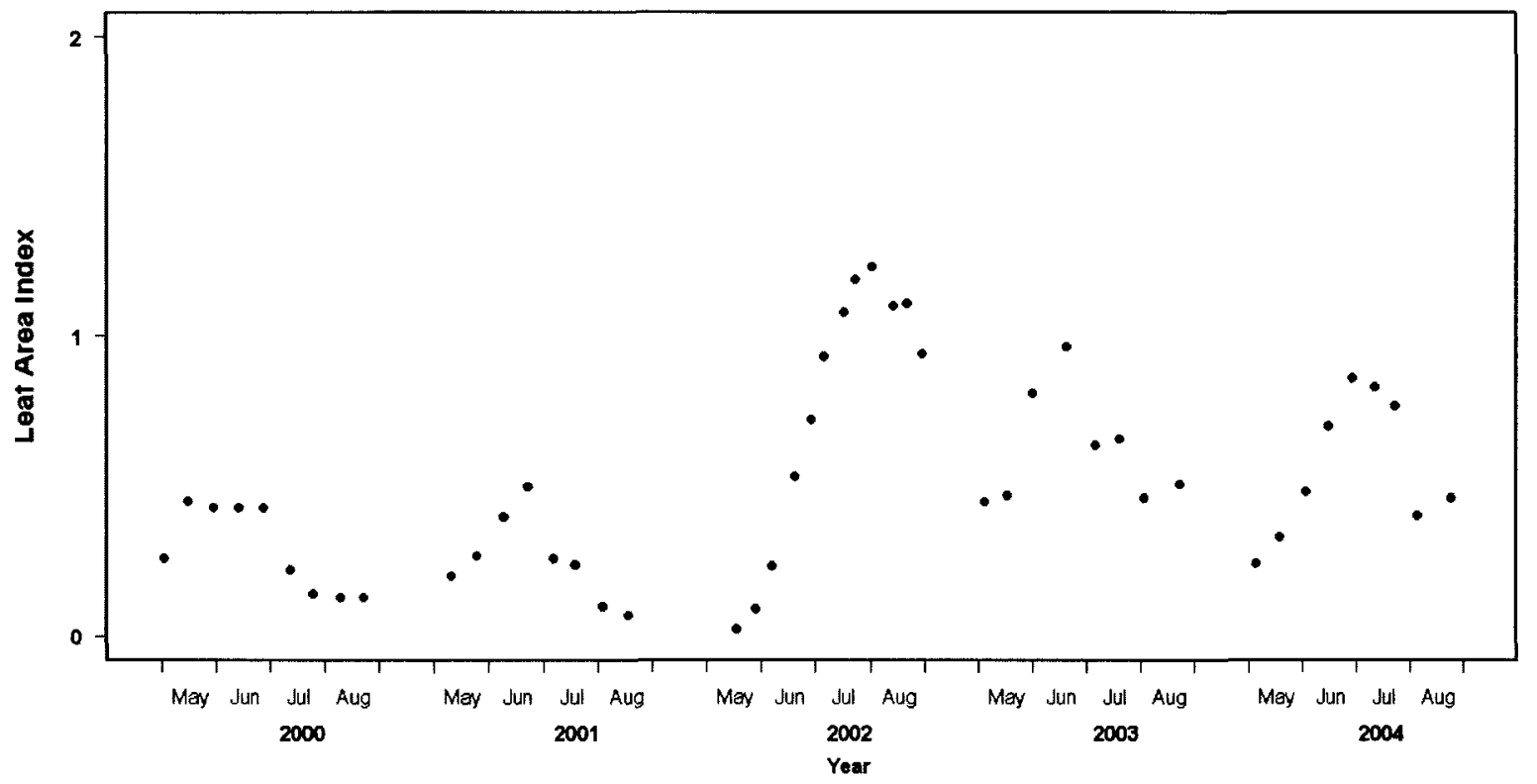

Figure 4-8 Measured LAI of native grass during the growing season for 2000 to 2004

\subsubsection{Evaluation on the impact of ET methods on crop yield simulations}

Crop yield simulations differed between years and ET estimation methods (Figures 4-6 and 4-9). The three ET methods all contributed to large overestimations of crop yields in 2000, 2001 and 2003, while in 2002 and 2004 all three modelling methods provided crop yield predictions within the range of insured crop yields (Table 4-7). In comparison to the mean of insured crop yields of all plots for each year, overestimations by the three methods in 2000,2001 and 2003 ranged from $757.15 \mathrm{~kg} \mathrm{ha}^{-1}$ to $1915.00 \mathrm{~kg} \mathrm{ha}^{-1}$ and in 2002 and 2004 simulated crop yields were lower by around $500 \mathrm{~kg} \mathrm{ha}^{-1}$ (Figure 4-9). Simulated LAI of spring wheat over 5 years (Figure 4-10) does not vary much between years, in comparison to measurements of grass LAI (Figure 4-8). Years in which there was more disagreement between LAI predictions are also years with the higher discrepancies 
between predicted and measured crop yield, however, and overprediction of LAI is likely leading to overprediction of crop yield. Higher LAI in 2000, 2003 and 2004 corresponded to higher crop yields in these years and similar between-method LAI predictions in 2001 and 2002 also corresponded to similar crop yields in both years. Therefore, large overestimations of crop yield in 2000, 2001 and 2003 were probably because the Daisy model simulated higher LAI of spring wheat in these years.

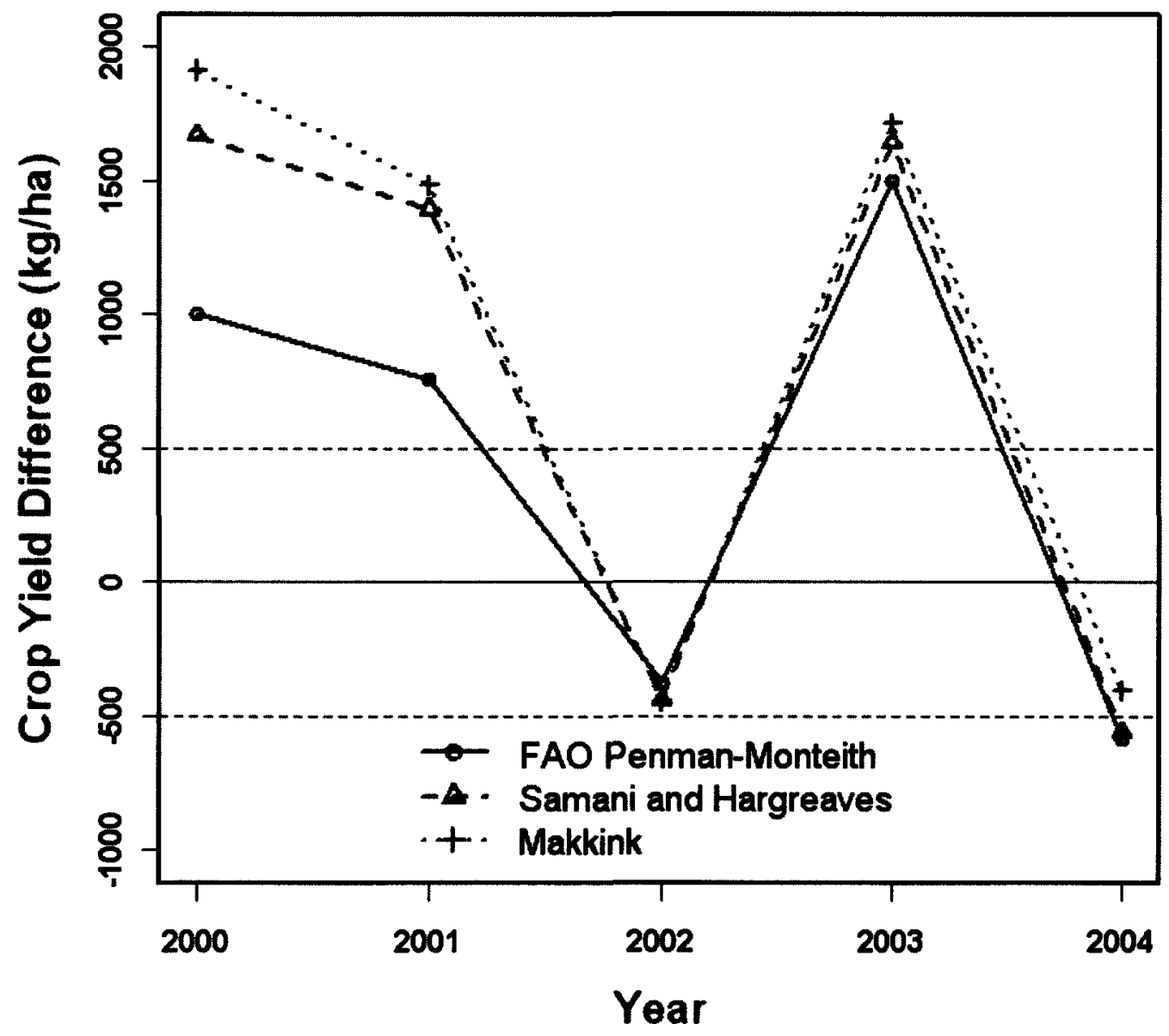

Figure 4-9 Difference between DAISY simulated crop yields resulting from three ET estimation methods and insured crop yields for the period of 2000 to 2004 (Crop yield difference of 0 refers to the simulated crop yield equal to the mean of insured crop yields of all the land plots at the study site for each year) 


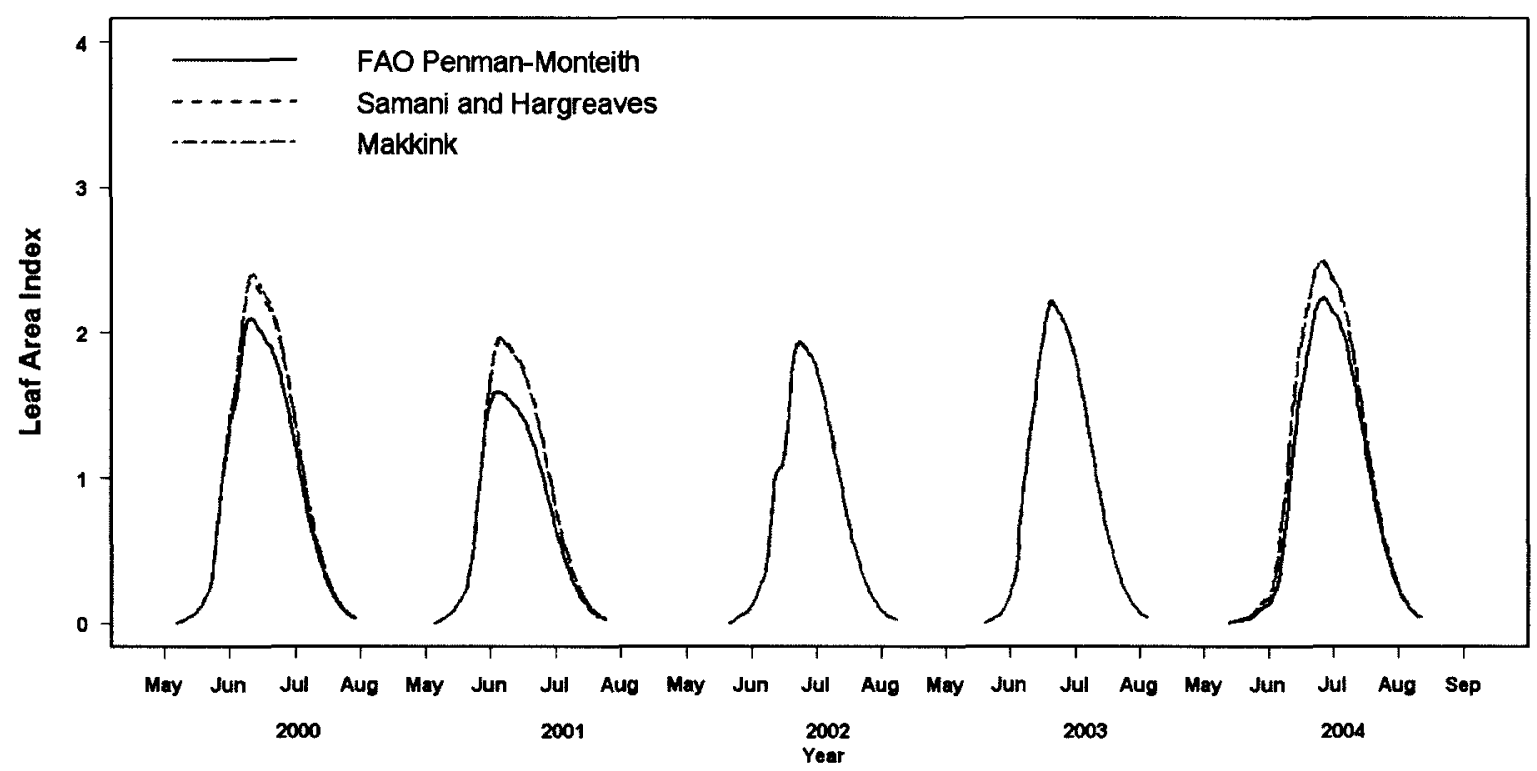

Figure 4-10 Simulated LAI of spring wheat resulting from three ET estimation methods during the growing season of 2000 to 2004

Another possible factor for large overestimations of crop yield in 2000, 2001 and 2003 was overestimations of root extraction of soil water in the growing season. Figures 4-11 and 4-12 show daily simulations of soil water, root extraction, accumulated net photosynthesis and crop yield using three ET methods in the growing seasons of dry year 2001 and wet year 2002. They show that daily net photosynthesis highly depended on root extraction. This is because root extraction determined transpiration through the leaf stomata control of water loss. Limited root extraction causes the leaf stomata to close to reduce transpiration and as a result $\mathrm{CO}_{2}$ assimilation and net photosynthesis were also reduced. In addition, in 2001 lower net photosynthesis simulations by the FAO Penman-Monteith method compared to the others generally corresponded to lower root 
extraction simulations by this method and finally lower crop yield predictions.

Figure 4-11 and Figure 4-12 also show that root extraction and net photosynthesis depended on both soil water and crop growth stage. For the period from mid-May to June $10^{\text {th }}$ in 2001 , crops at the vegetative stage grew quickly and required a large amount of water, accordingly a large amount of root extractions occurred during this period. With decreasing soil water, root extractions decreased from the end of May, resulting in less net photosynthesis accumulations. After precipitation fell on June 3, 4 and 5, soil water increased, leading to sharp increases of root extraction and net photosynthesis in the following days. Starting from mid-June, crops moved into the reproductive stage and a great quantity of crop yield was accumulated. At this stage even though soil water remained low, due to developed root system, crops were still able to extract water at a relatively moderate level. As crops approached the completion of the reproduction stage, with less availability of soil water, root extraction decreased and both net photosynthesis and crop yield also decreased. Similar patterns emerged in 2002, but with higher water availability. Soil water increased after precipitation fell on June 18 and 19, resulting in an obvious increase of root extraction and net photosynthesis. Starting from the end of June, crops moved into the reproductive stage and even though soil water remained low, a moderate amount of water can still be extracted by crops. 


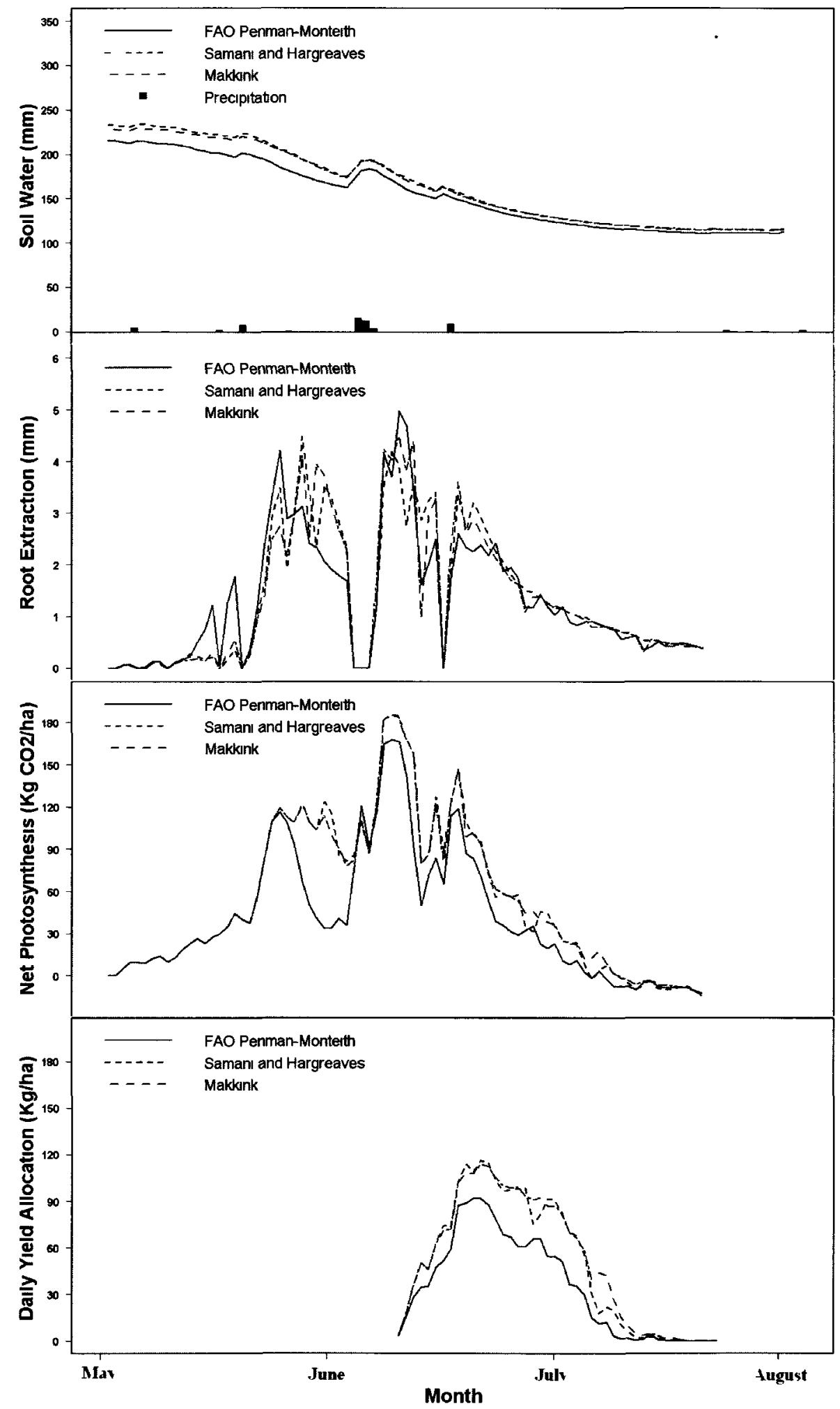

Figure 4-11 Daily predictions of soil water, root extraction, net photosynthesis and daily yield allocation using the three ET estimation methods in the growing season of 2001, compared to precipitation (top pane) 


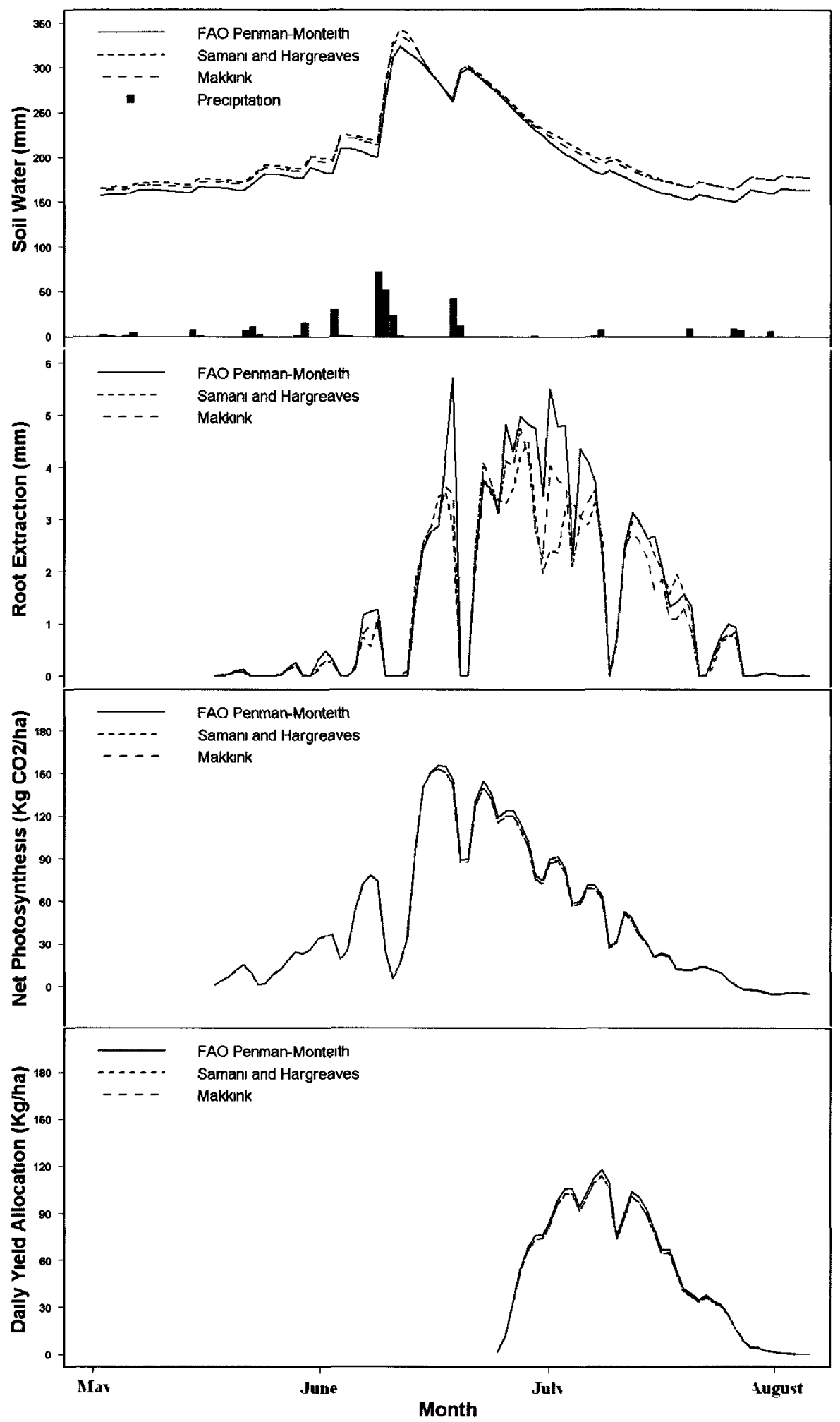

Figure 4-12 Daily predictions of soil water, root extraction, net photosynthesis and daily yield allocation using the three ET estimation methods in the growing season of 2002, compared to precipitation (top pane) 
When relating crop yield simulations resulting from the three ET estimation methods (Figure 4-6) to ET estimations by these methods over grass (Table 4-8) in the growing seasons of 2000 to 2004, methods with better ET estimations generally corresponded to better crop yield simulations. The FAO Penman-Monteith method, consistently providing the best ET estimations with the lowest MBE and RMSE for 5 years, led to the best crop yield simulations in 4 out of 5 years. The Samani and Hargreaves and the Makkink method provided similar ET estimations in the growing seasons of 2000 to 2004 (Table 4-8), also corresponding to similar crop yield simulations for all 5 years. Therefore, the results above suggested the tendency that methods with better ET estimations generally correspond to better crop yield simulations. 
Table 4-8 Summary of error analysis of daily ET estimations by the FAO Penman-Monteith, Samani and Hargreaves, and Makkink methods compared to measurements in the growing seasons for 2000 to 2004 over grass

\begin{tabular}{ccccccc}
\hline \hline \multirow{2}{*}{ Month } & \multicolumn{2}{l}{ FAO Penman-Monteith } & \multicolumn{2}{l}{ Samani and Hargreaves } & \multicolumn{2}{l}{ Makkink } \\
\cline { 2 - 7 } & MBE & RMSE & MBE & RMSE & MBE & RMSE \\
\hline 2000 & -0.20 & 0.41 & -0.23 & 0.46 & -0.25 & 0.47 \\
\hline 2001 & -0.21 & 0.40 & -0.26 & 0.49 & -0.25 & 0.46 \\
\hline 2002 & -0.06 & 0.62 & -0.16 & 0.72 & -0.17 & 0.67 \\
\hline 2003 & -0.48 & 0.84 & -0.56 & 0.97 & -0.56 & 0.94 \\
\hline 2004 & -0.56 & 0.82 & -0.62 & 0.96 & -0.66 & 0.97 \\
\hline \hline
\end{tabular}

\subsubsection{Effect of management data on crop yield simulations}

Simulated crop yields by the Daisy model varied with the amount of fertilizer applied

(Figure 4-13). When the amount of fertilizer was supplied in the range of 0 to $60 \mathrm{~kg} / \mathrm{ha}$, crop yield increased linearly by $217.09 \mathrm{~kg} / \mathrm{ha}$ on average in response to applied fertilizer in increments of $10 \mathrm{~kg} / \mathrm{ha}$. When more than $60 \mathrm{~kg} / \mathrm{ha}$ fertilizer was supplied, crop yield remained constant, because no more fertilizer could be taken up by the plants. The amount of fertilizer significantly affected crop yield simulations. Therefore the use of uniformly typical management data over the study period probably contributed to the differences between insured and simulated crop yields. 


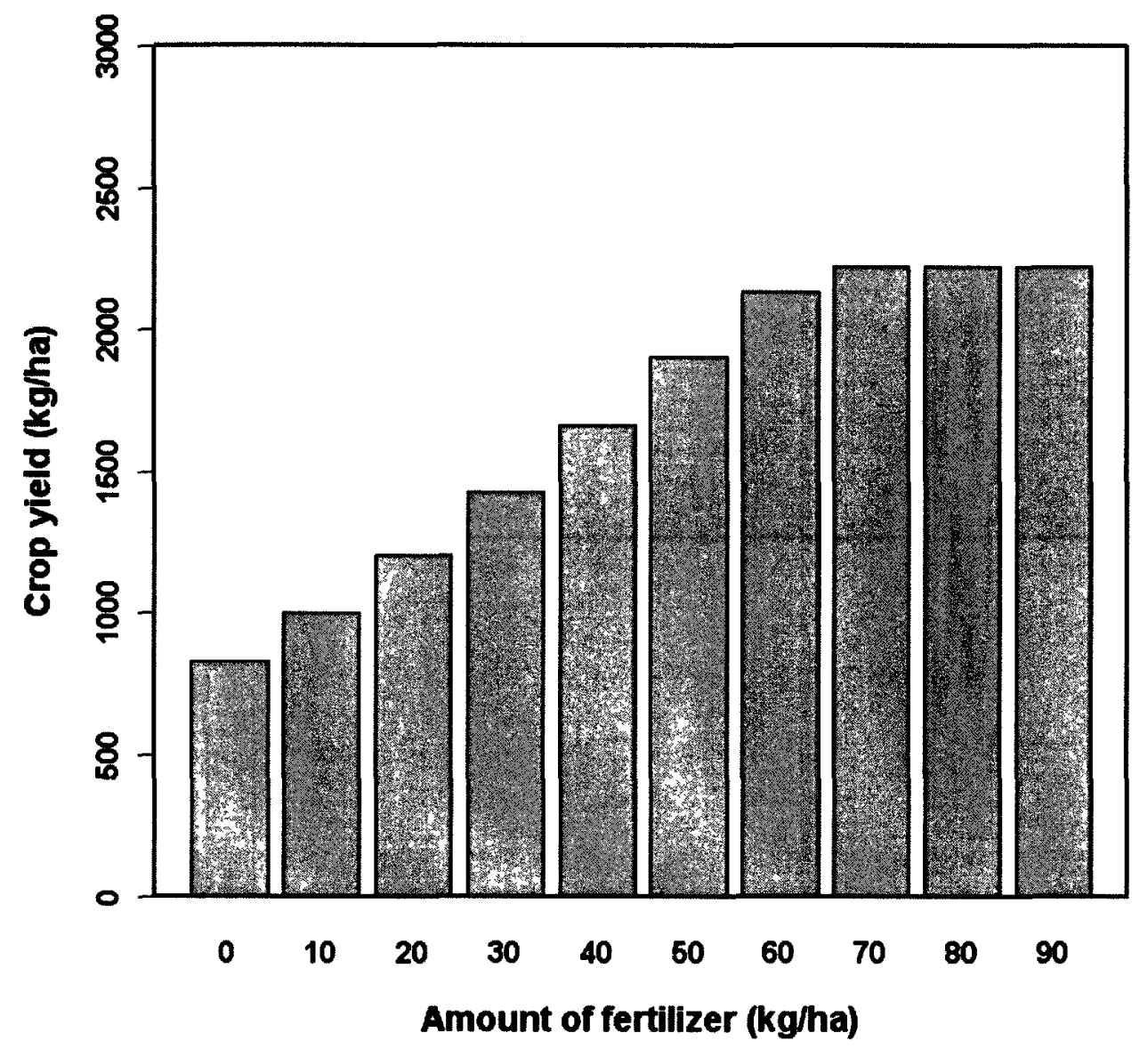

Figure 4-13 Variability of crop yield simulation in response to the amount of fertilizer supplied in 2001 


\section{Chapter 5 Synthesis}

\subsection{Summary of research approach}

This study aims to evaluate three ET estimation methods (FAO Penman-Monteith, Samani and Hargreaves, and Makkink) and their impacts on crop yield simulations. The study site is centred on a flux tower in Lethbridge, Alberta with mixed grass vegetation cover. Data used in this study included meteorological, soil, management and crop yield data for the period of 2000 to 2004. Firstly, the dependences of ET measurements and estimations by the FAO Penman-Monteith, Samani and Hargreaves, and Makkink methods on meteorological variables, including solar radiation, temperature, relative humidity and wind speed, were evaluated by comparison of standard scores of daily 5-year means, and correlations between them. Secondly, ET estimations by each method were evaluated against measurements under the same meteorological and environmental conditions. Thirdly, the impacts of ET estimation methods on crop yield simulations were evaluated against insured crop yields in the surrounding fields for the period of 2000 to 2004 .

\subsection{Conclusions}

The following conclusions were drawn from this study: 
1) ET measurements and estimations by the FAO Penman-Monteith, Samani and Hargreaves, and Makkink methods highly depended on solar radiation and temperature, and were less related to relative humidity and wind speed. Solar radiation was the most important controlling factor with the consistent highest $\mathrm{R}^{2}$ of more than 0.7 . Temperature was also an important controlling factor with $\mathrm{R}^{2}$ of more than 0.6 .

2) None of the three ET methods consistently provided ET estimations in good agreement with measurements over the whole year for the period of 2000 to 2004 . Their performance differed and depended on the time of year. Among the three methods, the FAO Penman-Monteith method provided the best ET estimations based on the lowest error statistics (MBE and RMSE), probably due to its theoretically physical basis and consideration of VPD. All three methods performed better in the growing months $\left(\mathrm{R}^{2}>\right.$ 0.5 ) and could not provide reliable ET estimations in the remaining months.

3) Performance of the three ET methods varied between years. In the wet year 2002 all methods provided close ET estimations to measurements except in June, but in the other dry years they tended to provide considerable underestimations in the growing months. In addition, in these dry years the FAO Penman-Monteith method performed best among the three ET methods. This implies that in the arid environments the ET methods that consider VPD as a controlling factor should be preferred, while in the humid environments the ET methods that mainly depend on solar radiation and temperature are sufficient to provide reliable ET estimations. 
4) Crop yield simulations varied with the year and ET method. In 2000, 2001 and 2003, with dry growing seasons, all three ET methods lead to large overestimations of crop yield, while in 2002 and 2004, with wet growing seasons, all methods provided closer crop yield simulations, within the range of insured crop yields. Among the three ET methods, the FAO Penman-Monteith method provided much closer crop yield simulations to the insured crop yields than the Samani and Hargreaves, and Makkink methods in 2000 and 2001, whereas in the other years differences of crop yield simulations between the three methods were small.

\subsection{Limitations and Recommendations for Future Research}

A number of limitations were raised in this study. These limitations and corresponding suggestions for future research are described in this section.

Some ET measurements for cold days at the study site were missing because the measurement instruments were not able to function successfully under conditions of low temperature and occasional snow cover, so interpolations were used. Therefore the evaluation of ET estimation methods against measurements in these days presented low reliability. To obtain accurate evaluation of ET estimation methods, confining the evaluation in optimal periods with confident measurements is a preferred approach, 
although this problem is limited in this study due to the focus on the growing season.

Soil data from NSDB can not provide accurate soil parameters for a specific location. Polygons with uniform soil attribute records generally cover a large area, as a result soil parameters of each polygon can have low accuracy for specific points. This may reduce the reliability of ET estimates and crop yield simulations, because soil texture and soil hydraulic parameters directly influence the water holding capacity of soil and root extraction as predicted in this study.

It is said that in arid and semi-arid environments the local calibration and validation for ET estimation methods are important, because almost all the ET methods were developed, calibrated and validated for temperate environments (DehghaniSanij et al., 2004). However, this study directly used ET submodels built in the Daisy model and did not conduct calibration. This increased the uncertainty of ET estimations and probably contributed to underestimations in the growing seasons of the study period, especially in the dry years. Therefore, to evaluate or apply ET method at specific study sites, if high degree of accuracy is required or long-term data record are available, local calibration of ET methods before estimation may provide better ET estimates.

Crop yield simulation was conducted based on uniformly typical management activities for 
the period of 2000 to 2004 , which differs from the actual activities which are temporally and spatially variable, depending on the local meteorological and environmental conditions. As indicated by sensitivity analysis, crop yield simulations varied significantly with different amount of fertilizer supplied. Therefore the use of uniformly typical management data over the study period may reduce the reliability of simulated crop yields. 


\section{References}

AAFC (Agriculture and Agri-Food Canada). (2007c). Soil Landscapes of Canada Version 3.1.1. Retrieved September 20, 2008, from Canadian Soil Information System (CanSIS) Web site: http://sis.agr.gc.ca/cansis/nsdb/slc/v3.1.1/intro.html.

Abrahamsen, P. and Hansen, S., 2000. Daisy: An Open Soil-Crop-Atmosphere system Model. Environmental Modelling and Software.

AGS (Alberta Geological Survey). (2009). Alberta Township System (ATS). Retrieved July 28, 2009, from Alberta Geological Survey website: http://www.ags.gov.ab.ca/gis/map_converters/map_conversion explanation.html.

Allen, R.G., 2000. Using the FAO-56 dual crop coefficient method over an irrigated region as part of an evapotranspiration intercomparison study. Journal of Hydrology. 229, 27-41.

Allen, R.G., Pereira, L.S., Raes, D., Smith, M., 1998. Crop evapotranspiration. Guidelines for computing crop water requirements. FAO Irrigation and Drainage Paper 56, Rome, Italy, $300 \mathrm{pp}$.

Allen, R.G., Tasumi, M., Trezza, R., 2007. Satellite-based energy balance for mapping evapotranspiration with internalized calibration (METRIC)-model. J. Irrig. Drain. E., 133, 380-394.

Almorox, J., Benito, M., Hontoria, C., 2004. Estimation of monthly Angstrom-Prescott equation coefficients from measured daily data in Toledo, Spain. Renewable Energy, 30, 931-936.

Armstrong, R.N., Pomeroy, J.W., Martz, L.W., 2008. Evaluation of three evaporation estimation methods in a Canadian prairie landscape. Hydrol. Process. 22: $2801-2815$.

Ballantine, I. E. M., Forde, B. J., 1970. The effect of light intensity and temperature on plant growth and chloroplast ultrastructure in Soybean. Am. J. Bot. 57: 11 50-59.

Barr, A.G., Black, T.A., Hogg, E.H., Kljun, N., Morgenstern, K., Nesic, Z., 2004. Inter-annual variability in the leaf area index of a boreal aspen-hazelnut forest in relation to net ecosystem productivity. Agricultural and Forest Meteorology, 126: 237-255. 
Bastiaanssen, W.G.M., 2000. SEBAL-based sensible and latent heat fluxes in the irrigated Gediz Basin, Turkey. J. Hydrol. 229, 87-100.

Bastiaanssen, W.G.M., Menenti, M., Feddes, R.A., Holtslag, A.A.M., 1998. A remote sensing surface energy balance algorithm for land (SEBAL): 1.Formulation. J. Hydrol. 212-213, 198-212.

Bastiaanssen, W.G.M., Pelgrum, H., Wang, J., Ma, Y., Moreno, J.F., Roerink, G.J., van der, W.T., 1998. A Surface Energy Balance Algorithm for Land (SEBAL): Part 2 validation. $J$. Hydrol. 212-213, 213-229.

Batchelor, C.H., 1984. The accuracy of evapotranspiration functions estimated with the FAO modified Penman equation. J. Irrigation Sci. 4-5, 223-234.

Bates, B.C.; Kundzewicz, Z.W.; Wu, S.; Palutikof, J.P. Climate change and water. Technical paper of the intergovernmental panel on climate change. IPCC Secretariat: Geneva, Switzerland, 2008.

Bathke, G.R., Cassel, D.K., Hargove, W.L., Porter, P.M., 1992. Modification of soil physical properties and root growth response. Soil Sci. 154, 316-329.

Bausch, W.C., and T.M. Bernard. 1992. Spatial averaging Bowen ratio system: Description and lysimeter calibration. Trans. ASAE 35:121-128.

Bjorkman, O., 1968. Carboxydismutase activity in shade-adapted and sun-adapted species of higher plants. Physiol. Plant. 21, 1-10.

Bjorkman, O., Ludlow, M. M., Morrow, P. A., 1972. Photosynthetic performance of two rainforest species in their native habitat and analysis of their gas exchange. Carnegie Inst. Washington Yearb. 71, 94-102.

Bohning, R. H., Burnside, C. A., 1956. The effect of light intensity on rate of apparent photosynthesis in leaves of sun and shade plants. Am. J. Bot. 43, 557-61

Bole, J. B., Pittman, U. J., 1980. Spring soil water, precipitation, nitrogen fertilizer: effect on barley yield. Can. J. Soil Sci. 60, 461-469.

Boni, G., Entekhabi, D., Castelli, F., 2001. Land data assimilation with satellite measurements for the estimation of surface energy balance components and surface control 
on evaporation. Water Resour. Res.37, 1713-1722.

Bosen, J. F. 1960. 'A formula for approximation of saturation vapor pressure over water', Month. Weather Rev., 88(8), 275-276.

Bosman, H.H., 1987. The influence of installation practices on evaporation from Symon's tank and American Class A-pan evaporimeters. Agricultural and Forest Meteorology, 41, 307-323.

Bosman, H.H., 1990. Methods to Convert American Class A-Pan and Symon's Tank Evaporation to That of a Representative Environment. Water SA, 16, 227-236.

Brooks RJ, Semenov MA, Jamieson PD. 2001. Simplifying sirus: sensitivity analysis and development of a metamodel for wheat yield prediction. European Journal of Agronomics $14,43-60$.

Brown, K.W., Rosenberg, N.J., 1973. A resistance model to predict evapotranspiration and its application to a sugar beet field. Agron. J. 65, 199-209.

Brunsell, N.A., Gillies, R.R., 2003. Scale issues in land-atmosphere interactions: implications for remote sensing of the surface energy balance. Agricultural and Forest Meteorology 117, 203-221.

Brutsaert, W. Catchment-scale evaporation and the atmospheric boundary layer, 1986. Water Resour. Res., 22, 39-45.

Calder, I.R., 1976. The measurement of water losses from a forested area using a "natural" lysimeter. Journal of hydrology, 30, 311-325.

Carlson, T.N., Buffum, M.J., 1989. On estimating daily evapotranspiration from remote surface temperature measurements. Remote Sens. Environ. 29, 197-207.

Carlson, T.N.; Capehart, W.J.; Gillies, R.R., 1995. A new look at the simplified method for remote sensing of daily evapotranspiration. Remote Sens. Environ.54, 161-167.

Caselles, V.; Sobrino, J.A.; Coll, C., 1992. On the use of satellite thermal data for determining evapotranspiration in partially vegetated areas. Int. J. Remote Sens.13, 2669-2682. 
Chaudhury, T.N., 1985. Response of wheat to irrigation with small amount of water applied in various ways. Agric. Water Manage. 10, 357-364.

Chavan, D.A., Pawar, K.R., 1988. Water use rate by wheat at various stages of growth as influenced by irrigation levels based on pan evaporation. J. Maharastra Agric. Univ. Pune $13,236-237$.

Chehbouni, A., Nouvellon, Y., Lhomme. J.,-P., Watts, C., Boulet, G., Kerr, Y.H., Moran, M.S., Goodrich, D.C., 2001. Estimation of surface sensible heat flux using dual angle observations of radiative surface temperature. Agricultural and Forest Meteorology 108, $55-65$.

Christiansen, J. E., 1968. "Pan evaporation and evapotranspiration from climatic data." $J$. Irrig. Drain. Div., 94, 243-265.

Cleverly, J.R., Dahm, C.N., Thibaut, J.R., Gilroy, D.J., Coonrod, J.E.A., 2002. Seasonal estimates of actual evapotranspiration from Tamarix ramosissima stands using three-dimensional eddy covariance. Journal of Arid Environments 52, 181-197.

Dadhwal, V.K., Ray, S.S., 2000. Crop assessment using remote sensing. Part II. Crop condition and yield assessment. Indian Journal Agricultural Economics 55 (2), 54-67.

Daughtry, C.S.T., Kustas, W.P., Moran, M.S., Pinter, P.J.JR., Jackson, R.D., Brown, P.W., Nichols, W.D., Gay, L.W., 1990. Spectral estimates soil heat flux of net radiation and soil heat flux. Remote Sens. Environ. 32, 111-124.

Davidson, E.A., Janssens, I.A., 2006. Temperature sensitivity of soil carbon decomposition and feedbacks to climate change. Nature. 440, 165-173.

De Bruin, H.A.R. 1981. The determination of (reference crop) evapotranspiration from routine weather data, Proc. and Inform., 28, 25-37. Comm. Hydr. Research TNO, The Hague.

De Bruin, H.A.R., 1987 'From Penman to Makkink', in Hooghart, C. (Ed.), Evaporation and Weather, Proceedings and Information. Comm. Hydrological Research TNO, The Hague. pp. 5-30.

de Jong van Lier, Q., Libardi, P.L., 1997. Extraction of soil water by plants: development and validation of a model. Brazilian J. Soil Sci. 21, 535-542. 
DehghaniSanij, H., Yamamoto, T., Rasiah, V., 2004. Assessment of evapotranspiration estimation models for use in semi-arid environments. Agricultural Water Management, 64, 91-106.

Denmead, O.T., Shaw, R.H., 1960. The effects of soil moisture stress at different stages of corn growth on the development and yield of corn. Agron. J. 52, 272-274.

Dugas, W.A., Fritschen, L.J., Gay, L.W., Held, A.A., Matthias, A.D., Reicosky, C., Steduto, P., Steiner, J.L, 1991. Bowen ratio, eddy correlation and portable chamber measurements of sensible and latent heat flux over irrigated spring wheat. Agricultural and Forest Meteorology 56, 1-20.

Dumanski, J., Onofrei, C., 1989. Techniques of crop yield assessment for agricultural land evaluation. Soil Use Manage. 5, 9-16.

Eck, H.V., 1984. Irrigated corn yield responses to nitrogen and water. Agron. J. 76, 412-428.

Edwards, W.R.N., 1986. Precision weighing lysimetry for trees, using a simplified tarred-balance design. Tree Physiology 1, 127-144.

Ehlig CF., 1962. Measurement of energy status of water in plants with a thermocouple psychrometer. Plant Physiology 37, 288-90.

Ezzahar, J., Chehbouni, A., Hoedjes, J.C.B., Er-Raki, S., Chehbouni, A., Boulet, G., Bonnefond, J.M., De Bruin, H.A.R., 2007. The use of the scintillation technique for monitoring seasonal water consumption of olive orchards in a semi-arid region. Agricultural Water Management 89,173-184.

Feddes, R.A., Rijtema, P.E., 1972. Water withdrawal by plant roots. J. Hydrology 17, $33-59$.

Flanagan, L.B., Johnson, B.G., 2005. Interacting effects of temperature, soil moisture and crop biomass production on ecosystem respiration in a northern temperate grassland. Agricultural and Forest Meteorology 130: 237-253

Flanagan, L.B., Wever, L.A., Carlson, P.J., 2002. Seasonal and interannual variation in carbon dioxide exchange and carbon balance in a northern temperate grassland. Global Change Biology 8: 599-615 
Fritschen, L. J. 1966, 'Energy balance method', Proceedings, American Society of Agricultural Engineers Conference on Evapo-transpiration and its role in Water Resources Management, December 5-6, Chicago, IL. St. Joseph, MI. pp. 34-37.

Gao, W., Coulter, R.L., Lesht, B.M., Qiu, J., Wesely, M.L., 1998. Estimating clear-sky regional surface fluxes in the Southern Great Plains atmospheric radiation measurement site with ground measurements and satellite observations. J. Appl. Meteorol. 37, 5-22.

Gardner, W.R., Ehlig, C.F., 1963. The influence of soil water on transpiration by plants. J. Geophys. Res. 68, 5719-5724.

Gilmanov, T.G., L.L. Tieszen, B.K. Wylie, L.B. Flanagan, A.B. Frank, M.R. Haferkamp, T.P. Meyers, J.A. Morgan. 2005. Integration of $\mathrm{CO}_{2}$ flux and remotely sensed data for primary production and ecosystem respiration analyses in the Northern Great Plains: Potential for quantitative spatial extrapolation. Global Ecology and Biogeography 14: 271-292.

Gowda, P.H., Chavez, J.L., Colaizzi, P.D., Evett, S.R., Howell, T.A., Tolk, J.A., 2007. ET mapping for agricultural water management: present status and challenges. Irrig. Sci., 26, 223-237.

Grace, J., 1988. Temperature as a determinant of plant productivity. In: Long, S.P., Woodward, F.I. (Eds.), Plants and Temperature. The Company of Biologists, Cambridge, pp. 91-107.

Grange, R.I., Hand, D.W., 1987. A review of the effects of atmospheric humidity on the growth of horticultural crops. J. Horticultural Science. 62(2), 125-134.

Guitjens, J. C. 1982. 'Models of alfalfa yield and evapotranspiration', J. Irrig. Drain. Div. Proc. Am. Soc. Civ. Eng., 108(IR3), 212-222.

Gurney, R.J., Camillo, P.J., 1984. Modelling daily evapotranspiration using remotely sensed data. J. Hydrol. 69, 305-324.

Hansen S., 1984. Estimation of potential and actual evapotranspiration. Nordic Hydrology $15,205-212$.

Hansen, S., Jensen, H.E., Nielsen, N.E. and Svendsen, H., 1990. DAISY: Soil Plant Atmosphere System Model. NPO Report No. A 10. The National Agency for 
Environmental Protection, Copenhagen, pp. 272-281.

Harbeck, G. E., 1962. `A practical ®eld technique for measuring reservoir evaporation utilizing mass-transfer theory', Geological Survey Professional Paper 272-E. US Government Printing O• ce, Washington, D.C. pp. 101-105.

Hargreaves, G. H., 1975. “Moisture availability and crop production.” Trans. ASAE, 18 5, 980-984.

Hargreaves, G.H., Allen, R.G.,, 2003. History and Evaluation of Hargreaves Evapotranspiration Equation, J. Irrig. and Drain. Engrg., 129, pp. 53-63.

Hargreaves, G.H., Samani, Z.A., 1985. Reference crop evapotranspiration from temperature. Appl. Eng. Agric. 1 (2), 96-99.

Hatfield, J.L., 1983. Evapotranspiration Obtained from Remote Sensing Methods. Adv. Irrig. 2, 395-416.

Hatfield, J.L., Perrier, A., Jackson, R.D., 1983. Estimation of evapotranspiration at one time-of-day using remotely sensed surface temperatures. Agri. Water Manage. 7, 341-350.

Healy, M.J.R. 1984. The Use of $R 2$ as a Measure of Goodness of Fit. J.R.Statist.Soc. A147, 608-609.

Howe, O.W., Rhoades, H.F., 1955. Irrigation practice for corn production in relation to stage of plant development. Soil Sci. Soc. Am. Proc. 19, 94-98.

Hsiao, T.C., 1973. Plant responses to water stress. Ann. Rev. Plant Physiol. 24, 519-570.

Hutchinson, C.F., 1991. Uses of satellite data for famine early warning in sub-Saharan Africa. International Journal of Remote Sensing 12, 1405-1421.

Idso, S.B., Jackson R.D., Reginato R.J., 1975. Estimating evaporation: a technique adaptable to remote sensing. Science. 189, 991-992.

Idso, S.B., Schmugge, T.J., Jackson, R.D., Reginato, R.J., 1975. The utility of surface temperature measurements for the remote sensing of surface soil water status. J. Geophys. Res. 80, 3044-3049. 
Irmak, S., Haman, D.Z., Bastug, R., 2000. Determination of crop water stress index for irrigation timing and yield estimation of corn. Agron. J. 92, 1221-1227.

Itenfisu, D., Elliott, R.L., Allen, R.G., and Walter, I.A., 2000. "Comparison of reference evapotranspiration calculations across a range of climates." Proc. of the National Irrigation Symposium, ASAE, R G. Evans, B.L., Benham, and T.P. Trooien, eds., Nov. 14-16, Phoenix, 216-227.

Jackson, R.D., 1985. Evaluating evapotranspiration at local and regional scales. Proc. IEEE. 73, 1086-1096.

Jackson, R.D., Idso, S.B., Reginato, R.J., Pinter, P.J., 1981. Canopy temperature as a crop water stress indicator. Water Resour. Res. 17, 1133-1138.

Jackson, R.D., Reginato, R.J., Idso, S.B., 1977. Wheat canopy temperature: a practical tool for evaluating water requirements. Water Resour. Res. 13, 651-656.

Jacobs A.F.G., Bruin H.A.R., 1998. Makkink's equation for evapotranspiration applied to unstressed maize. Hydrological Processes. 12, 1063-1066.

Jacovides, C.P., Kontoyiannis, H., 1995. Statistical procedures for the evaluation of evapotranspiration computing models. Agric. Water Manage. 27, 365-371.

Jensen, M.E., Burman, R.D., Allen, R.G., 1990. Evapotranspiration and irrigation water requirements. Manuals and Rep. on Engr. Practice No. 70, ASCE, New York.

Jensen, D.T., Hargreaves, G.H., Temesgen, B., Allen, R.G.,1997. "Computation of ETo under non-ideal conditions." J. Irrig. Drain. Div., 123, 394-400.

Jensen, C., Stougaard, B., Olsen, P. (1994a). Simulation of nitrogen dynamics at three Danish locations by use of the DAISY model. Acta Agric. Scand., Sect. B, Soil and Plant Science, 44, 75-83.

Johnson, R.C., Kanemasu, E.T., 1983. Yield and development of winter wheat at elevated temperatures. Agron. J. 75, 561-565.

Kairu, E.N.D.R., 1991. A review of methods for estimating evapotranspiration particularly those that utilize remote sensing. GeoJournal. 25, 371-376.

Kalma, J.D., McVicar, T.R., McCabe, M.F., 2008. Estimating land surface evaporation: a 
review of methods using remotely sensed surface temperature data. Surv Geophys. 29, 421-469.

Katerji, N., Mastrorilli, M., van Hoorn, J.W., Lahmer, F.Z., Hamdy, A., Oweis, T., 2009. Durum wheat and barley productivity in saline-drought environments. European Journal of Agronomy. 31, 1-9.

Kemp, D.R., Blacklow,W.M., 1982. The responsiveness to temperature of the extension rates of leaves of wheat growing in the field under different levels of nitrogen fertilizer. $J$. Exp. Bot. 33, 29-36.

Kite, G.W., Droogers, P., 2000. Comparing evapotranspiration estimates from satellites, hydrological models and field data. Journal of Hydrology 229, 3-18.

Kohler, M.A., Nordenson, T.J., Fox, W.E. 1955. 'Evaporation from pans and lakes', Weather Bureau Research Paper 38. US Department of Commerce, Washington, D.C.

Kustas, W.P.,1990. Estimates of evapotranspiration with a one- and two-layer model of heat transfer over partial canopy cover. J Appl Meteorol 29,704-715.

Kustas, W.P.; Norman, J.M., 1996. Use of remote sensing for evapotranspiration monitoring over land surfaces. Hydrol. Sci. J. 41, 495-516.

Larcher, W., 1994. Physiological Plant Ecology: ecophysiology and stress physiology of function groups. 3th ed. Verlag Eugen Ulmer, Stuttgart.

LeDrew, E.F., 1979. A diagnostic examination of the complementary relationship between actual and potential evapotranspiration. J. Appl. Meteorol., 18: 49 501.

Leuning, R., Moncrieff, J., 1990. Eddy covariance CO2 flux measurements using open-path and closed-path $\mathrm{CO} 2$ analyzers-corrections for analyzer water vapor sensitivity and damping of fluctuations in air sampling tubes. Boundary-Layer Meteorology. 53, 63-76.

Li, F., Lyons, T.J., 1999. Estimation of regional evapotranspiration through remote sensing. J. Appl. Meteorol.38, 1644-1654.

Li, Z.L., Tang, R., Wan, Z., Bi, Y., Zhou, C., Tang, B., Yan, G., Zhang, X., 2009. A Review of Current Methodologies for Regional Evapotranspiration Estimation from Remotely 
Sensed Data. Sensors, 9, 3801-3853.

Macdonald, R.B., Hall, F.G., 1980. Global crop forecasting. Science 208 (4445), 670-679.

Mache, R., Loiseaux, S. 1973. Lightsaturation of growth and photosynthesis of the shade plant Marchantia polymorpha. J. Cell Sci. 1 2:391-401.

McCabe, M.F., Wood, E.F., 2006. Scale influences on the remote estimation of evapotranspiration using multiple satellite sensors. Remote Sens. Environ. 105, 271-285.

Meijninger, W., de Bruin, H.A.R., 2000. The sensible heat fluxes over irrigated areas in western Turkey determined with a large aperture scintillometer. Journal of Hydrology 229, $42-49$.

Moran, M.S., Jackson, R.D., Raymond, L.H., Gay, L.W., Slater, P.N., 1989. Mapping surface energy balance components by combining Landsat Thematic Mapper and ground-based meteorological data. Remote Sens. Environ. 30, 77-87.

Morgenstern, K., Black, T.A., Humphreys, E.R., Griffis, T.J., Drewitt, G.R., Cai, T., Nesic, Z., Spittlehouse, D.L., Livingston, N.J., 2004. Sensitivity and uncertainty of the carbon balance of a Pacific Northwest Douglas-fir forest during an E1 Niño/La Niña cycle. Agricultural and Forest Meteorology, 123, 201-219.

Morton, F.I., 1969. Potential evaporation as a manifestation of regional evaporation. Water Resour. Res., 5(6),1244-1255.

Morton, F.I., 1990. 'Studies in evaporation and their lessons for the environmental sciences', Can. Wat. Resour. J. 15(3), 261-285.

Morton, F.I., 1994. 'Evaporation research $Ð$ A critical review and its lessons for the environmental sciences', Crit. Rev. Environ. Sci. Tech., 24(3), 237-280.

Musick, J.T., Dusek, D.A., 1980. Irrigated corn yield response to water. Trans. ASAE 23, 92-98 103.

Oechel, W. C., 1976. Seasonal patterns of temperature response of $\mathrm{CO}_{2}$ fiux and acclimation in arctic mosses growing in situ. Photosynthetica 10,447-56. 
Penman, H.L., 1948. Natural evaporation from open water, bare soil and grass, Proc. $R$. Soc. Lond., 193, 120-145.

Petersen, C.T., Jørgensen, U., Svendsen, H., Hansen, S., Jensen, H.E. and Nielsen, N.E.,1995. Parameter assessment for simulation of biomass production and nitrogen uptake in winter rape. Eur. J. Agron., 4(1), 77-89.

Pirmoradian, N., Sepaskhah, A.R., 2005. A very simple model for yield prediction of rice under different water and nitrogen applications. Biosystems Engineering 93(1), 25-34.

Pockman W.T., Sperry J.S., Oteary J.V.V., 1995. Sustained and significant negative water pressure in xylem. Nature 378, 715-716.

Ponton, S., Flanagan, L.B., Alstad, K.P., Johnson, B.G., Morgenstern, K., Kljun, N., Black, T.A., Barr, A.G., 2006. Comparison of ecosystem water-use efficiency among Douglas fir forest, aspen forest and grassland using eddy covariance and carbon isotope techniques. Global Change Biology 12: 294-310

Porter, J.R., Semenov, M.A., 2005. Crop responses to climatic variation. Philosophical Transactions of the Royal Society B: Biological Sciences 360, 2021-2038.

Prasad, A.K., Chai, L., Singh, R.P., Kafatos, M., 2006. Crop yield estimation model for Iowa using remote sensing and surface parameters. International Journal of Applied Earth Observation Geoinformatics 8 (1), 26-33.

Prihar, S.S., Sandhu, B.S., 1987. Irrigation of Field Crops-Principles and Practices. I.C.A.R., New Delhi, India.

Proffitt, A.P.B., Berliner, P.R., Oosterhuis, D.M., 1985. A comparative efficiency of wheat grown under high and low frequency irrigation. Agron. J. 77, 655-662.

Rango, A., 1994. Application of remote sensing methods to hydrology and water resources. Hydrol. Sci. J. 39, 309-320.

Reginato, R.J., Jackson, R.D., Pinter, P.J., 1985. Evapotranspiration calculated from remote multispectral and ground station meteorological data. Remote Sens. Environ. 18, 75-89. 
Revheim. K.J.A., and R.B. Jordan. 1976. Precision of evaporation measurements using the Bowen ratio. Boundary Layer Meteorol. 10:97-1 11.

Richard, J.L., Morris L.M., 2000. An Introduction to Mathematical Statistics and Its Applications, Third Edition, p. 282.

Richardson, A.D., Hollinger, D.Y., Davis, K.J., Flanagan, L.B., Katul, G.G., Munger, J.W., Stoy, P.C., Verma, S.B., Wofsy, S.C., 2006. A multi-site analysis of uncertainty in tower-based measurements of carbon and energy fluxes. Agricultural and Forest Meteorology 136: 1-18

Richter, H., 1997. Water relations of plants in the field: some comments on the measurement of selected parameters. Journal of Experimental Botany, 48, No. 306, 1-7.

Ritchie, J.T., 1971. Dryland evaporative flux in a subhumid climate: I. Micrometeorological influences. Agron. J., 63, 51-55.

Roerink, G.J., Su, Z., Menenti, M., 2000. S-SEBI: a simple remote sensing algorithm to estimate the surface energy balance. Phys. Chem. Earth (B). 25, 147-157.

Sadler, E.J., Evans, D.E., 1989. Vapor pressure deficit calculations and their effect on the combination equation. Agric. and For. Meterology. Vol. 49, 55-80.

Samani, Z., 2004. Discussion of "History and evaluation of Hargreaves evapotranspiration equation". J. Irrig. Drain. Eng. ASCE 130 (5), 447-448.

Seguin, B., 1984. Estimation of evapotranspiration a prairie using Infra-rouge thermal instruments. In Proceedings of 2 nd Int. Coll. on spectral signatures of objects in remote sensing, Bordeaux, France, 427-446.

Seguin, B., Courault, D., Guérif, M., 1994. Surface temperature and evapotranspiration: Application of local scale methods to regional scales using satellite data. Remote Sens. Environ. 49, 287- 295.

Seguin, B.; Itier, B., 1983. Using midday surface temperature to estimate daily evaporation from satellite thermal IR data. Int. J. Remote Sens. 4, 371-383.

Shepherd, R.G., 1989. "Correlations of permeability and grain-size". Ground Water 27 (5), 633-638. 
Sims, D.A., Rahman, A.F., Cordova, V.D., Baldocchi, D.D., Flanagan, L.B., Goldstein, A.H., Hollinger, D.Y., Mission, L., Monson, R.K., Schmid, H.P.. Wofsy, S.C., Xu, L., 2005. Midday values of gross $\mathrm{CO}_{2}$ flux and light use efficiency during satellite over passes can be used to directly estimate eight-day mean flux. Agricultural and Forest Meteorology 131, $1-12$.

Singh, P., 1989. Water stress and plant parameters for wheat. Indian Soc. Agric. Engrgs. 85, 34-40.

Singh, V.P., 1989. Hydrologic Systems, Vol. II, Watershed Modelling. Prentice-Hall, Inc.

Singh, V.P., Xu, C.Y., 1997. Evaluation and generalization of 13 mass-transfer equations for determining free water evaporation. Hydrological Processes, 11, 311-323.

Smith, M., Allen, R. G., Monteith, J. L., Pereira, L. S., Perrier, A., Pruitt, W. O., 1991. "Report on the expert consultation on procedures for revision of FAO guidelines for prediction of crop water requirements." Land and Water Development Division, United Nations Food and Agriculture Service, Rome, 75.

Smith, M., Allen, R., Pereira, L., 1996. Revised FAO methodology for crop water requirements. In: Proceeding of the ASAE International Conference on Evapotranspiration and Irrigation Scheduling, 3-6 November, San Antonio, TX, pp. 116-123.

Stanhill, G., Cohen, S., 2001. Global dimming: a review of the evidence for a widespread and significant reduction in global radiation with discussion of its probable causes and possible agricultural consequences. Agricultural and Forest Meteorology 107, 255-278.

$\mathrm{Su}, \mathrm{Z} ., 2002$. The surface energy balance system (SEBS) for estimation of turbulent heat fluxes. Hydrol. Earth Syst. Sci.. 6, 85-99.

Sutton, O.G., 1949. 'The application to micrometeorology of the theory of turbulent flow over rough surfaces', R. Meteorol. Soc., Quart. J., 75, (236).

Temesgen, B., Eching, S., Davidoff, B., Frame, K., 2005. Comparison of some reference evapotranspiration equations for California. J. Irrig. Drain. Eng. ASCE 131 (1), 73-84.

Van Bavel, C.H.M., 1966. Potential evaporation: The combination concept and its experimental verification. Water Resour. Res., 2(3), 455467. 
Van Bavel, C.H.M. 1968. 'Discussion of "Climate and Evaporation from Crops"', J. Irrig. Drain. Div., Proceedings, Am. Soc. Civ. Eng., 68, 533-535.

van Ittersum, M.K., Leffelaar, P.A., van Keulen, H., Kropff, M.J., Bastiaans, L., Goudriaan, J.. 2003. On approaches and applications of the Wageningen crop models. European Journal of Agronomy 18, 201-234.

Vanderlinden, K., Gira'ldez, J.V., Van Mervenne, M., 2004. Assessing reference evapotranspiration by the Hargreaves method in Southern Spain. J. Irrig. Drain. Eng. ASCE 129 (1), 53-63.

Ventura, F., Spano, D., Duce, P., Snyder, R.L., 1999. An evaluation of common evapotranspiration equations. J. Irrigation Sci. 18, 163-170.

Verma, S.B., 1990. Micrometeorological Methods for Measuring Surface Fluxes of Mass and Energy. Remote Sensing Reviews. 5(1), 99-115.

Verstraeten, W.W., Veroustraete, F., Feyen, J., 2008. Assessment of evapotranspiration and soil moisture content across different scales of observation. Sensors 8,70-117.

Wever, L.A., Flanagan, L.B., Carlson, P.J., 2002. Seasonal and inter annual variation in evapotranspiration, energy balance, and surface conductance in a northern temperate grassland. Agricultural and Forest Meteorology 112, 31-49.

Whitmore, J.S., 2000. Chapter 7. Hardy and drought - evasive cereal crops. In Whitmore, J.S (Ed.), Drought Management on Farmland (pp.79-97). London: Springer.

Wilks, D.S., Riha, S.J., 1996. High-frequency climatic variability and crop yields. Climatic Change 32, 231-235.

Willigen, P.de. 1991. Nitrogen turnover in the soil-crop system; comparison of fourteen simulation models. Fert. Res. 27, 141-149.

Wilson, K.B., Hanson, P.J., Mulholland, P.J., Baldocchi, D.D., Wullschleger, S.D., 2001. A comparison of methods for determining forest evapotranspiration and its components: sapflow, soil water budget, eddy covariance and catchment water balance. Agricultural and Forest Meteorology. 106, 153-168. 
Winter, T.C., Rosenberry, D.O., Sturrock, A.M., 1995. Evaluation of 11 equation for determining evaporation for a small lake in the north central United States, Wat. Resour. Res., 31(4), 983-994.

Xie, Y., Kiniry, J.R., Williams, J.R., 2003. The ALMANAC model's sensitivity to input variables. Agricultural Systems. 78, 1-16.

Xu, C.Y., Chen, D., 2005. Comparison of seven models for estimation of evapotranspiration and groundwater recharge using lysimeter measurement data in Germany. Hydrol. Process. 19, 3717-3734.

Xu, C.Y., Singh, V.P., 1998. Dependence of evaporation on meteorological variavles at different time-scales and intercomparison of estimation methods. Hydrol. Process. 12, 429-442.

Yang, J., Li, B., Liu, S., 2000. A large weighing lysimeter for evapotranspiration and soil water groundwater exchange studies. Hydrological Processes 14, 1887-1897.

Zhang, Y.C., Rossow, W.B., Lacis, A.A., 1995. Calculation of surface and top-of-atmosphere radiative fluxes from physical quantities based on ISCCP data sets: 1 Methods and sensitivity to input data uncertainties. J Geophys Res Atmosphere 100(1), 1149-1165. 